\author{
UNIVERSIDADE DE SÃO PAULO \\ ESCOLA DE ENFERMAGEM DE RIBEIRÃO PRETO
}

\title{
Estado nutricional e consumo alimentar de indivíduos de diferentes áreas socioeconômicas de Ribeirão Preto: comparação entre 1991/93 e 2001/03
}

Ribeirão Preto 
Estado nutricional e consumo alimentar de indivíduos de diferentes áreas socioeconômicas de Ribeirão Preto: comparação entre 1991/93 e 2001/03

Dissertação apresentada à Escola de Enfermagem de Ribeirão Preto da Universidade de São Paulo, para obtenção do Título de Mestre em Enfermagem em Saúde Pública, inserida na linha de pesquisa: Processo Saúde-Doença e Epidemiologia.

Orientadora: Prof ${ }^{a}$ Dr $^{\mathrm{a}}$ Rosane Pilot Pessa Ribeiro

Ribeirão Preto

2006 


\section{AUTORIZO A REPRODUÇÃO E DIVULGAÇÃO TOTAL OU PARCIAL DESTE TRABALHO, POR QUALQUER MEIO CONVENCIONAL OU ELETRÔNICO PARA FINS DE ESTUDO E PESQUISA, DESDE QUE CITADA A FONTE.}

FICHA CATALOGRÁFICA

Pallos, Daniela Vieira

Estado nutricional e consumo alimentar de indivíduos de diferentes áreas socioeconômicas de Ribeirão Preto: comparação entre 1991/93 e 2001/03 / Daniela Vieira Pallos. - Ribeirão Preto, 2006.

118p. il.; 30cm

Dissertação (Mestrado - Programa de pós-graduação em Enfermagem em Saúde Pública) - Escola de Enfermagem de Ribeirão Preto da Universidade de São Paulo.

Orientadora: Ribeiro, Rosane Pilot Pessa

1. Estado Nutricional 2. Consumo de Alimentos 3. Fatores Socioeconômicos

4. Hábitos Alimentares 


\section{FOLHA DE APROVAÇÃO}

Daniela Vieira Pallos

Estado nutricional e consumo alimentar de indivíduos de diferentes áreas socioeconômicas de Ribeirão Preto: comparação entre 1991/93 e 2001/03

Dissertação apresentada à Escola de

Enfermagem de Ribeirão Preto da Universidade de São Paulo para obtenção do título de Mestre em Enfermagem em Saúde Pública, inserida na linha de pesquisa Processo Saúde-Doença e Epidemiologia.

Aprovado em:

\section{Banca Examinadora}

Prof ${ }^{\mathrm{a}} \mathrm{Dr}^{\mathrm{a}}$ Rosane Pilot Pessa Ribeiro

Instituição: Escola de Enfermagem de Ribeirão Preto da Universidade de São Paulo Julgamento: Assinatura:

Prof $^{a}$ Dr $^{\mathrm{a}}$ Rosana Aparecida Spadoti Dantas

Instituição: Escola de Enfermagem de Ribeirão Preto da Universidade de São Paulo Julgamento: Assinatura:

Prof. Dr. José Ernesto dos Santos

Instituição: Faculdade de Medicina de Ribeirão Preto da Universidade de São Paulo Julgamento: Assinatura: 


\section{DEDICATÓRIA}

Dedico este trabalho aos meus pais, Edson e Valdeti que compreenderam e apoiaram, ao estilo de cada um, a importante decisão de sair de minha cidade natal e buscar crescimento pessoal e profissional.

Ao companheiro sempre presente e muito paciente, Inedilson Anelli, cuja sensibilidade e carinho me auxiliam nos obstáculos que a vida nos convida a enfrentar.

À grande amiga/irmã Viviane Cunha Cardoso, pela companhia, pelos sábios conselhos e, principalmente, por possuir uma linda e rara qualidade: autenticidade.

À Maria Luiza Junqueira com quem dividi momentos ímpares de minha vida, dos quais sinto saudade. Pessoa que me ensinou que "permitir-se" é também viver. 


\section{AGRADECIMENTOS}

À Espiritualidade onipresente que trabalha incessantemente para modificar a atmosfera espiritual em que habitamos e nos convidam a evoluir um dia após o outro.

À minha orientadora Prof ${ }^{a}$ Dr $^{a}$ Rosane Pilot Pessa Ribeiro cujo profissionalismo é digno de respeito e admiração e com quem pude estabelecer vínculos de confiança e amizade baseados na transparência e humildade do ser humano que é.

Ao Prof. Dr. William W. Dressler (Bill) pela oportunidade de podermos trabalhar juntos e aproveitar dos momentos valiosos em que esteve no Brasil compartilhando de forma generosa sua experiência profissional e seu carisma pessoal.

Ao Prof. Dr. José Ernesto dos Santos e à Prof ${ }^{a}$ Dr $^{a}$ Rosana Aparecida Spadoti Dantas pelas oportunas considerações ao trabalho no Exame de Qualificação e na análise da pro-forma.

À Prof ${ }^{a}$ Dr $^{a}$ Cláudia Benedita dos Santos e ao Prof. Dr. Moacyr Lobo da Costa Júnior pelo apoio e sugestões na análise estatística deste trabalho.

À equipe de colaboradores do CADI: Camila Borges, Débora Florenzano, Mislene de Camargo Molina, Emília Chayamiti, Rosana Meirelles, Prof. Dr. Manoel Antonio dos Santos, Prof. Mauro Campos Baliero, pelo aprendizado, convivência e amizade.

Às amigas Denise Mesquita, Érica Cezar, Leila Gardim, Ana Carolina Mota (Carol), Vanessa Formisano e Hercília Xavier, pelos momentos de descontração e pela compreensão nos períodos em que estive ausente.

Ao mais recente amigo, Ângelo Paracchini Filho, cuja generosa participação neste trabalho foi de suma importância.

Ao CNPq que colaborou para o desenvolvimento deste trabalho com bolsa auxílio pesquisa. 


\section{EPÍGRAFES}

"O meu bom senso não me diz o que é, mas deixa claro que há algo que precisa ser sabido. Esta é a tarefa da ciência que, sem o bom senso do cientista, pode se desviar e se perder. Não tenho dúvida do insucesso do cientista a quem falte a capacidade de adivinhar, o sentido da desconfiança, a abertura à dúvida, a inquietação de quem não se acha demasiado certo das certezas. Tenho pena $e$, ás vezes, medo, do cientista demasiado seguro da segurança, senhor da verdade e que não suspeita sequer da historicidade do próprio saber.”

(Paulo Freire - "Pedagogia da Autonomia")

"Aprendi algumas coisas; poucas aprendi na escola. Não saber é o início da aprendizagem." (Rubem Alves - "Fomos maus alunos")

"As pessoas que vivem cometendo erros produzem acertos. A escola é o antiprazer da incógnita." (Gilberto Dimenstein "Fomos maus alunos")

\footnotetext{
"Hoje se criam escolas e faculdades para ensinar os novos saberes. Eu sonho com o dia em que se criarão faculdades para ensinar a antiga ignorância.” (Nietzsche)
} 


\section{RESUMO}

PALLOS, D. V. Estado nutricional e consumo alimentar de indivíduos adultos de diferentes áreas socioeconômicas de Ribeirão Preto: comparação entre 1991/93 e 2001/03. 2006. Dissertação de Mestrado - Escola de Enfermagem de Ribeirão Preto da Universidade de São Paulo, Ribeirão Preto - SP.

Os estudos sobre os hábitos e comportamentos alimentares da sociedade são importantes para auxiliar na compreensão da relação que se estabelece entre as práticas alimentares e o surgimento de doenças na população. Desde meados do século XX, o Brasil vem apresentando mudanças no padrão de morbi-mortalidade de sua população, ou seja, ao mesmo tempo em que indivíduos de áreas economicamente mais carentes sofrem com o problema da desnutrição, outra grande parcela populacional convive com doenças degenerativas ou crônico não-transmissíveis. Esse fenômeno, chamado de transição nutricional, surgiu primeiramente nos países desenvolvidos e atualmente atinge os países em desenvolvimento de forma mais acelerada. Diante desta realidade, este trabalho teve por objetivo comparar o estado nutricional e o consumo alimentar de 575 indivíduos adultos moradores de quatro bairros da cidade de Ribeirão Preto - SP, com características socioeconômicas distintas e em dois momentos diferentes, 1991/93 e 2001/03. Para avaliação do estado nutricional foi realizado o cálculo do Índice de Massa Corporal (IMC), no qual os indivíduos foram pesados e medidos e classificados segundo os padrões da Organização Mundial de Saúde. As informações sobre o consumo alimentar foram obtidas pelo método do recordatório de 24 horas e a ingestão de calorias, carboidratos, proteínas, gorduras totais e suas frações, colesterol e fibras foi calculada com auxílio de software nutricional. Também, analisou-se a qualidade da alimentação dos indivíduos pela avaliação do número de porções alimentares consumidas, segundo os oito grupos de alimentos da Pirâmide Alimentar Brasileira. Os dados foram transferidos para a planilha do SPSS (Statistical Package for Social Sciences) onde os cálculos estatísticos foram realizados (análise de variância - ANOVA, teste de Bonferroni e teste-t). Como resultados houve diminuição do consumo de alimentos do grupo de pães e cereais e aumento do consumo de carnes e ovos, açúcar e alimentos ricos em gorduras saturadas e colesterol. O consumo de frutas, verduras, hortaliças e fibras aumentou de 1991/93 para 2001/03, entretanto a ingestão permaneceu bem abaixo dos níveis recomendados. Refrigerantes e produtos prontos industrializados também cresceram muito no período. Notou-se ainda que os moradores do bairro com menor renda familiar média tiveram aumento significativo do IMC juntamente com elevação do consumo de gorduras totais e saturadas e do número de porções de carnes e ovos. Já os habitantes do bairro de maior renda familiar média diminuíram o consumo de gorduras totais e saturadas e mantiveram a ingestão adequada do número de porções de carnes e ovos. Esse paradoxo que o país enfrenta tem despertado interesse de vários segmentos na busca de soluções, cujos resultados serão promissores se envolverem não só as ciências nutricionais, mas outras áreas como a economia, a sociologia, a administração e a psicologia, associado ao trabalho de conscientização do papel dos atores sociais (pais, educadores, profissionais da saúde, governantes) responsáveis pela reversão deste quadro tão complexo.

DESCRITORES: Estado Nutricional, Consumo de Alimentos, Fatores Socioeconômicos, Hábitos Alimentares. 


\begin{abstract}
PALLOS, D.V. Nutritional state and food consumption in adults of different socioeconomical areas in Ribeirão Preto, SP, Brazil: a comparison between 1991/93 and 2001/03. 2006. Master Degree Thesis - Nurse School of Ribeirão Preto at Universidade de São Paulo, Ribeirão Preto, SP.
\end{abstract}

The studies about habits and eating behaviors in society are important to help in the understanding the relation that is established between food practices and the appearance of illnesses in the population. Brazil has been presenting changes in patterns of morbidmortality in its population since the middle of the $20^{\text {th }}$. Century, i.e., since people belonging to low income classes suffer from underfeeding, people belonging to other social classes present degenerative illnesses or chronic non-transmitted illnesses. This phenomenon called nutritional transition first appeared in developed countries and now it also affects developing countries in an accelerated way. Considering this fact, this research aims at comparing the nutritional state and food consumption in 575 adults living in four different neighborhoods in Ribeirão Preto, SP in Brazil. They belong to distinct socioeconomical classes and the research focused two different periods: 1991/93 and 2001/03. To evaluate the nutritional state, a calculation of the Body Mass Index (IMC) was made, following the World Health Organization patterns, in which people are weighed and measured accordingly. Information about eating habits were made through the 24 hours remembering method and the ingestion of calories, carbohydrates, proteins, total fat and its fractions, cholesterol and fibers were calculated using a nutritional software. It was also analyzed the quality of feeding, considering the evaluation of the number of food portions consumed, according to the eight groups of food items, in the Brazilian Feeding Pyramid. The data were transferred to spreadsheets of Statistical Package for Social Sciences (SPSS) where the statistical calculations were made (variance analysis - ANOVA, Bonferroni Test and Test-t). As a result there was a decrease in cereals and bread group's consumption and an increase in the consumption of meat, eggs, sugar and food rich in saturated fat and cholesterol. The consumption of fruits, vegetables and fibers increased from 1991/93 to 2001/03, but the ingestion remained under the recommended levels. The use of soft drinks or sodas and industrialized products such as ready-made dishes also increased greatly. It was verified that in the inhabitants of the neighborhood with lower familiar income that they had an increase in the Body Mass Index which occurred at the same time with the consumption of total fats and saturated fats and the number of portions of meat and eggs. By the other side, the inhabitants of the neighborhood with higher familiar income reduced the consumption of total fats and saturated fats and kept the adequate ingestion of portions of meat and eggs. This paradox that our country faces has called the interest of may society sectors, aiming at solutions, which will be successful if they get involved not only the nutritional sciences, as well as other areas like economics, sociology, administration and psychology, associated to a work of awareness from social actors like parents, teachers, health professionals and government to revert such complex situation.

Key words: Nutritional Status, Food Consumption, Socioeconomic Factors, Food Habits. 


\section{RESUMEN}

PALLOS, D.V. - Estado nutricional y consumo de alimentos en adultos de diferentes áreas socio-económicas de Ribeirão Preto, SP, Brasil: comparación entre 1991/93 y 2001/03. 2006. Grado de Magíster - Escuela de Enfermería de Ribeirão Preto en la Universidad de São Paulo - Ribeirão Preto - SP.

Los estudios acerca los hábitos y comportamientos alimenticios en la sociedad son importantes para ayudar en la comprensión de la relación que se establece entre las practicas alimentares y el aparecimiento de enfermedades en la población. Desde la mitad del siglo veinte, Brasil viene presentando cambios en el patrón o modelos de morbomortalidad de su población, o sea, al mismo tiempo que las personas de regiones más necesitadas económicamente sufren problemas con la desnutrición, otra gran parte de la población convive con enfermedades degenerativas o no-transmisibles. Ese fenómeno llamado de transición nutricional surgió en primero lugar en los países desarrollados y hoy día afecta los países en desarrollo, de una manera muy rápida. Delante esa realidad, este trabajo ha tenido como meta comparar el estado nutricional y el consumo de alimentos en 575 personas adultas que habitan en cuatro barrios en la ciudad de Ribeirão Preto, SP, en Brasil, teniendo características socio-económicas distintas y en dos periodos de tiempo distintos, 1991/93 y 2001/03. Para la evaluación del estado nutricional fue realizado el cálculo del Índice de Masa Corpórea (IMC), donde los sujetos fueron pesados y mensurados y clasificados según los patrones de la Organización Mundial de Salud. Las informaciones acerca del consumo de alimentos fueron obtenidas por el método de recordación en las 24 horas y la ingestión de calorías, carbohidratos, proteínas, grasa total y sus fracciones, colesterol y fibras fue calculada con la ayuda de un programa nutricional de ordenador. Además, se ha analizado la calidad de la alimentación de los sujetos por la evaluación del número de porciones alimentares consumidas, según los ocho grupos de alimentos de la Pirámide Alimentar Brasilera. Los datos fueron trasladados para planillas de SPSS (Statistical Package for Social Sciences) donde las calculaciones estadísticas fueron hechas (análisis de variancia - ANOVA, Prueba de Bonferroni y Ensayo-t). Como resultados ha habido una disminución del consumo de alimentos del grupo de cereales y pan y se aumentó el consumo de carnes, huevos, azúcar y alimentos ricos en grasas saturadas y de colesterol. El consumo de frutos, hortalizas y fibras creció de 1991/93 para 2001/03, todavía su ingestión permaneció inferior a los niveles recomendados. El consumo de bebidas no alcohólicas o sodas y productos industrializados también ha crecido mucho en este periodo. También se ha notado que los moradores del barrio con menor renta familiar han tenido un aumento significativo en el IMC juntamente con el aumento de consumo de grasas totales y saturadas, además del aumento del consumo de carnes y huevos. Por otro lado, los moradores del barrio con más renta familiar mediana han diminuido el consumo de grasas totales y saturadas y han mantenido la ingestión adecuada de carnes y huevos. Esta paradoja que nuestro país sufre despertó el interés de muchos sectores de la sociedad en la búsqueda de soluciones, cuyos resultados solo serán bien sucedidos si además de las ciencias nutricionales otras ciencias como la economía, la sociología, la administración y psicología se asocien en tarea de aclaración de los actores sociales acerca de su responsabilidad por la reversión de tan compleja situación.

DESCRIPTORES: Estado Nutricional, Consumo de Alimentos, Factores Socioeconómicos, Hábitos Alimenticios. 


\section{LISTA DE TABELAS}

Tabela 1 - Distribuição da população de homens e mulheres nos estudos SEPA (1) e CADI

(2), segundo os bairros visitados. Ribeirão Preto, 1991/93 e 2001/03 37

Tabela 2 - Classificação do estado nutricional de adultos segundo valores de IMC. OMS, 1997 39

Tabela 3 - Distribuição percentual das gorduras totais ingeridas (média e desvio-padrão) pelos indivíduos nos bairros dos estudos SEPA (1) e CADI (2). Ribeirão Preto, 1991/93 e 2001/03 54

Tabela 4 - Distribuição percentual das gorduras saturadas ingeridas (média e desviopadrão) pelos sujeitos dos estudos SEPA (1) e CADI (2) nos bairros visitados. Ribeirão

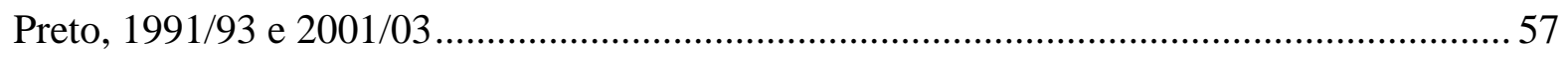




\section{LISTA DE GRÁFICOS}

Gráfico 1 - Distribuição de homens e mulheres nos bairros dos estudos SEPA (1) e CADI

(2). Ribeirão Preto, 1991/93 e 2001/03 44

Gráfico 2 - Distribuição dos indivíduos dos estudos SEPA (1) e CADI (2), segundo faixa etária e bairros. Ribeirão Preto, 1991/93 e 2001/03 45

Gráfico 3 - Distribuição média do IMC dos indivíduos participantes dos estudos SEPA (1)

e CADI (2), segundo os bairros visitados. Ribeirão Preto, 1991/93 e 2001/03........................ 47

Gráfico 4 - Calorias totais ingeridas pelos indivíduos (média) dos estudos SEPA (1) e CADI (2) nos bairros visitados. Ribeirão Preto, 1991/93 e 2001/03......................................... 49

Gráfico 5 - Consumo médio de carboidratos pelos indivíduos dos estudos SEPA (1) e CADI (2) nos bairros visitados. Ribeirão Preto, 1991/93 e 2001/03......................................... 50

Gráfico 6 - Consumo médio de proteínas pelos participantes dos estudos SEPA (1) e CADI

(2), segundo os bairros visitados. Ribeirão Preto, 1991/93 e 2001/03 52

Gráfico 7 - Distribuição percentual do consumo médio de gorduras totais pelos participantes dos estudos SEPA e CADI. Ribeirão Preto, 1991/93 e 2001/03........................ 55 
Gráfico 8 - Distribuição percentual do consumo de gorduras saturadas (médias) pelos indivíduos dos estudos SEPA (1) e CADI (2) nos bairros visitados. Ribeirão Preto, 1991/93

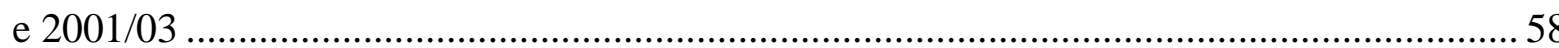

Gráfico 9 - Percentual da ingestão de gorduras monoinsaturadas (médias) pelos indivíduos dos estudos SEPA (1) e CADI (2), segundo os bairros visitados. Ribeirão Preto, 1991/93 e 2001/03 59

Gráfico 10 - Percentual do consumo de gorduras polinsaturadas (médias) pelos indivíduos dos estudos SEPA (1) e CADI (2), nos bairros visitados. Ribeirão Preto, 1991/93 e 2001/03........... 60

Gráfico 11 - Consumo médio de colesterol pelos participantes dos estudos SEPA (1) e CADI (2) nos bairros visitados. Ribeirão Preto, 1991/93 e 2001/03.................................... 62

Gráfico 12 - Consumo médio de fibras pelos participantes dos estudos SEPA (1) e CADI (2), segundo os bairros avaliados. Ribeirão Preto, 1991/93 e 2001/03 63

Gráfico 13 - Consumo médio de cereais pelos participantes dos projetos SEPA (1) e CADI (2), segundo os bairros visitados. Ribeirão Preto, 1991/93 e 2001/03 65

Gráfico 14 - Consumo médio de hortaliças pelos participantes dos projetos SEPA (1) e CADI (2) nos bairros visitados. Ribeirão Preto, 1991/93 e 2001/03.................................... 67 
Gráfico 15 - Consumo médio de frutas pelos participantes dos projetos SEPA (1) e CADI

(2), segundo os bairros visitados. Ribeirão Preto, 1991/93 e 2001/03 ................................. 68

Gráfico 16 - Consumo médio de leguminosas nos estudos SEPA (1) e CADI (2), segundo os bairros visitados. Ribeirão Preto, 1991/93 e 2001/03 .................................................... 69

Gráfico 17 - Consumo médio de carnes e ovos pelos indivíduos dos projetos SEPA (1) e CADI (2), segundo os bairros avaliados. Ribeirão Preto, 1991/93 e 2001/03 ..................... 71

Gráfico 18 - Consumo médio de leite e derivados pelos participantes dos projetos SEPA (1) e CADI (2), segundo os bairros visitados. Ribeirão Preto, 1991/93 e 2001/03................ 72

Gráfico 19 - Consumo médio de açúcar pelos participantes do projeto SEPA (1) e CADI (2) nos bairros visitados. Ribeirão Preto, 1991/93 e 2001/03 74

Gráfico 20 - Consumo médio de gorduras pelos participantes dos estudos SEPA (1) e CADI (2), segundo os bairros visitados. Ribeirão Preto, 1991/93 e 2001/03 ................................ 75 


\section{LISTA DE FIGURAS}

Figura 1 - Padrão de consumo alimentar segundo o número de porções dos grupos

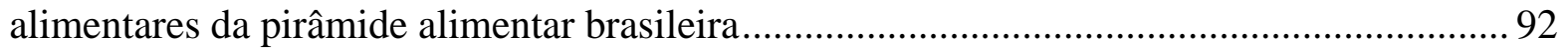

Figura 2 - Consumo médio do número de porções alimentares ingeridas pelos participantes do estudo SEPA (1991/93), segundo padrão de recomendação da pirâmide alimentar

brasileira

Figura 3 - Consumo médio do número de porções alimentares ingeridas pelos participantes do estudo CADI (2001/03), segundo padrão de recomendação da pirâmide alimentar brasileira ...... 


\section{LISTA DE ABREVIATURAS E SIGLAS}

$\begin{array}{ll}\text { ANOVA } & \text { Análise de variância } \\ \text { CADI } & \text { Cultura e Adaptação Individual } \\ \text { ENDEF } & \text { Estudo Nacional sobre Despesa Familiar } \\ \text { FAO } & \text { Organização das Nações Unidas para a Alimentação e a Agricultura } \\ \text { IBGE } & \text { Instituto Brasileiro de Geografia e Estatística } \\ \text { IMC } & \text { Índice de Massa Corporal } \\ \text { IPEA } & \text { Fundação Instituto de Pesquisas Econômicas e Aplicadas } \\ \text { OMS } & \text { Organização Mundial de Saúde } \\ \text { PNSN } & \text { Pesquisa Nacional sobre Saúde e Nutrição } \\ \text { POF } & \text { Pesquisa de Orçamento Familiar } \\ \text { PRECAVAS } & \text { Prevention of Cardiovascular Disease in Developing Countries } \\ \text { SEPA } & \text { Social Environment and Physiologic Adaptation } \\ \text { SPSS } & \text { Statistical Package for Social Sciences } \\ \text { WHO } & \text { World Health Organization }\end{array}$




\section{SUMÁRIO}

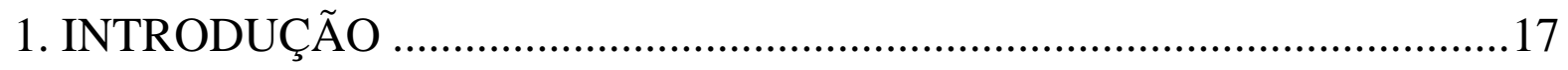

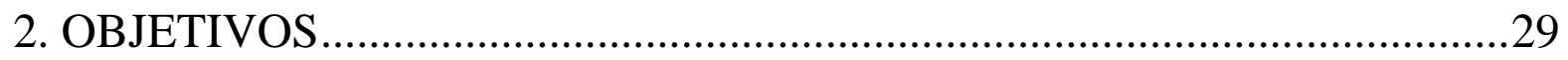

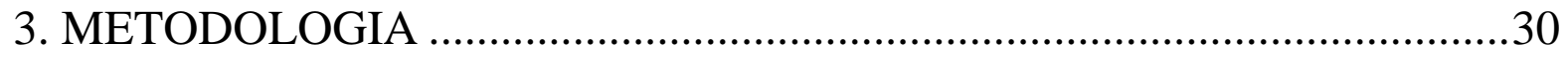

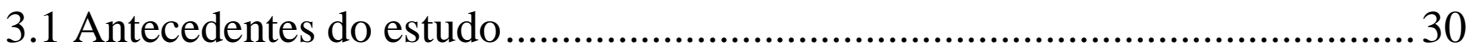

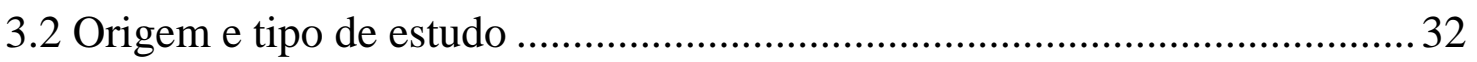

3.3 Local da pesquisa ................................................................................... 33

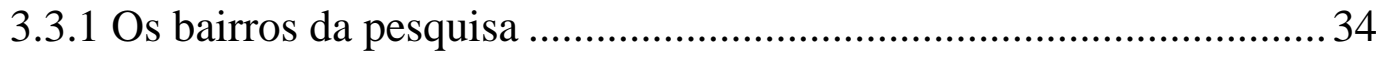

3.4 Seleção e tamanho da amostra ...................................................................... 37

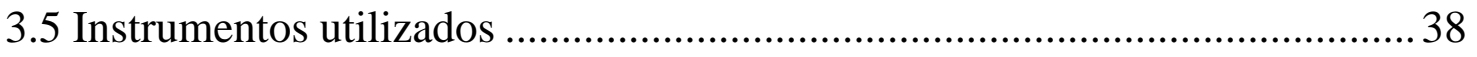

3.6 Procedimento de coleta dos dados ………................................................ 40

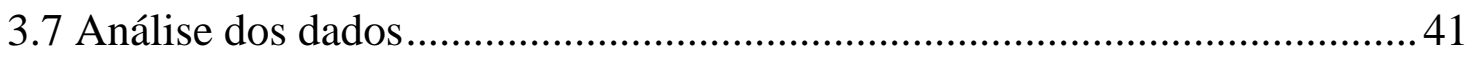

3.7.1 Ingestão de calorias e nutrientes..........................................................41

3.7.2 Qualidade da alimentação................................................................... 42

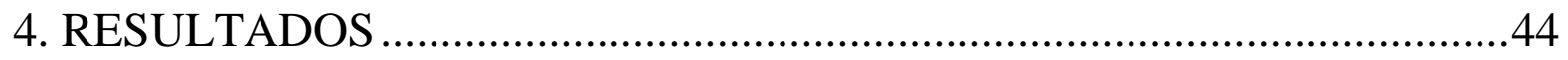

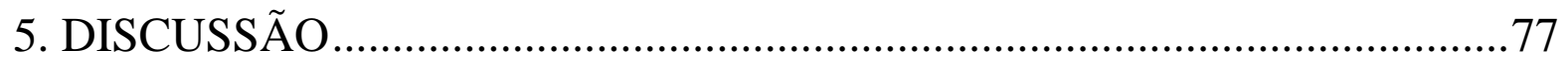

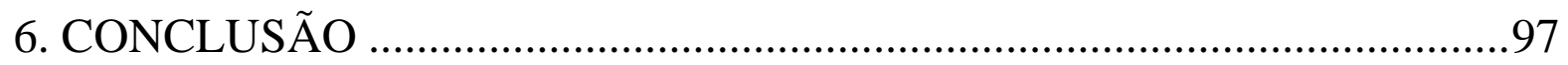

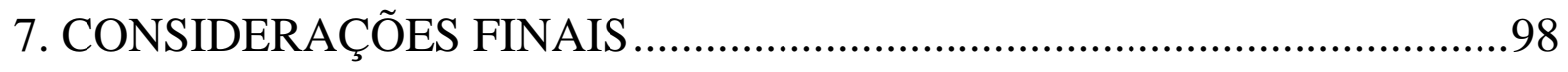

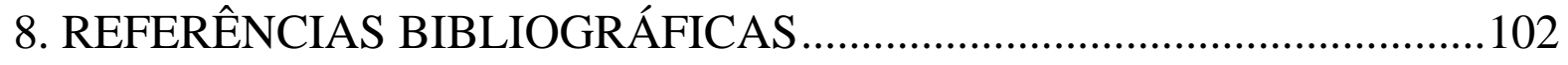

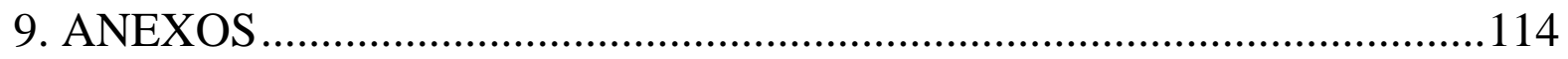




\section{INTRODUÇÃO}

\section{Alimentação e Cultura}

O estudo da alimentação humana é objeto de extrema complexidade, suscetível de mobilizar numerosas disciplinas científicas: a Epidemiologia, a Economia, a Sociologia, a Antropologia, a Nutrição, a História, a Psicologia, as disciplinas tecnológicas, entre outras. Cada uma produz, a partir de seu ponto de vista e das suas problemáticas principais, séries de dados que permitem estudar grandes tendências e alterações de comportamento e consumo alimentares (POULAIN; PROENÇA, 2003).

Conhecer e avaliar o consumo alimentar de grupos ou mesmo de indivíduos sempre foi uma tarefa muito difícil devido às práticas alimentares estarem inseridas nas dimensões simbólicas da vida social, envolvidas nos mais diversos significados, desde o âmbito cultural até as experiências pessoais (GARCIA, 2004).

Procurar saber e entender o papel da cultura na alimentação ajuda muito a esclarecer os comportamentos que se têm diante da comida e do ato de comer.

Braga (2004) refere que na Antropologia, a cultura pode ser entendida como um sistema simbólico, ou seja um conjunto de mecanismos de controle, planos, receitas, regras e instruções que governam o comportamento humano. Esses símbolos e significados são partilhados entre os membros do sistema cultural, assumindo um caráter público e, portanto, não individual ou privado (GEERTZ, 1979).

Tendo em vista essa afirmação, pode-se inferir que os hábitos alimentares fazem parte de um sistema cultural repleto de símbolos, significados e classificações, de modo que nenhum alimento está livre das associações culturais que a sociedade lhes atribui. O comportamento relativo à comida liga-se diretamente ao sentido de nós mesmos e à nossa 
identidade social, e isso parece valer para todos os seres humanos. Reagimos aos hábitos alimentares de outras pessoas, quem quer que sejam elas, da mesma forma que elas reagem aos nossos (MINTZ, 2001). A comida é uma forma de comunicação, na qual o indivíduo explicita inclusive sua visão de mundo, ou seja, “comer é revelar-se”. Percebe-se que a eleição dos alimentos satisfaz às necessidades do corpo, mas também, em grande medida, às necessidades da sociedade (BLEIL, 1998).

Portanto, o que se come, quando, com quem, por que e por quem é determinado culturalmente, transformando o alimento (substância nutritiva) em comida. Comida de criança, comida de domingo, comida de festa, etc. Esses são alguns exemplos de classificações dadas aos alimentos (BRAGA, 2004).

Um aspecto que não deixa de ser relevante e também faz parte do papel da cultura na alimentação é a formação do gosto que permite os indivíduos classificar as qualidades do sabor e como se formam suas preferências, por exemplo, pelo doce, amargo, salgado, picante, etc.

As características visuais, como a cor, forma e aparência de conjunto, também afetam a aceitabilidade e as preferências alimentares, pois configuram aspectos do simbolismo alimentar (BRAGA, 2004).

É notável, pois, que existe uma grande diferença entre comer, um ato social e nutrirse, uma atividade biológica.

Quando se analisa a formação dos hábitos de consumo em uma dada sociedade, deve-se não somente considerar sua nutrição fisiológica e todas as implicações que ela traz para a saúde dos indivíduos, mas principalmente, levar em consideração os aspectos culturais, sociais e econômicos envolvidos na escolha e preparação dos alimentos. 


\section{Mudanças no padrão da alimentação mundial}

São características dos períodos históricos cronologicamente divididos, as mudanças na alimentação dos povos e no estado nutricional de seus indivíduos. Entretanto, nos últimos três séculos e, especialmente, após a II Guerra Mundial, as transformações vêm acontecendo de forma cada vez mais veloz (POPKIN, 2002).

Bleil (1998) traz em seu artigo estudos que revelam alguns fatos ocorridos a partir de 1850 no Ocidente que possibilitaram uma aceleração nas mudanças alimentares. Os progressos na agricultura livraram da fome grande parte da população européia. Por outro lado, a urbanização, a tecnologia e o comércio tiveram impulso nunca dantes verificado. Produtos como o açúcar, o café e o chocolate conheceram público cada vez maior (SORCINELLI , 1998).

No século XX, o mundo vivenciou uma mudança radical no consumo alimentar dos

povos, principalmente nas últimas décadas com a globalização da economia e a industrialização crescente que exercem um papel importante devido à gama de produtos e serviços distribuídos em escala mundial e ao suporte publicitário envolvido (GARCIA, 2003).

Estamos vivenciando um processo mundial de transição demográfica, epidemiológica e nutricional verificada há mais tempo nos países desenvolvidos e, recentemente, nos países em desenvolvimento essas mudanças estão ocorrendo de forma mais acelerada.

A transição demográfica envolve modificações no nível do desenvolvimento de cada sociedade correspondendo a modificações no padrão de morbimortalidade (PINHEIRO; FREITAS; CORSO, 2004). Na maioria dos países economicamente mais favorecidos da América Central e da América do Sul, verifica-se a clássica mudança para 
um padrão de morbimortalidade em que predominam as doenças cardiovasculares, o câncer, o diabetes, a obesidade e outras doenças conhecidas como crônico-degenerativas ou crônico não-transmissíveis (MONTEIRO et al., 1995).

A transição epidemiológica é o resultado das variações comportamentais dos padrões de morbimortalidade e fecundidade, que determinam mudanças na estrutura populacional ao se processarem as alterações na maneira de adoecer e morrer. Seria, ao mesmo tempo, uma evolução gradual dos problemas de saúde caracterizados por alta morbidade e mortalidade por doenças infecciosas que passa a se caracterizar predominantemente por doenças crônicas não-transmissíveis (FERRARI; SAWAYA, 1997; PINHEIRO; FREITAS; CORSO, 2004; ZLOTNIK, 2002).

Por fim, é sabido que a transição nutricional integra os dois processos de transição demográfica e epidemiológica (PINHEIRO; FREITAS; CORSO, 2004), embora seu papel como causa e conseqüência da transição epidemiológica não esteja completamente entendido (MONTEIRO et al., 1995). Na definição de Popkin et al. (1993) esse processo diz respeito a mudanças seculares em padrões nutricionais que resultam de modificações na estrutura da dieta de indivíduos e que se correlacionam com mudanças econômicas, sociais, demográficas e relacionadas à saúde.

Todas essas transformações observadas nos países da América, no oeste da Europa e parte da Ásia (China) e África afetam o modo de viver das pessoas de forma substancial (POPKIN, 2002; DU et al., 2002).

Existe uma tendência crescente para o consumo de itens alimentares de maior densidade energética que é promovida pela indústria por meio da produção abundante de alimentos altamente calóricos, saborosos e de custo relativamente baixo (GARCIA, 2003). Aspectos singulares da transição nutricional ocorrida no século XX são encontrados em 
cada país e região do mundo, mas elementos comuns convergem para uma dieta rica em gorduras (particularmente as de origem animal), açúcar e alimentos refinados e reduzida em carboidratos complexos e fibras - freqüentemente denominada “dieta ocidental” - e esse padrão alimentar tem se expandido, sobretudo, em situações de prosperidade econômica (DREWNOWSKI, 2000; GARCIA, 2003; MARINHO et al., 2003; MONTEIRO et al., 1995).

Monteiro et al. (1995) enfatizam que tanto nos países desenvolvidos como naqueles em desenvolvimento nota-se que o predomínio desse padrão alimentar associado ao declínio progressivo da atividade física dos indivíduos têm aumentado de forma substancial, o que acaba resultando nas alterações concomitantes da composição corporal, em particular o aumento da obesidade, à alta prevalência de doenças crônico-degenerativas e à diminuição do tempo de vida livre de doenças.

As relações entre as mudanças demográficas, sócio-econômicas e epidemiológicas que levam à transição nutricional são complexas. De modo geral, as coortes mais jovens estão mudando mais rapidamente. Sabe-se que um estado de desnutrição prematura, seguido de uma alimentação inadequada ao longo da infância e idade adulta associados ao hábito de não praticar atividade física aumentam consideravelmente o surgimento das doenças crônico-degenerativas (ADAIR, 2002). Essas mudanças parecem ocorrer primeiro em áreas urbanas, estendendo-se depois aos segmentos de renda mais elevada das áreas rurais, freqüentemente coexistindo com estratos da população ainda submetidos a déficits energéticos (MONTEIRO et al., 1995).

Com isso, as práticas alimentares contemporâneas têm sido objeto de preocupação das ciências da saúde desde que os estudos epidemiológicos passaram a sinalizar estreita relação entre a dieta e algumas doenças crônicas associadas à alimentação. 


\section{A transição nutricional no Brasil e as pesquisas nacionais de consumo alimentar}

A urbanização resultante da migração e do aumento natural da população tornou-se

um fenômeno comum nos países em desenvolvimento, particularmente no Brasil. Grandes alterações econômicas e demográficas ocorreram no país nas últimas três décadas (19601990). Nesse período, a renda nacional mais do que triplicou e a participação do setor agrícola na economia foi reduzida de $17,8 \%$ para 6,9\%. Ao mesmo tempo, a população dobrou e a proporção de pessoas residindo em área urbana aumentou de 45\% para 75\%, enquanto as taxas de fertilidade caíram de mais de 6 para menos de 3 filhos por mulher (FERRARI; SAWAYA, 1997).

Em São Paulo, a renda familiar dobrou entre os anos de 1980 e 1990, o número de famílias com baixo poder aquisitivo caiu $50 \%$ e a escolaridade materna cresceu em 1,5 anos. Contudo, a tradução dos indicadores nutricionais e de saúde em um país com dimensões territoriais tão grandes e diversidades regionais tão marcantes, encobre realidades locais que apresentam particularidades, com ilhas de riqueza e a continuidade de situações de risco em bolsões de pobreza, observando-se claramente a interferência do fator renda quando os dados são desagregados (DOMENE, 2003).

Segundo Monteiro et al. (2002), o Brasil ocupa posição privilegiada para o entendimento do processo de transição nutricional ocorrido nas últimas décadas. Para esses autores, há quatro motivos que justificam esta colocação. O primeiro são as rápidas mudanças demográficas, socioeconômicas, ambientais e culturais que ocorreram no último quarto de século; o segundo é a disponibilidade das pesquisas nacionais de caráter transversal que o país desenvolve e fornecem subsídios para o entendimento dos padrões seculares no perfil nutricional da população; o terceiro são as dimensões continentais do Brasil (é o quinto maior país do mundo) e sua economia diversificada (a região Norte 
menos desenvolvida e a região Sul mais favorecida economicamente); isto proporcionaria entender o processo de transição nutricional em diferentes níveis de desenvolvimento econômico. Finalmente, o quarto motivo relaciona-se com a forte desigualdade social existente no país que permite comparar, individualizar e avaliar, dentro do processo de transição nutricional, os estratos populacionais mais ricos dos estratos populacionais mais pobres nas diferentes regiões do território brasileiro.

No Brasil, como nos demais países em desenvolvimento, ainda são escassos os estudos sobre consumo alimentar, pois são poucas as fontes de dados disponíveis e a maioria dos trabalhos existentes privilegiam somente a produção ou o abastecimento (OLIVEIRA; THÉBAUD-MONY, 1997).

A investigação direta do consumo alimentar, a partir da aplicação de inquéritos dietéticos, constitui a forma ideal para se caracterizar os padrões dietéticos vigentes em uma dada população e sua evolução ao longo do tempo. Entretanto, a grande variabilidade que usualmente caracteriza o consumo alimentar dos indivíduos exige o estudo de grandes amostras por períodos relativamente longos de tempo, condição que encarece os inquéritos dietéticos e os torna pouco factíveis (MONTEIRO; MONDINI; COSTA, 2000).

De modo geral, a tendência da evolução de padrões dietéticos tem sido avaliada com base em dados sobre disponibilidade de alimentos. Esses dados, compilados anualmente pela Organização das Nações Unidas para a Alimentação e a Agricultura (FAO), indicam a quantidade potencial média de alimentos disponíveis para consumo humano em cada país e são calculados com base em estimativas da produção, da importação e da exportação de produtos alimentares e em percentual arbitrado de desperdício, sendo, na maioria das vezes, a única fonte regular e padronizada de informações sobre padrões alimentares (MONDINI; MONTEIRO, 1994). 
Uma melhor alternativa, na ausência de inquéritos dietéticos, é representada pelas pesquisas de orçamento familiar (POF). As POFs são inquéritos domiciliares que, a partir do levantamento sistemático dos gastos com alimentos e bebidas e dos preços praticados nos locais de compra desses itens alimentares, permitem estimar a disponibilidade individual de alimentos de cada família. Quando realizadas com regularidade, propiciam a formação de séries temporais, essenciais para a identificação de mudanças em padrões de consumo alimentar. Além disso, as POFs permitem a desagregação de informações para estratos socioeconômicos e geográficos, possibilitando o estudo de grupos específicos da população. São limitações das POFs, contudo, a não-consideração da fração desperdiçada dos alimentos, o não-registro dos alimentos doados ou consumidos fora do domicílio e a inexistência de informações sobre a distribuição intra familiar dos alimentos (MONDINI; MONTEIRO, 1994; MONTEIRO; MONDINI; COSTA, 2000).

Os dados nacionais sobre consumo alimentar podem ser encontrados no Estudo Nacional sobre Despesa Familiar (ENDEF) de 1974/1975, realizado pelo Instituto Brasileiro de Geografia e Estatística (IBGE), além das Pesquisas de Orçamento Familiar (POFs) de 1986/1988, de 1995/1996 e, mais recentemente, a de 2002/2003 também realizadas pelo IBGE, além da Pesquisa Nacional sobre Saúde e Nutrição (PNSN) de 1989, desenvolvida em parceria com o Ministério da Saúde, o IBGE e a Fundação Instituto de Pesquisas Econômicas e Aplicadas (IPEA).

Para preencher a lacuna existente no Brasil sobre os estudos de consumo alimentar, o Ministério da Saúde dispõe de uma pesquisa realizada com universidades brasileiras nos anos de 1996/1997 e que levantou o consumo alimentar em 5 cidades do país: Campinas, Curitiba, Goiânia, Ouro Preto e Rio de Janeiro. O trabalho intitula-se "Estudo Multicêntrico sobre Consumo de Alimentos” e o diferencial em relação às pesquisas nacionais existentes 
está na metodologia do trabalho que utiliza inquéritos para avaliar o consumo familiar mensal e o questionário de freqüência para avaliar o consumo individual (GALEAZZI; DOMENE; SICHIERI, 1997).

Nos últimos anos inúmeros estudos têm constatado aumento na prevalência de obesidade nos países em desenvolvimento, onde o excesso de peso se apresenta atualmente como grave problema de saúde pública (MONTEIRO; CONDE, 1999; MARINHO et al., 2003; MENDONÇA; ANJOS, 2004; PINHEIRO; FREITAS; CORSO, 2004).

A economia de gasto de energia humana no trabalho e a maior oferta de alimentos mudaram radicalmente o modo de viver do brasileiro. Os processos de urbanização, industrialização e a nova era global foram responsáveis pela profissionalização das mulheres que "abandonam” os lares em busca do mercado de trabalho e, com isso, cresce vertiginosamente as refeições feitas fora de casa (SORCINELLI, 1998). Soma-se a isso a escassez de tempo para o preparo e consumo de alimentos; pela presença de produtos gerados com novas técnicas de conservação e de preparo, que agregam tempo e trabalho; pelo vasto leque de itens alimentares; pela crescente oferta de preparações e utensílios transportáveis; pela oferta de produtos provenientes de várias partes do mundo; pelo arsenal publicitário associado aos alimentos; pela flexibilização de horários para comer agregada à diversidade de alimentos; pela crescente individualização dos rituais alimentares, etc (GARCIA, 2003).

Este modus vivendi urbano parece ter influência direta nas práticas alimentares dos indivíduos de uma dada população.

É sabido que características qualitativas da dieta são igualmente importantes na definição do estado de saúde, em particular no que se refere às doenças crônicas da idade adulta (SICHIERI; CASTRO; MOURA, 2003). 
A maior parte dos estudos sobre a relação entre características da dieta e obesidade evidencia uma associação positiva entre proporção da energia procedente de gorduras e risco de obesidade. A relação entre consumo de gorduras saturadas, níveis plasmáticos de colesterol e risco de doença coronariana foi uma das primeiras a ser comprovada empiricamente. Assim como ocorre com as gorduras saturadas, o consumo elevado de colesterol também pode aumentar o risco de doença coronariana (STAMLER; SHEKELLE, 1988; BRAY; POPKIN, 1998). O risco do câncer de mama, próstata e cólon-reto parece aumentar com o consumo total de gordura e com o consumo de gordura de origem animal, enquanto dietas com legumes, verduras e frutas cítricas, ou seja, com níveis elevados de fibras, vitaminas e minerais, certamente protegem os indivíduos de cânceres de pulmão, boca, faringe, esôfago, estômago e cólon-reto (WHO, 1990).

Recentemente, no Brasil, o IBGE publicou os resultados da última POF realizada em 2002/2003 e as conclusões desta pesquisa corroboram estudos anteriores que avaliaram as tendências e práticas alimentares da população brasileira nos últimos 30 anos (MONDINI; MONTEIRO, 1994; MONTEIRO et al., 1995; MONDINI; MONTEIRO, 2000; IBGE, 2004).

Pode-se notar que alimentos e grupos de alimentos cuja participação na dieta aumentou entre 1974-1975 e 2002-2003 incluem carnes em geral (aumento de quase 50\%), leite e derivados (aumento de 36\%), óleos e gorduras vegetais (aumento de 16\%), biscoitos (aumento de 400\%) e refeições prontas (aumento de 80\%). Alimentos e grupos de alimentos que mostraram tendência inversa incluem arroz (redução de 23\%), feijões e demais leguminosas (redução de 30\%), raízes e tubérculos (redução de 30\%), peixes (redução de quase 50\%), ovos (redução de 84\%) e gordura animal (redução de 65\%). Açúcar e refrigerantes mostraram tendências opostas no período, com redução do primeiro 
(23\%) e aumento do segundo (400\%). A participação na dieta de frutas, verduras e legumes permaneceu relativamente constante durante todo o período (entre 3\% e 4\%) e bastante aquém, portanto, da recomendação de 6\%-7\%, segundo a WHO (1990).

Além disso, a pesquisa revela a evolução do perfil antropométrico-nutricional entre 1974-1975 e 2002-2003 e demonstra que a prevalência de déficits ponderais nas últimas três décadas indica declínio contínuo da exposição à desnutrição em todas as regiões do país e em todas as classes de rendimento. Conclui ainda, que a prevalência do excesso de peso na população adulta brasileira em 2002-2003 é um problema que alcança grande expressão em todas as regiões do país, no meio urbano e no meio rural e também em todas as classes de rendimentos. No caso específico das mulheres, os aumentos generalizados da prevalência do excesso de peso são observados apenas no período de 1974-1975 a 1989. No segundo período (de 1989 a 2002-2003), a prevalência do excesso de peso na população feminina continua aumentando apenas na região Nordeste e, de modo geral, entre famílias com rendimento mensal de até meio salário mínimo per capita. Nas demais regiões e nas classes de maior renda, a prevalência do excesso de peso se estabiliza ou mesmo declina (IBGE, 2004).

Em linhas gerais, as conclusões deste trabalho demonstram um desequilíbrio de ingestão alimentar que reflete em alterações da composição corporal dos indivíduos. Portanto, tem-se constantemente pensado em formas de modificar esse perfil populacional estimulando as pessoas a desenvolverem hábitos de vida mais saudáveis por meio de uma alimentação equilibrada e mudanças no estilo de vida.

Uma das propostas seria o uso de instrumentos que permitissem à população tomar conhecimento de sua ingestão alimentar, conscientizando-a das práticas saudáveis de uma alimentação nutricionalmente balanceada. 
No Brasil, profissionais da área da saúde têm utilizado a Pirâmide Alimentar Brasileira que nada mais é do que um guia alimentar que representa graficamente a distribuição dos vários grupos de alimentos (cereais, frutas, vegetais, leguminosas, leite, carnes, gorduras e açúcares) segundo o número de porções diárias que devem ser ingeridas visando à saúde global dos indivíduos e a prevenção de doenças (PHILIPPI et al., 1999b).

Diante desse contexto, o presente trabalho tem por base estudos realizados na cidade de Ribeirão Preto que objetivaram a análise de fatores sociais, culturais e alimentares que contribuem para o risco do surgimento das doenças cardiovasculares, especialmente pressão alta e lipidemia (DRESSLER; SANTOS; VITERI, 1986, 1993; DRESSLER et al., 1987; DRESSLER; SANTOS; BALIEIRO, 1999; DRESSLER; SANTOS, 2000, 2001).

Essa linha de pesquisa teve início em 1984 e nos anos de 1991 e 2001 novos estudos foram realizados com o intuito de aprimorar a teoria e o método empregados na pesquisa inicial e enriquecer as análises.

Essas investigações foram desenvolvidas numa parceria da Faculdade de Medicina de Ribeirão Preto da Universidade de São Paulo com a Universidade do Alabama (EUA) e, particularmente, este trabalho utiliza os dados alimentares e antropométricos obtidos nos anos de 1991/93 e 2001/03, respectivamente. 


\section{OBJETIVOS}

\section{Geral}

Avaliar e comparar o estado nutricional e o consumo alimentar de indivíduos adultos residentes em Ribeirão Preto-SP com diferentes níveis socioeconômicos, no período entre 1991/93 e 2001/03.

\section{Específicos}

- Determinar o estado nutricional dos participantes por meio do cálculo do Índice de Massa Corporal (IMC) obtido pela relação peso/altura².

- Calcular a ingestão alimentar referente ao consumo de calorias totais, proteínas, carboidratos, gorduras totais e suas frações (saturada, monoinsaturada e polinsaturada), colesterol e fibras.

- Analisar a qualidade da alimentação por meio da freqüência de ingestão dos alimentos segundo os grupos alimentares (cereais, frutas, vegetais, leguminosas, leite, carnes, gorduras e açúcares). 


\section{METODOLOGIA}

\subsection{Antecedentes do estudo}

Desde a década de 80 vêm sendo desenvolvidas pesquisas em Ribeirão Preto-SP que auxiliam na construção de uma abordagem teórico-metodológica. No ano de 1984, especificamente, Fernando Viteri e os colaboradores William W. Dressler, José Ernesto dos Santos, Adolfo Chaves e Grell Gerald desenvolveram o projeto "Prevention of Cardiovascular Disease in Developing Countries” - PRECAVAS, com o intuito de formular correlações biológicas e psicológicas com a pressão sangüínea nos habitantes desta cidade. Foi selecionada ao acaso uma amostra de 80 famílias com diferente nível socioeconômico e com atividades ocupacionais distintas (bóias-frias, trabalhadores rurais, industriários e bancários). Neste estudo investigou-se como os efeitos das mudanças socioculturais no Brasil poderiam afetar a saúde, a respeito do risco de doenças cardiovasculares. Além dos hábitos alimentares, dados sobre a saúde (composição corporal, histórico médico e pressão sangüínea), o estilo de vida, o suporte social e a condição econômica dos entrevistados também foram analisados. Este primeiro estudo sugeriu que fatores sociais poderiam ser importantes para a etiologia da hipertensão arterial nessa comunidade (DRESSLER; SANTOS; VITERI, 1986, 1993; DRESSLER et al., 1987, 1991; DRESSLER, 1991; DRESSLER et al., 1991).

Posteriormente a estes achados, um segundo trabalho foi efetuado para corrigir algumas imperfeições do primeiro projeto.

Este estudo foi nomeado SEPA - "Social Environment and Physiologic Adaptation” e desenvolvido no período entre 1991 e 1994 sob o financiamento da National 
Science Foundation-USA. O investigador principal foi o Prof. Dr. William W. Dressler e o co-investigador foi o Prof. Dr. José Ernesto dos Santos.

Nesta pesquisa, empregou-se um número maior de pessoas (amostra de 304 indivíduos) se comparado ao primeiro estudo e buscaram-se inovações em teoria e métodos antropológicos, adotando os conceitos de consenso cultural ${ }^{*}$ e consonância cultural ${ }^{* *}$ (DRESSLER, 1996).

Foram investigados os dados sobre saúde, hábitos alimentares, estilo de vida, suporte social e condições socioeconômicas. Os resultados globais desta pesquisa podem ser resumidos da seguinte forma: quanto maior a proximidade do comportamento de cada indivíduo com as expectativas compartilhadas dos indivíduos locais dos domínios culturais de estilo de vida e suporte social, melhor será sua adaptação física e psicológica. Esses resultados sugeriram que no mínimo parte da associação da posição social e do resultado adaptativo são mediados pela habilidade relativa dos indivíduos em agir sobre as expectativas compartilhadas de sua cultura a respeito dessas posições (DRESSLER; BALIEIRO; SANTOS, 1996, 1997, 1998, 1999; DRESSLER; SANTOS 2000, 2001; SANTOS, OTHS; DRESSLER, 2001).

Finalmente, entre 2001 e 2004 e também sob a coordenação dos mesmos investigadores do projeto SEPA foi desenvolvido o projeto CADI - “Cultura e Adaptação Individual" no qual a amplitude de diversidade socioeconômica foi sistematicamente amostrada em Ribeirão Preto.

\footnotetext{
* Refere-se ao modo como um modelo cultural é compartilhado e valorizado pelos indivíduos.

** Refere-se ao grau com que o indivíduo, em seu próprio comportamento ou crença, se aproxima do modelo cultural compartilhado em um específico domínio cultural.
} 
O propósito desta terceira investigação foi examinar a relação entre os vários fatores (sociais, culturais e alimentares) que poderiam contribuir para o risco de doenças cardiovasculares, especialmente pressão arterial e lipidemia. Os fatores analisados incluíram fatores sociais e culturais que poderiam aumentar o estresse na vida de uma pessoa, além de fatores alimentares que poderiam favorecer o desenvolvimento de obesidade e criar padrões mais suscetíveis ao desenvolvimento de hiperlipidemias (DRESSLER et al., 2003; OTHS; CAROLO; SANTOS, 2003).

Desse modo, o projeto CADI objetivou estender e ampliar os achados dos dois projetos anteriores.

\subsection{Origem e tipo de estudo}

Este trabalho foi originado a partir dos dados coletados do projeto CADI ("Cultura e Adaptação Individual”) realizado em 2001/03 e de seu estudo anterior denominado SEPA (“Social Environment and Physiologic Adaptation”), de 1991/93.

Trata-se de um estudo transversal e retrospectivo que busca avaliar e comparar o consumo alimentar e o estado nutricional de uma parte da população de Ribeirão Preto representada pelas diferenças socioeconômicas de cada bairro visitado. Esse estudo realizou-se em dois momentos distintos, ou seja, foi feita uma avaliação dos dados coletados entre 1991 e 1993 e uma avaliação dos dados coletados entre 2001 e 2003.

Quanto aos aspectos éticos, o Comitê de Ética em Pesquisa do Hospital das Clínicas da Faculdade de Medicina de Ribeirão Preto sob o processo nº 9028/2001 emitiu parecer de aprovação para que a pesquisa pudesse ser desenvolvida no país. (ANEXO A) 


\subsection{Local da pesquisa}

Esta pesquisa teve como local de estudo a cidade de Ribeirão Preto-SP, município com 535.698 habitantes e área total de $642 \mathrm{~km}^{2}$. A população feminina alcança 52\% do total de habitantes e a população masculina perfaz os 48\% restantes (SEADE, 2005).

Com uma localização privilegiada, Ribeirão Preto está a 317 km a nordeste de São Paulo. A cidade tem ainda ligação com Brasília, Belo Horizonte, Campinas e com o porto de Santos, distante pouco mais de $400 \mathrm{~km}$. Com PIB superior a US\$ 18 bilhões, a região desenvolve-se baseada em uma economia dinâmica, moderna e produtiva. Na região, estão concentrados 34 mil propriedades rurais, 65 mil estabelecimentos comerciais e de serviços e 3.100 indústrias (STAR GUIA NET, 2001).

Em primeiro lugar deve-se destacar o desempenho da agricultura. A qualidade dos solos (uma grande mancha de terra roxa) e do clima fazem com que esta seja uma das principais regiões agrícolas do estado de São Paulo e do país, caracterizando-se por uma grande produção e por elevados níveis de rendimento das culturas, com destaque para a cana de açúcar, a laranja, a soja, o amendoim, a fruticultura em geral, entre outras (PREFEITURA, 2005).

Em relação à indústria deve-se destacar a força da agroindústria, que está muito relacionada ao desempenho do setor primário. A região é a maior produtora mundial de açúcar e álcool. As usinas representam uma das principais atividades econômicas da região. São 21 usinas que empregam em torno de 8.000 empregados. Isso acaba estimulando o desenvolvimento de outros setores, como por exemplo, o de máquinas agrícolas e equipamentos para usinas. Além das usinas, fazem-se presente na região, várias indústrias de suco de laranja, beneficiadoras de café, soja, amendoim, etc.; indústrias alimentícias, 
indústrias de ração, fertilizantes, entre outras. Ou seja, existe um amplo complexo agroindustrial na região (PREFEITURA, 2005).

Ribeirão Preto também é um centro de referência nacional nas áreas de educação, saúde e pesquisas. Nela há 146 escolas de $1^{\circ}$ e $2^{\circ}$ graus, oito faculdades com 42 cursos, duas escolas profissionalizantes e outras duas com cursos de curta duração - SENAC e SENAI - ligadas a entidades de comércio e da indústria. Com 11 hospitais e quase 2.000 médicos, a cidade conta com um dos maiores centros de pesquisas médicas do Brasil, o Hospital das Clínicas da Faculdade de Medicina da Universidade de São Paulo (STAR GUIA NET, 2001).

Percebe-se, portanto, que Ribeirão Preto é o centro de uma região privilegiada em termos econômicos. O dinamismo econômico do município colabora com o desempenho econômico da região e é por este influenciado, ampliando as chances de sucesso dos negócios aqui instalados e a qualidade de vida dos que aqui residem (PREFEITURA, 2005).

Devido a esses fatores, a cidade foi escolhida como local de desenvolvimento deste estudo por representar um local apropriado de pesquisa e devido ao seu considerável contingente de variabilidade sociocultural e dietético na sua comunidade.

\subsubsection{Os bairros da pesquisa}

Para o desenvolvimento deste estudo, quatro bairros foram selecionados com o intuito de representar a amplitude de diversidade socioeconômica em Ribeirão Preto.

Portanto, os bairros escolhidos em 2001/03 (projeto CADI) foram os mesmos estudados na pesquisa anterior de 1991/93 (projeto SEPA), a seguir: Maria Casagrande, Conjunto Habitacional José Sampaio, Vila Tibério e Jardim Recreio. 
Vale ressaltar que desde o último estudo feito entre 1991 e 1993 houve uma campanha municipal de erradicação das favelas em Ribeirão Preto. Assim, o bairro Maria Casagrande que outrora fora considerado uma favela, hoje recebe a denominação de conjunto habitacional com casas simples construídas com monoblocos de concreto, dois quartos e um banheiro e todas as moradias dispõem de água encanada e esgoto. Neste local, os moradores pagam aluguel pelo uso das moradias, não são os proprietários das mesmas.

Nos anos subseqüentes à pesquisa de 1991/93 foram feitos contatos com os moradores da antiga favela do Maria Casagrande e havia informações que estimavam uma porcentagem de $50 \%$ da população original da favela que se transferiu para as casas de concreto construídas e, embora, estas novas moradias representassem melhoria nas condições de vida de seus moradores, essa expectativa não representou mudanças significativas no estilo de vida desta população. Portanto, como forma de maximizar e comparar os achados de 1991/93 com as observações feitas em 2001/03, o bairro Maria Casagrande continuou fazendo parte de um dos locais selecionados para a pesquisa.

Em geral os moradores dessa região possuem uma baixa condição socioeconômica e comumente ocupam postos de trabalho que exigem pouca especialização. O bairro é todo pavimentado, com um pequeno comércio (um mercado, um varejão e alguns bares), um posto de saúde e uma escola municipal com nível infantil e fundamental.

Outro local visitado foi o Conjunto Habitacional José Sampaio, cuja construção teve início em 1988, numa parceria do governo local e uma construtora. O bairro conta com serviços básicos, tais como: escolas municipais de níveis infantil e fundamental, posto de saúde, bem como pequenas lojas, restaurantes, mercados, varejão, bares e farmácias. Os moradores pertencem predominantemente à classe média baixa e possuem empregos estáveis. 
A Vila Tibério é um dos bairros mais antigos da cidade de Ribeirão Preto e também foi selecionado para o estudo. Surgiu no início do século $\mathrm{XX}$, com a vinda de imigrantes italianos e espanhóis. É um tradicional bairro de classe média e média-baixa e localiza-se próximo à região central do município. Muitas de suas ruas são pavimentadas com paralelepípedos e a maioria das casas foi construída sem recuo no alinhamento da calçada. Há uma grande variabilidade no comércio instalado nessa região, com supermercados, bares, farmácias, restaurantes, hotéis, livrarias, postos de gasolina, além de uma ampla rede de serviços públicos, tais como escolas de ensino infantil, fundamental e médio e postos de saúde. No que diz respeito ao perfil ocupacional, esta população tende a se estabelecer de forma variada no ramo de pequenos negócios, ou trabalham como gerentes e subgerentes em serviços públicos e no comércio em geral.

Por fim, o último bairro investigado foi o Jardim Recreio que se localiza bem afastado do centro, próximo ao campus da Universidade de São Paulo (USP), e seus moradores pertencem à classe média alta. É um bairro relativamente novo, bastante arborizado e possui ruas bem largas. As casas, em sua maioria, têm terrenos amplos e no bairro não é permitida a instalação de serviços e estabelecimentos comerciais, à exceção de uma tradicional escola de ensino infantil e fundamental, mantida por uma entidade religiosa, e a presença de um hotel antigo que hoje se encontra desativado.

Há uma atuante associação de moradores que cuida da preservação do local e grande parte dos que lá residem são formados prioritariamente por professores universitários, gerentes de cargo elevado e também empresários e profissionais liberais. 


\subsection{Seleção e tamanho da amostra}

Os levantamentos de 1991/93 e 2001/03 foram semelhantes em relação aos sujeitos e campos de estudo, logo, foram selecionados indivíduos adultos de ambos os sexos na faixa etária entre 18 e 65 anos de idade.

A Tabela 1 mostra a distribuição dos participantes deste estudo pelos quatro bairros da cidade escolhidos para essa pesquisa.

Tabela 1 - Distribuição da população de homens e mulheres nos estudos SEPA (1) e CADI (2), segundo os bairros visitados. Ribeirão Preto, 1991/93 e 2001/03.

\begin{tabular}{c|c|c|c|c|c|c}
\hline Bairros & \multicolumn{3}{|c|}{ SEPA (1) } & \multicolumn{3}{c}{ CADI (2) } \\
\hline & Homens & Mulheres & Total & Homens & Mulheres & Total \\
\hline Maria Casagrande & 34 & 49 & 83 & 20 & 46 & 66 \\
\hline José Sampaio & 30 & 45 & 75 & 25 & 40 & 65 \\
\hline Vila Tibério & 27 & 46 & 73 & 31 & 40 & 71 \\
\hline Jardim Recreio & 32 & 41 & 73 & 30 & 39 & 69 \\
\hline Total & 123 & 181 & 304 & 106 & 165 & 271 \\
\hline
\end{tabular}

Para realizar a amostragem dos habitantes dos bairros foi obtida no Departamento de Água e Esgoto de Ribeirão Preto (DAERP) uma listagem contendo todos os endereços de cada bairro. De posse desta lista, realizou-se um sorteio aleatório, no qual foram sorteadas as residências nas quais os moradores foram convidados a participar. Esta técnica de amostragem probabilística foi aplicada nos dois estudos. 
Decidiu-se por entrevistar em média 40 famílias em cada bairro e essa escolha foi fundamentada na experiência do projeto SEPA, uma vez que os resultados obtidos naquele momento proporcionaram um consistente poder estatístico. Adotou-se, portanto, semelhante procedimento em ambos os períodos avaliados.

\subsection{Instrumentos utilizados}

Para a coleta das informações sobre consumo alimentar dos participantes do estudo foi empregado o método recordatório de 24 horas (ANEXO B) que consiste na anotação da informação sobre a ingestão alimentar (alimentos e bebidas) do dia anterior ao agendado para a entrevista. Esse método retrospectivo foi aplicado pelas entrevistadoras em um dia de semana e em um dia de final de semana no intuito de registrar o consumo habitual dos sujeitos.

O método recordatório de 24 horas é de fácil e rápida administração, tem baixo custo e pode ser aplicado em grupos de baixo nível de escolaridade (KAMIMURA et al., 2002).

Foi utilizado nas entrevistas um livro de fotos com vários tipos de alimentos e preparações para facilitar a identificação das porções alimentares consumidas pelos entrevistados (ZABOTTO; VIANA; GIL, 1996).

Quanto à obtenção dos dados de peso e altura, foram utilizadas uma balança portátil com capacidade de $150 \mathrm{Kg}$ e uma fita métrica fixada na parede para anotação da altura dos indivíduos.

As medidas antropométricas foram tomadas por uma enfermeira devidamente treinada para a realização dos procedimentos e os indivíduos foram pesados sem calçados, 
com roupas leves e sem portar acessórios. Para a anotação da altura os sujeitos também se apresentavam descalços ou com meias (LOHMAN; ROCHE; MARTORELL, 1988).

Os valores de IMC, obtidos com os dados de peso e altura e calculados a partir da relação peso/altura ${ }^{2}\left(\mathrm{Kg} / \mathrm{m}^{2}\right)$, (HOFFMAN; HEYSMFIELD; WAITZBERG, 2004) foram utilizados segundo os padrões da Organização Mundial de Saúde (WHO, 1997). (Tabela 2)

Tabela 2 - Classificação do estado nutricional de adultos segundo valores de IMC. OMS, 1997.

\begin{tabular}{c|c}
\hline IMC $\mathbf{( K g / \mathbf { m } ^ { 2 } )}$ & Classificação \\
\hline$<16,0$ & Magreza grau III \\
\hline $16,0-16,9$ & Magreza grau II \\
\hline $17,0-18,4$ & Magreza grau I \\
\hline $18,5-24,9$ & Eutrofia \\
\hline $25,0-29,9$ & Pré-obeso \\
\hline $30,0-34,9$ & Obesidade grau I \\
\hline $35,0-39,9$ & Obesidade grau II \\
\hline$\geq 40,0$ & Obesidade grau III \\
\hline
\end{tabular}

Para analisar a qualidade da alimentação, as medidas caseiras dos alimentos e bebidas consumidos pelos indivíduos que foram registradas no primeiro recordatório de 24 horas (dia de semana), foram transformadas em porções segundo critérios estabelecidos pela Pirâmide Alimentar Brasileira (PHILIPPI et al., 1999b). 
Esses valores foram digitados em planilha do Excel para que as médias da freqüência de consumo das porções alimentares nos diferentes grupos da Pirâmide pudessem ser calculadas e comparadas com a recomendação.

Utilizou-se a Pirâmide Alimentar Brasileira que é uma das formas gráficas recomendadas para representar a distribuição dos alimentos visando uma melhor compreensão por parte da população.

Trata-se de um instrumento de orientação nutricional usado por vários profissionais da área da saúde com objetivo de promover mudanças de hábitos alimentares melhorando a saúde global dos indivíduos e ajudando na prevenção de doenças (PHILIPPI, 1999a).

\subsection{Procedimento de coleta dos dados}

A coleta dos dados do estudo realizado em 1991/93 aconteceu no período entre março de 1991 e junho de 1993 e a obtenção dos dados no estudo de 2001/03 foi realizada entre agosto de 2001 e agosto de 2003.

Em 1991/93 os assistentes de pesquisa foram um psicólogo, duas nutricionistas e uma enfermeira. Já em 2001/03, a totalidade dos dados foi coletada por cinco assistentes de pesquisa, dentre eles duas psicólogas, duas nutricionistas (incluindo a minha participação) e uma enfermeira.

A abordagem dos sujeitos da pesquisa foi feita da seguinte forma: os moradores das casas cujos endereços haviam sido sorteados eram convidados, em suas residências, a participar do estudo. Esse primeiro contato era feito por dois assistentes de pesquisa (uma psicóloga e uma nutricionista) que explicavam verbalmente os objetivos do estudo, os procedimentos que seriam realizados, a duração média dos mesmos e o critério para a participação (morador do local e na faixa etária de 18 a 65 anos). Nesse momento, era 
entregue ao morador uma carta de apresentação do projeto com a explicação dos passos e procedimentos da pesquisa (ANEXO C). Posteriormente, era feito um contato via telefone ou diretamente na residência das pessoas para confirmar ou não a participação no projeto. Se o morador aceitasse o convite, era agendada a primeira entrevista. Entretanto, se houvesse recusa em participar, o assistente de pesquisa agradecia e registrava o motivo alegado.

Seguia-se, então, uma série de encontros que sempre eram iniciados pelas psicólogas que explicavam novamente o objetivo do estudo, os procedimentos que viriam posteriormente àquela entrevista e solicitava o consentimento do sujeito formalizando-o com o Termo de Consentimento Livre e Esclarecido (ANEXO D). No final desta primeira entrevista a psicóloga agendava o próximo encontro com a nutricionista e a terceira e quarta entrevistas eram combinadas com a nutricionista e a enfermeira, respectivamente.

As entrevistas, na maioria das vezes, eram feitas nos próprios domicílios, salvo em alguns casos de preferência do entrevistado, como local de trabalho, por exemplo.

Adotou-se como critério de exclusão da residência sorteada quando esta tinha sido visitada por três vezes em dias distintos e em três horários alternados, ou seja, matutino, vespertino e noturno e aos finais de semana, sem encontrar alguma pessoa na residência.

\subsection{Análise dos Dados}

\subsubsection{Ingestão de calorias e nutrientes}

Para análise dos dados quantitativos foi considerada a amostra total dos indivíduos participantes dos estudos de 1991/93 e 2001/03, ou seja, 304 e 271 sujeitos, respectivamente.

Os dados de alimentação dos sujeitos obtidos nos dois recordatórios de 24 horas em 1991/93 foram calculados com auxílio do Programa de Apoio à Nutrição, versão 2.5 da 
Escola Paulista de Medicina - Unifesp (ANÇAO et al., 1996) e os dados alimentares dos sujeitos obtidos em 2001/03 foram analisados pelo DietPro, versão 3.0 da Universidade Federal de Viçosa-MG (AGROMIDIA, 2000). Optou-se pela escolha de um novo programa de cálculo alimentar em 2001/03 por ser mais completo, mais atualizado e dotado de mais recursos para avaliação nutricional.

Após os cálculos dos nutrientes, as respectivas médias dos dois recordatórios de 24 horas foram transferidas para uma planilha do Excel e esta foi transportada para o programa SPSS (Statistical Package for Social Sciences), onde os testes estatísticos foram realizados (SPSS, 1995).

Para descrição e comparação dos dados obtidos realizou-se a Análise de Variância (ANOVA) e as variáveis dependentes deste estudo foram as medidas de: IMC, calorias totais, proteínas, carboidratos, gorduras totais, gorduras saturada, monoinsaturada e polinsaturada, colesterol e fibras. Para cada variável estudada, os quatro bairros visitados (Maria Casagrande, Vila Tibério, José Sampaio e Jardim Recreio) e o tipo de estudo (1 = SEPA e 2 = CADI) foram os fatores fixos da análise. Ainda, entre os bairros, foi feito um teste que analisa as diferenças e significâncias estatísticas quando mais de dois fatores estão envolvidos (post hoc).

Adotou-se o nível de significância igual a 0,05 para comparação dos dados.

\subsubsection{Qualidade da alimentação}

Para análise dos dados qualitativos foi considerada uma parte da amostra total dos indivíduos participantes dos dois estudos.

Por meio de um sorteio aleatório selecionou-se uma amostra de $25 \%$ dos sujeitos da pesquisa de 1991/93 e de 2001/03, uniformemente distribuída de acordo com a faixa etária e 
os quatro bairros estudados. Portanto, o total de pessoas do estudo de 1991/93 (SEPA) foi de 76 e do estudo de 2001/03 (CADI) foi de 67.

Optou-se por analisar a frequiência de ingestão alimentar dos participantes apenas com os dados obtidos no primeiro recordatório de 24 horas realizado durante o dia de semana. Dessa maneira, supõe-se obter o registro da alimentação mais tipicamente consumida pela população estudada.

Obtiveram-se as médias da freqüência de consumo das porções alimentares segundo os grupos da Pirâmide Alimentar Brasileira (cereais, frutas, vegetais, leguminosas, leite, carnes, gorduras, e açúcares) e os valores, posteriormente, foram comparados à recomendação (PHILLIP et al., 1999b). 


\section{RESULTADOS}

\subsection{Características sócio-demográficas da amostra}

Este estudo que foi realizado em dois momentos distintos nos anos de 1991/93 (SEPA) e 2001/03 (CADI), contou com a participação total de 304 e 271 indivíduos adultos de ambos os sexos e com idade variando de 18 a 65 anos, respectivamente.

A porcentagem de mulheres foi maior nos dois estudos e em todos os quatro bairros estudados (Gráfico 1).

Gráfico 1 - Distribuição de homens e mulheres nos bairros dos estudos SEPA (1) e CADI (2). Ribeirão Preto, 1991/93 e 2001/03.

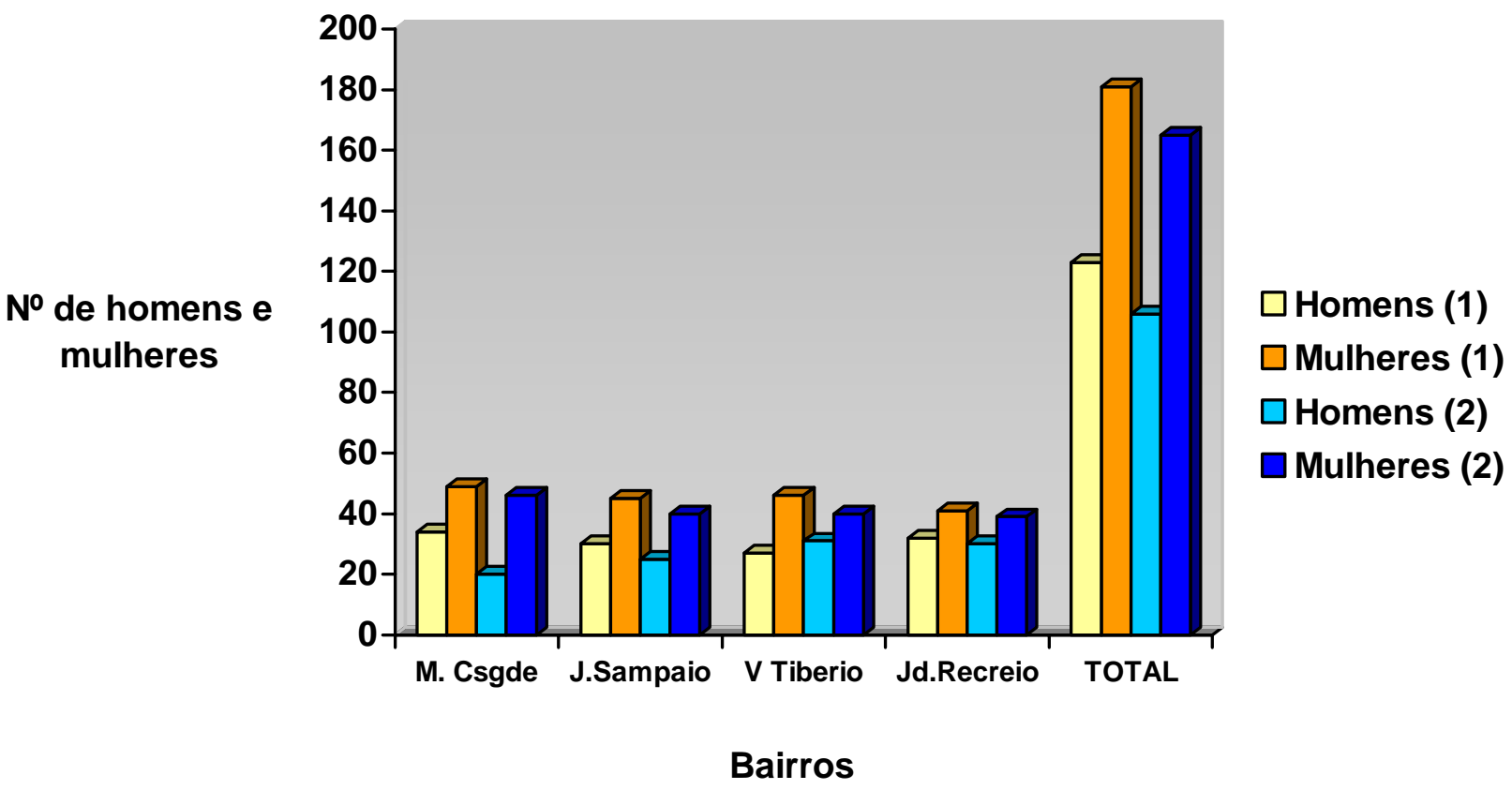


Quando estratificada a amostra por faixa etária, notou-se maior percentual de indivíduos adultos (30 a 49 anos) em relação às categorias dos adultos jovens (18 a 29 anos) e dos idosos (50 a 65 anos) (Gráfico 2).

Gráfico 2 - Distribuição dos indivíduos dos estudos SEPA (1) e CADI (2), segundo faixa etária e bairros. Ribeirão Preto, 1991/93 e 2001/03.

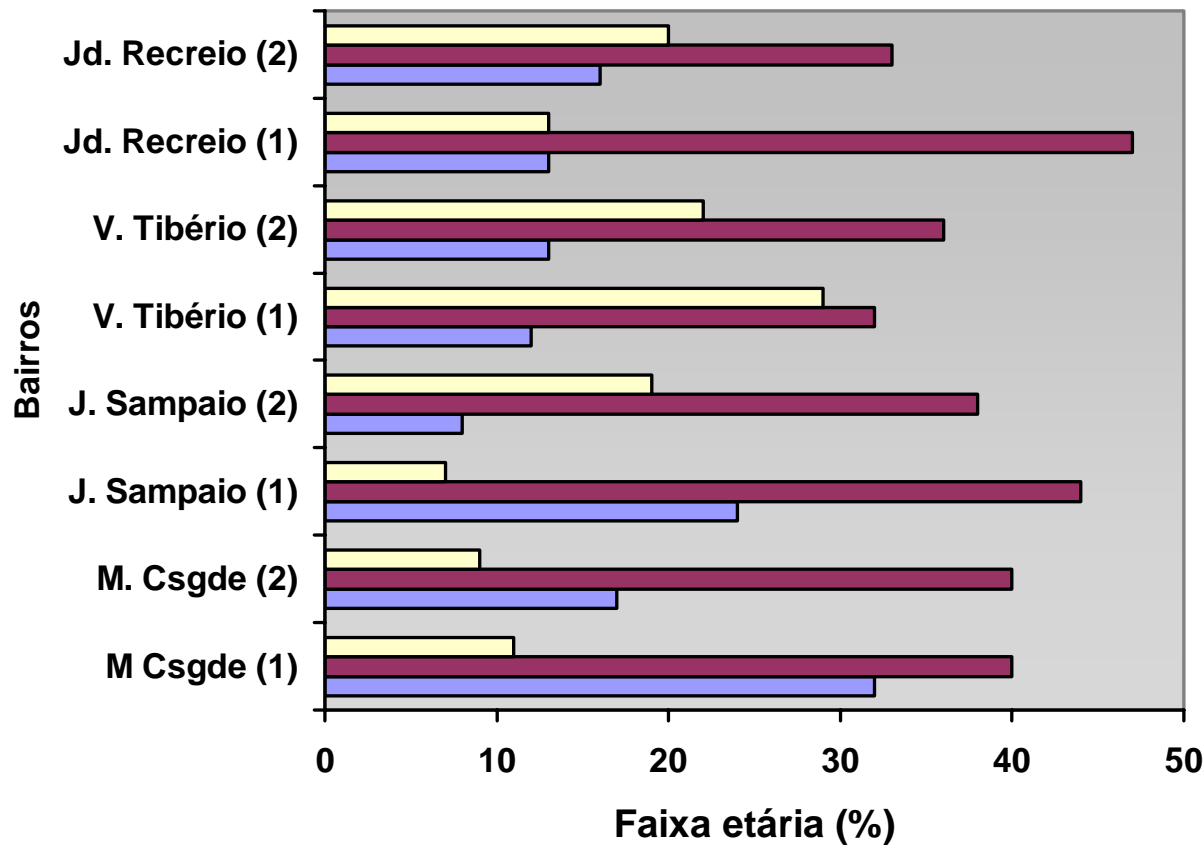

Quanto à situação socioeconômica da amostra investigada, a menor renda familiar média encontrada foi a do bairro Maria Casagrande ( $\mathrm{R} \$ 939,39)$, seguida do José Sampaio (R\$ 1301,54), Vila Tibério (R\$ 1346,48) e, por último, o Jardim Recreio, com maior valor de renda familiar média $(\mathrm{R} \$ 1914,49)$. Os valores de rendimento familiar foram atualizados tendo como base o salário mínimo do ano de $2003(\mathrm{R} \$ 200,00)$. 


\subsection{Avaliação do estado nutricional}

Uma das maneiras de se avaliar o estado nutricional de indivíduos e populações é fazendo-se o cálculo do Índice de Massa Corporal (IMC) pelas medidas de peso e altura. Embora a medida estabeleça o valor total da massa corporal e não seus compartimentos (massa magra, massa gorda, água), é um método prático, rápido e barato que tem sido bastante utilizado nas pesquisas científicas.

Neste estudo, os valores encontrados não foram estatisticamente significantes para o tipo de estudo, diferente do observado nos bairros e na intersecção bairro x estudo.

Logo, não havendo diferenças entre os estudos, não se pode afirmar que os sujeitos avaliados em 1991/93 apresentaram média de IMC $\left(24,53 \pm 4,87 \mathrm{Kg} / \mathrm{m}^{2}\right)$ menor que a média obtida em 2001/03 $\left(25,23 \pm 5,30 \mathrm{Kg} / \mathrm{m}^{2}\right)(\mathrm{p}=0,146)$.

Quanto aos bairros, isoladamente, no Maria Casagrande e no José Sampaio houve aumento do Índice de Massa Corporal entre um período e outro (respectivamente, 22,55 \pm $3,98 \mathrm{Kg} / \mathrm{m}^{2}$ em $1991 / 93$ para $24,75 \pm 5,29 \mathrm{Kg} / \mathrm{m}^{2}$ em $2001 / 03$ e $24,95 \pm 4,57 \mathrm{Kg} / \mathrm{m}^{2}$ em 1991/93 para 26,48 $\pm 5,79 \mathrm{Kg} / \mathrm{m}^{2}$ em 2001/03) e na Vila Tibério e Jardim Recreio houve discreta diminuição do índice (respectivamente, 25,97 $\pm 5,54 \mathrm{Kg} / \mathrm{m}^{2}$ em 1991/93 para 25,65 $\pm 4,93 \mathrm{Kg} / \mathrm{m}^{2}$ em $2001 / 03$ e $24,95 \pm 4,77 \mathrm{Kg} / \mathrm{m}^{2}$ em $1991 / 93$ para $24,07 \pm 5,00 \mathrm{Kg} / \mathrm{m}^{2}$ em 2001/03). Embora, a análise dos bairros tenha resultado em valores estatisticamente significantes $(\mathrm{p}=0,001)$, pode-se afirmar que somente o Maria Casagrande se diferenciou dos demais locais e que José Sampaio, Vila Tibério e Jardim Recreio não se diferenciaram entre si (Gráfico 3). 
Gráfico 3 - Distribuição média do IMC dos indivíduos participantes dos estudos SEPA (1) e CADI (2), segundo os bairros visitados. Ribeirão Preto, 1991/93 e 2001/03.

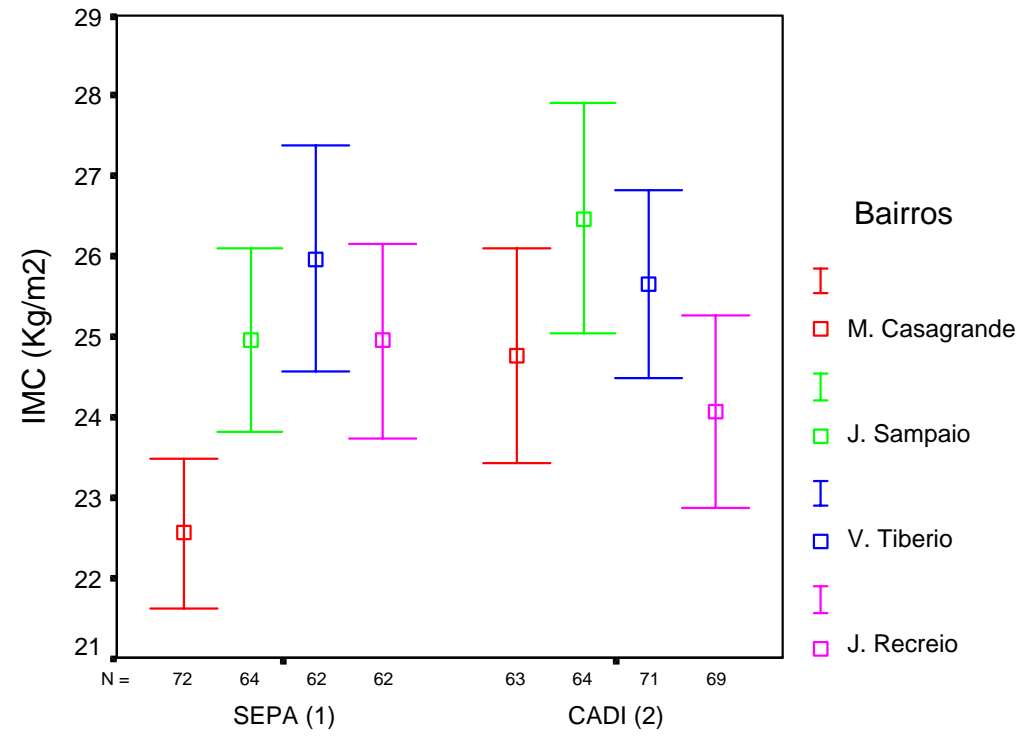

Estudos

Em relação à interação dos bairros com os estudos, que também apresentou diferenças estatisticamente significantes $(p=0,037)$, é correto afirmar que eles se comportaram diferentemente ao longo do estudo, todavia só se pode ressaltar que o Maria Casagrande foi o único local em que a média do IMC no estudo de 1991/93 foi menor que a média encontrada em 2001/03.

\subsection{Análise Alimentar}

\subsubsection{Consumo de nutrientes}

A análise do consumo de nutrientes dos indivíduos nos estudos de 1991/93 e 2001/03 permitiu realizar o cálculo das calorias, carboidratos, proteínas, gorduras totais e suas frações (monoinsaturada, polinsaturada e saturada), colesterol e fibras. 
Para a análise estatística dessas variáveis foi aplicada a análise de variância (ANOVA), tendo como fatores fixos os bairros e os estudos. Quando necessário, houve a realização do teste de Bonferroni para comparações múltiplas entre interações dos fatores (bairro $\mathrm{x}$ estudo) e entre o fator bairro individualmente. $\mathrm{E}$, finalmente, se os testes apontavam uma diferença estatisticamente significante na interação, realizava-se o teste-t para confirmar quais bairros se diferenciavam entre um estudo e outro.

O nível descritivo de significância adotado foi $\alpha=0,05$ e os resultados das análises foram obtidos utilizando o software estatístico Statistical Package for the Social Sciences (SPSS), versão 10.1 (SPSS, 1995).

\subsubsection{Calorias}

Quando analisada a variável dependente calorias verificou-se que em 1991/93 a média de ingestão foi de 2032,75 \pm 875,54 Kcal e em 2001/03 atingiu 2143,69 \pm 901,06 Kcal. Verificou-se discreto aumento de energia que não resultou em diferenças estatisticamente significativas entre os anos de estudo $(\mathrm{p}=0,171)$. Logo, é válido afirmar que a ingestão calórica praticamente se manteve no período.

Quanto ao comportamento dos bairros, notou-se que todos eles tiveram aumento do consumo de calorias, com exceção do Maria Casagrande que teve diminuição. Embora os locais tenham apresentado alterações na energia consumida, os valores não representaram diferenças estatisticamente significantes $(\mathrm{p}=0,269)($ Gráfico 4). 
Gráfico 4 - Calorias totais ingeridas pelos indivíduos (média) dos estudos SEPA (1) e CADI (2) nos bairros visitados. Ribeirão Preto, 1991/93 e 2001/03.

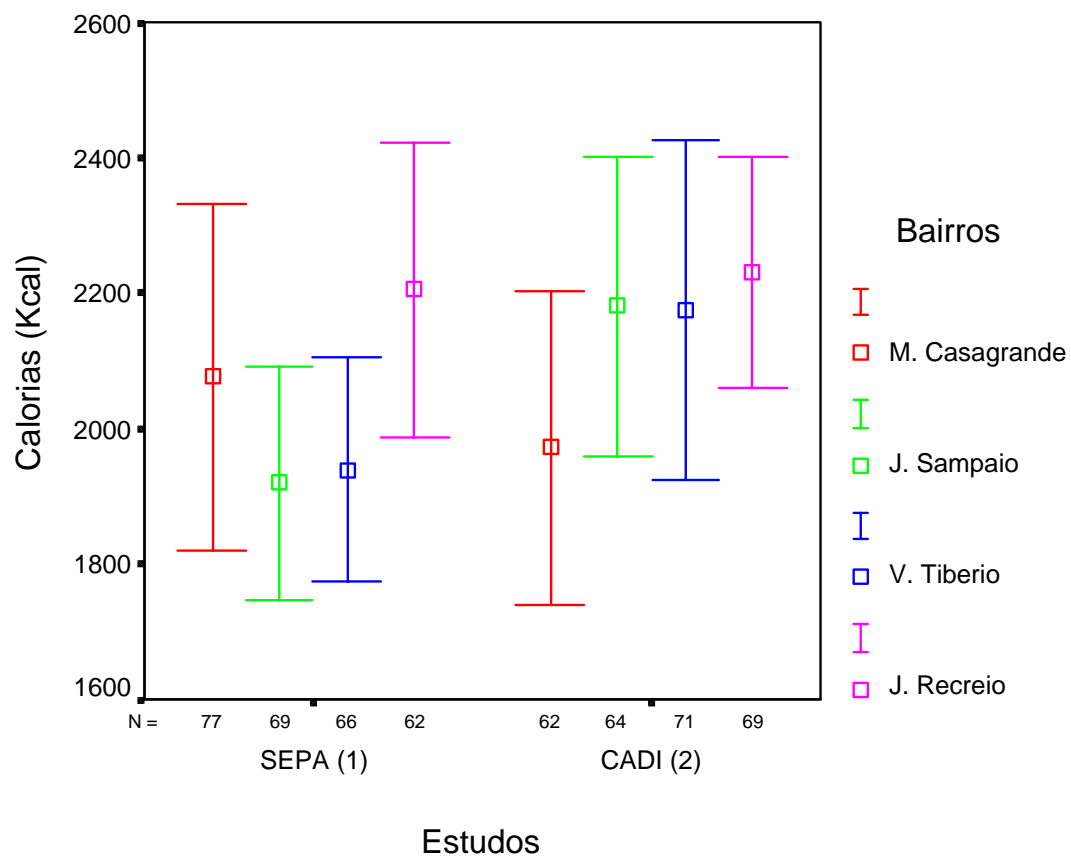

Finalmente, na intersecção dos estudos com os bairros, constatou-se que cada bairro considerado comportou-se de forma não diferenciada ao longo do estudo, pois não houve diferença estatística entre as médias de calorias totais ingeridas pelos indivíduos entre os dois períodos $(\mathrm{p}=0,267)$.

\subsubsection{Carboidratos}

O consumo médio de carboidratos elevou-se entre um estudo e outro e foi significativo estatisticamente $(\mathrm{p}=0,018)$. A ingestão em 1991/93 que era de $235,42 \pm$ $100,46 \mathrm{~g}$ (ou 46,3\% do valor calórico total), subiu para $256,47 \pm 102,00 \mathrm{~g}$ em 2001/03 (ou $47,9 \%$ do valor calórico total). Logo, pode-se afirmar que, em todo o estudo, a média de 
consumo de carboidratos realizada pelos indivíduos em 1991/93 foi menor que o consumo médio realizado em 2001/03.

Com relação aos bairros visitados, no geral, todos eles também aumentaram a ingestão média de carboidratos entre um período e outro, sendo que o Maria Casagrande e Vila Tibério apresentaram elevação discreta dos valores, praticamente mantendo a mesma média de ingestão, e José Sampaio e Jardim Recreio alterações mais evidentes. Apesar das observações registradas nos locais, os testes não apontaram diferenças estatisticamente significantes na análise dos bairros isoladamente $(\mathrm{p}=0,114)$ (Gráfico 5).

Gráfico 5 - Consumo médio de carboidratos pelos indivíduos dos estudos SEPA (1) e CADI (2) nos bairros visitados. Ribeirão Preto, 1991/93 e 2001/03.

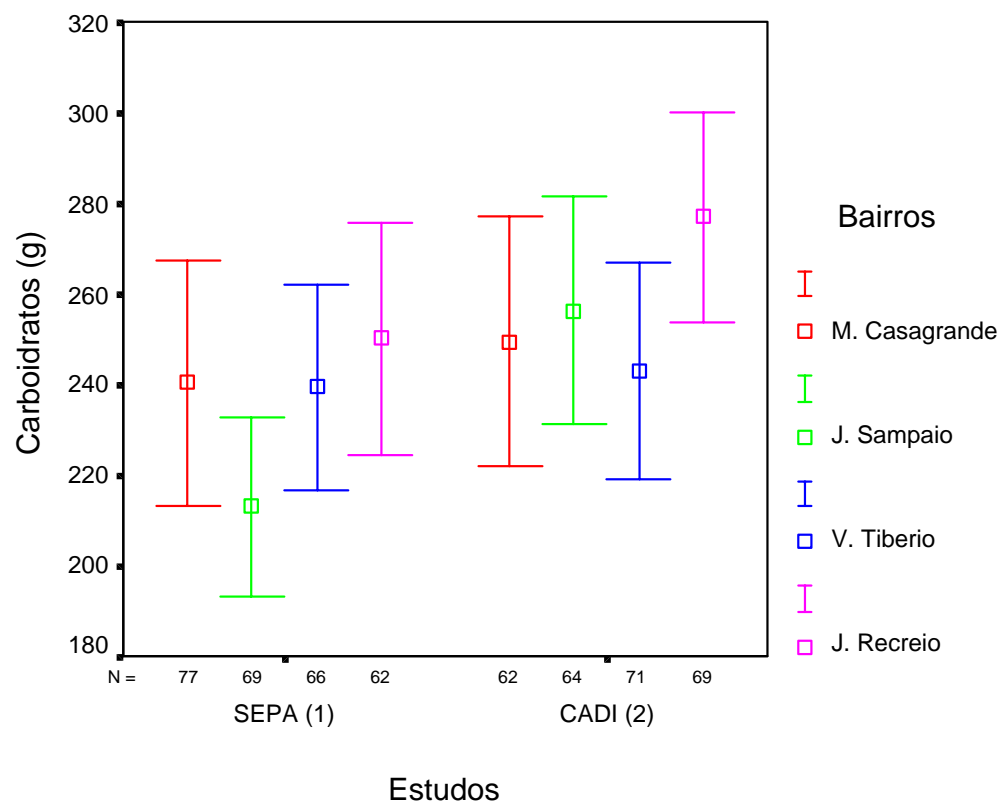

Do mesmo modo, a intersecção dos fatores (bairros x estudos) não foi significativa, ou seja, apesar dos bairros demonstrarem diferenças nos valores de carboidratos ingeridos 
entre 1991/93 e 2001/03, essas alterações não foram suficientes para apontar significância estatística no estudo $(\mathrm{p}=0,362)$.

\subsubsection{Proteínas}

Os dados de ingestão protéica nos indicam que em 1991/93 o consumo médio era de $71,72 \pm 30,88 \mathrm{~g}$ (ou 14\% do valor calórico total) e em 2001/03 a média subiu para 82,25 \pm 40,28g (ou 15\% do valor calórico total). Esses valores apresentaram significância estatística na análise realizada $(\mathrm{p}=0,001)$.

Quanto aos bairros, as alterações foram significativas e verificou-se aumento na média de ingestão protéica em todos eles $(p=0,018)$. Maria Casagrande que registrava consumo de $66,80 \pm 32,87 \mathrm{~g}$ em 1991/93 elevou para 71,05 $\pm 36,11 \mathrm{~g}$ em 2001/03, José Sampaio que consumia $71,95 \pm 29,59 \mathrm{~g}$ em 1991/93, subiu para $87,40 \pm 35,25 \mathrm{~g}$ em 2001/03, Vila Tibério passou de 69,50 $\pm 25,32 \mathrm{~g}$ em 1991/93 para 86,29 $\pm 54,49 \mathrm{~g}$ em 2001/03 e, finalmente, o Jardim Recreio que em 1991/93 ingeria média de 79,93 $\pm 34,03 \mathrm{~g}$ de proteínas, elevou seu consumo para $83,40 \pm 28,08 \mathrm{~g}$ em 2001/03. Maria Casagrande e Jardim Recreio se diferenciaram entre si e não entre os demais locais avaliados (José Sampaio e Jardim Recreio) (Gráfico6). 
Gráfico 6 - Consumo médio de proteínas pelos participantes dos estudos SEPA (1) e CADI (2), segundo os bairros visitados. Ribeirão Preto, 1991/93 e 2001/03.

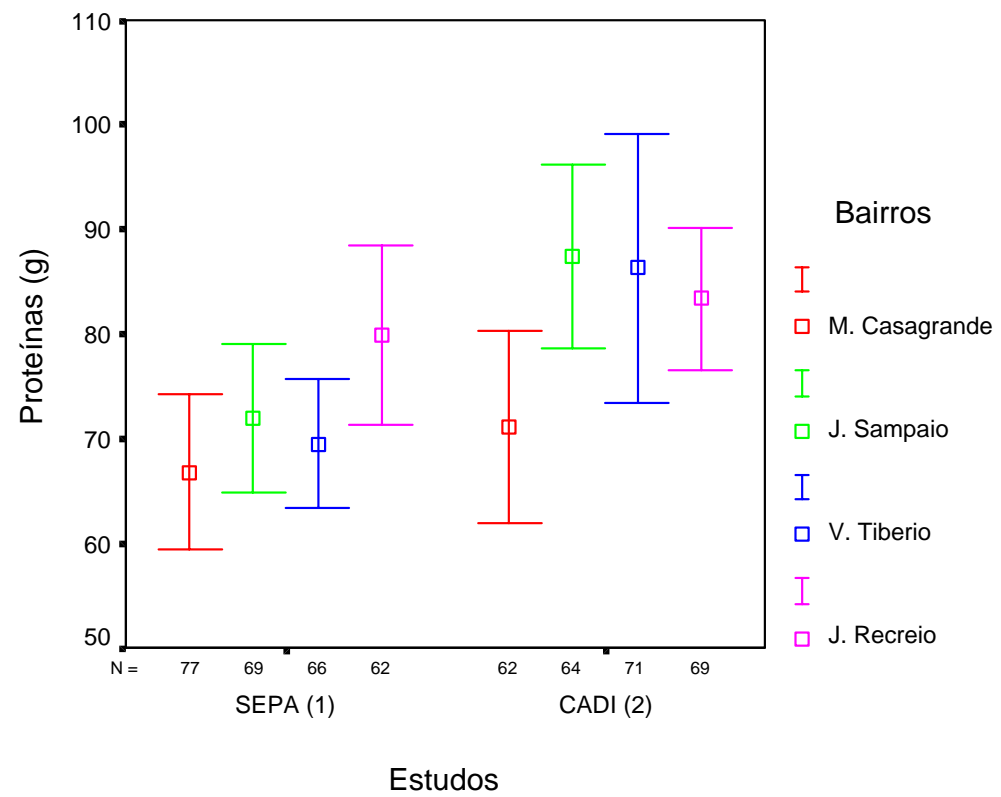

Embora o consumo médio de proteínas tenha se alterado nos bairros e nos estudos, isoladamente, a intersecção dos fatores (bairro $x$ estudo) não apontou resultados estatisticamente significantes $(\mathrm{p}=0,260)$, pois a elevação da ingestão protéica ocorreu em todos os bairros de um ano para outro e esse tipo de comportamento foi interpretado como uma alteração constante da variável estudada.

\subsubsection{Gorduras Totais}

O consumo médio de gorduras totais pelos participantes dos projetos SEPA (1991/93) e CADI (2001/03) diminuiu praticamente dois pontos percentuais entre um período e outro da pesquisa e apresentou resultados estatisticamente significantes $(\mathrm{p}=$ 
0,001). Em 1991/93, a ingestão média era de 34,8 \pm 8,38\% e em 2001/03 atingiu 33,2 \pm $6,05 \%$.

Nos bairros, observaram-se comportamentos diferenciados em relação ao consumo médio de gorduras totais. O Maria Casagrande foi o local que apresentou aumento da ingestão entre 1991/93 e 2001/03, além de ter se diferenciado dos demais que, por sua vez, não se diferenciaram entre si (Tabela 3). 
Tabela 3 - Distribuição percentual das gorduras totais ingeridas (média e desvio-padrão) pelos indivíduos nos bairros dos estudos SEPA (1) e CADI (2). Ribeirão Preto, 1991/93 e 2001/03.

\begin{tabular}{|c|c|c|c|c|c|}
\hline Bairro & Estudo & Média & Desvio-padrão & I.C. ${ }^{(1)}$ & $\mathrm{n}$ \\
\hline \multirow[t]{4}{*}{ Maria Casagrande } & 1 & 28,98 & 9,44 & \multirow{3}{*}[-5,60;-0,22]{} & 77 \\
\hline & & & & & \\
\hline & 2 & 31,88 & 6,55 & & 62 \\
\hline & Total & 30,27 & 8,37 & & 139 \\
\hline \multirow[t]{4}{*}{ José Sampaio } & 1 & 37,03 & 6,20 & \multirow{3}{*}[2,03;6,32]{} & 69 \\
\hline & & & & & \\
\hline & 2 & 32,85 & 6,30 & & 64 \\
\hline & Total & 35,02 & 6,57 & & 133 \\
\hline \multirow[t]{3}{*}{ Vila Tibério } & 1 & 35,94 & 7,36 & \multirow{2}{*}[-1,08;3,35]{} & 66 \\
\hline & 2 & 34,80 & 5,69 & & 71 \\
\hline & Total & 35,35 & 6,55 & & 137 \\
\hline \multirow[t]{3}{*}{ Jardim Recreio } & 1 & 38,31 & 6,34 & \multirow{2}{*}[1,63;3,58]{} & 62 \\
\hline & 2 & 32,94 & 5,46 & & 69 \\
\hline & Total & 35,48 & 6,46 & & 131 \\
\hline \multirow[t]{3}{*}{ Total } & 1 & 34,79 & 8,38 & & 274 \\
\hline & 2 & 33,17 & 6,05 & & 266 \\
\hline & Total & 33,99 & 7,37 & & 540 \\
\hline
\end{tabular}

(1) Intervalo de Confiança (95\%) para a diferença entre as médias. 
Quando analisamos a interação dos fatores, notamos que o Maria Casagrande foi o único bairro que teve aumento do consumo de gorduras totais de um ano para outro da pesquisa e que os demais bairros diminuíram a ingestão deste nutriente. Na Vila Tibério não encontramos diferenças estatisticamente significantes (Gráfico 7).

Gráfico 7 - Distribuição percentual do consumo médio de gorduras totais pelos participantes dos estudos SEPA e CADI. Ribeirão Preto, 1991/93 e 2001/03.

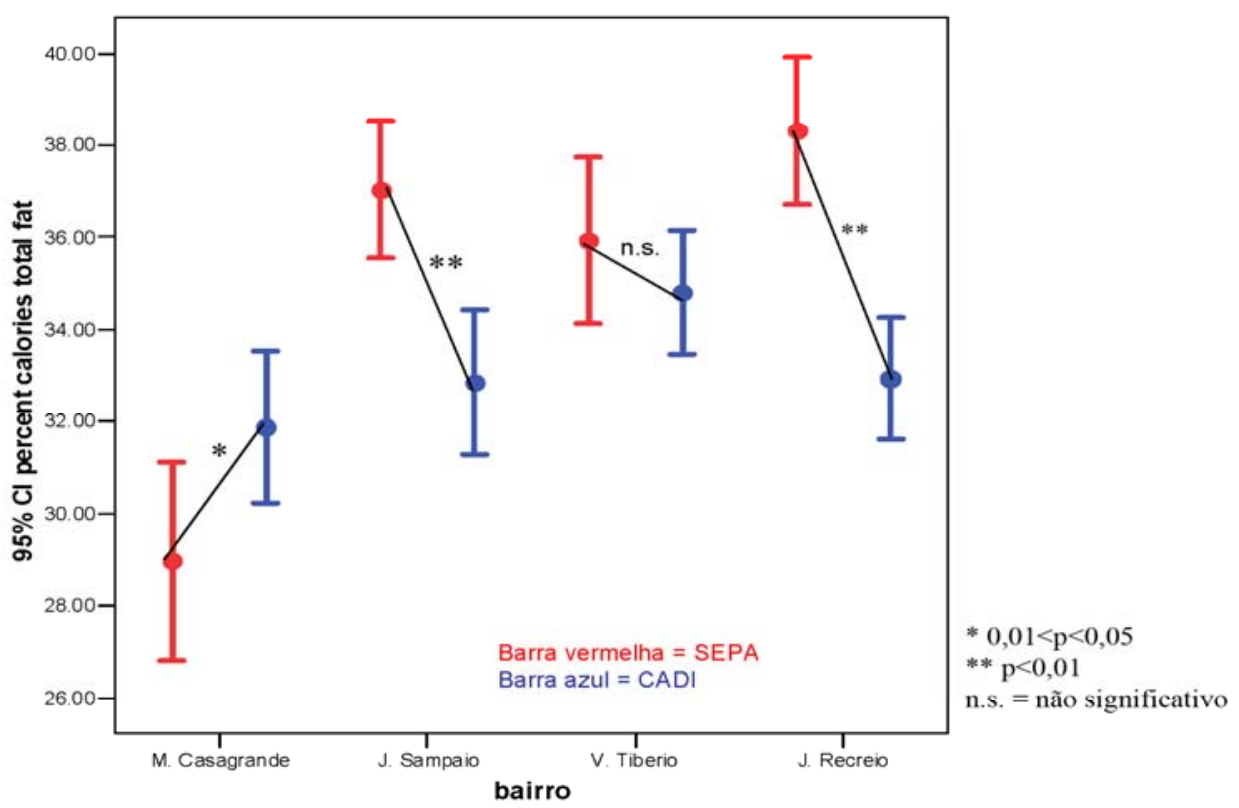

\subsubsection{Gorduras saturadas, monoinsaturadas e polinsaturadas}

Verificaram-se algumas mudanças na maneira como ocorreu a ingestão das frações de gordura saturada, monoinsaturada e polinsaturada pelos indivíduos da pesquisa. 
Com relação às gorduras saturadas, embora a análise dos estudos tenha sido estatisticamente significante $(\mathrm{p}=0,016)$, o valor da ingestão média do estudo de 1991/93 foi praticamente o mesmo que em 2001/03, apenas discretamente mais alto. Em 1991/93 a média de ingestão era de $11,84 \pm 4,14 \%$ e em $2001 / 03$ baixou para $11,36 \pm 3,02 \%$.

Observando os bairros isoladamente, convém ressaltar que dos quatro locais estudados no período de 10 anos, embora as médias ponderadas totais dos outros bairros tenham sido maiores que a média ponderada do Maria Casagrande, verificou-se que este apresentou resultados significativos de ingestão calórica proveniente das gorduras do tipo saturada e foi o único bairro com aumento da ingestão desse tipo de nutriente (Tabela 4). 
Tabela 4 - Distribuição percentual do consumo das gorduras saturadas ingeridas (média e desvio-padrão) pelos sujeitos dos estudos SEPA (1) e CADI (2) nos bairros visitados. Ribeirão Preto, 1991/93 e 2001/03.

\begin{tabular}{|c|c|c|c|c|c|}
\hline Bairro & Estudo & Média & Desvio-padrão & I.C. ${ }^{(1)}$ & $\mathrm{n}$ \\
\hline \multirow[t]{3}{*}{ Maria Casagrande } & 1 & 8,35 & 3,05 & \multirow{2}{*}[-3,04;-0,93]{} & 77 \\
\hline & 2 & 10,34 & 3,25 & & 62 \\
\hline & Total & 9,23 & 3,28 & & 139 \\
\hline \multirow[t]{3}{*}{ José Sampaio } & 1 & 12,62 & 3,82 & \multirow{2}{*}[0,10;2,49]{} & 69 \\
\hline & 2 & 11,32 & 3,06 & & 64 \\
\hline & Total & 12,00 & 3,52 & & 133 \\
\hline \multirow[t]{3}{*}{ Vila Tibério } & 1 & 12,94 & 3,96 & \multirow{2}{*}[-0,39;1,97]{} & 66 \\
\hline & 2 & 12,15 & 2,99 & & 71 \\
\hline & Total & 12,53 & 3,50 & & 137 \\
\hline \multirow[t]{3}{*}{ Jardim Recreio } & 1 & 14,13 & 3,10 & \multirow{2}{*}[1,63;3,58]{} & 62 \\
\hline & 2 & 11,52 & 2,54 & & 69 \\
\hline & Total & 12,75 & 3,10 & & 131 \\
\hline \multirow[t]{3}{*}{ Total } & 1 & 11,84 & 4,14 & & 274 \\
\hline & 2 & 11,36 & 3,02 & & 266 \\
\hline & Total & 11,60 & 3,64 & & 540 \\
\hline
\end{tabular}

${ }^{(1)}$ Intervalo de Confiança (95\%) para a diferença entre as médias. 
Finalmente, quando verificada a interação dos bairros com os estudos, notou-se que os bairros se comportaram de maneira diferente desde o início do trabalho em 1991/93 até o seu final em 2001/03. José Sampaio e Jardim Recreio foram dois locais em que a ingestão de gorduras saturadas teve diminuição de um ano para outro e o Maria Casagrande apresentou aumento do consumo deste tipo de gordura. A Vila Tibério foi o único bairro em que as diferenças dos valores encontrados não foram significativas (Gráfico 8).

Gráfico 8 - Distribuição percentual do consumo de gorduras saturadas (médias) pelos indivíduos dos estudos SEPA (1) e CADI (2) nos bairros visitados. Ribeirão Preto, 1991/93 e 2001/03.

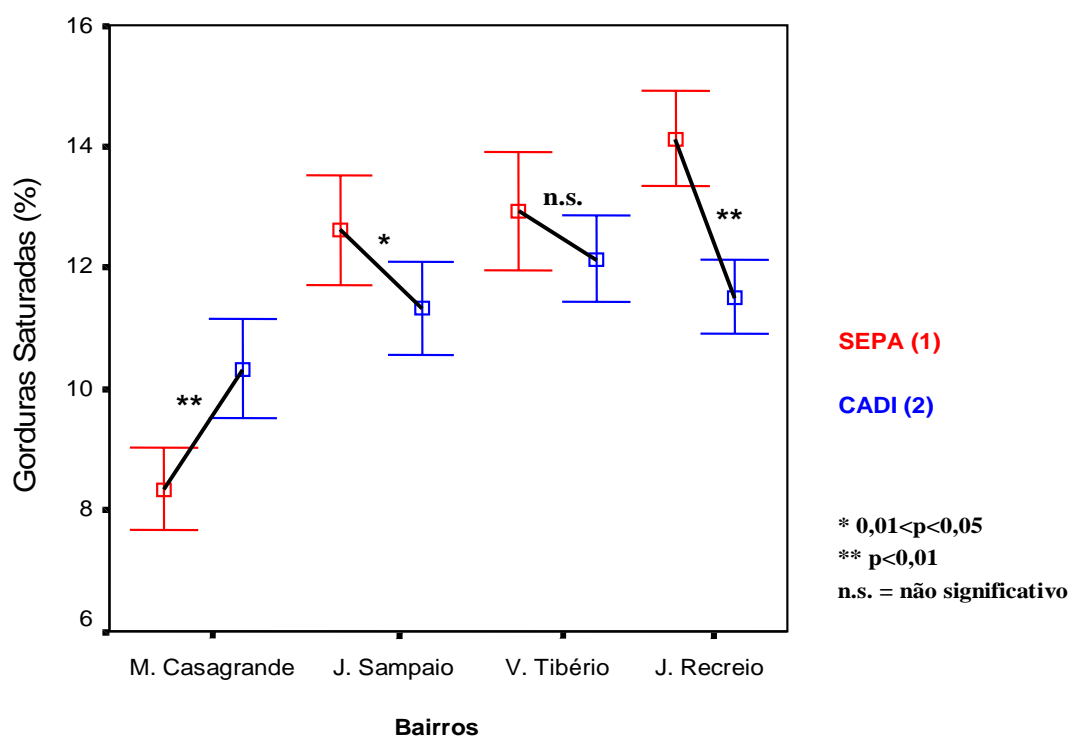

Quanto às gorduras do tipo monoinsaturadas, foram encontrados níveis de significância no tipo de estudo avaliado $(\mathrm{p}=0,000)$. Portanto, é válido afirmar que entre uma pesquisa e outra houve aumento da ingestão de gorduras monoinsaturadas. Em 
1991/93, a média de consumo foi de $8,6 \pm 2,94 \%$ e em 2001/03 os valores subiram para $12,15 \pm 3,39 \%$.

Avaliando os bairros, todos eles apresentaram aumento da ingestão média de gorduras monoinsaturadas entre 1991/93 e 2001/03 e esse comportamento resultou numa análise estatística não significante $(\mathrm{p}=0,592)$, embora tenha ocorrido alteração dos valores absolutos registrados na ingestão média desse tipo de nutriente pelos indivíduos de cada local visitado.

Quando analisada a interação dos fatores (bairros x estudos), encontraram-se diferenças estatísticas altamente significantes $(p=0,000)$ indicando que todos os bairros tiveram aumento do consumo de gorduras monoinsaturadas de 1991/93 para 2001/03, embora eles não tenham se diferenciado entre si (Gráfico 9).

Gráfico 9 - Percentual da ingestão de gorduras monoinsaturadas (médias) pelos indivíduos dos estudos SEPA (1) e CADI (2), segundo os bairros visitados. Ribeirão Preto, $1991 / 93$ e $2001 / 03$.

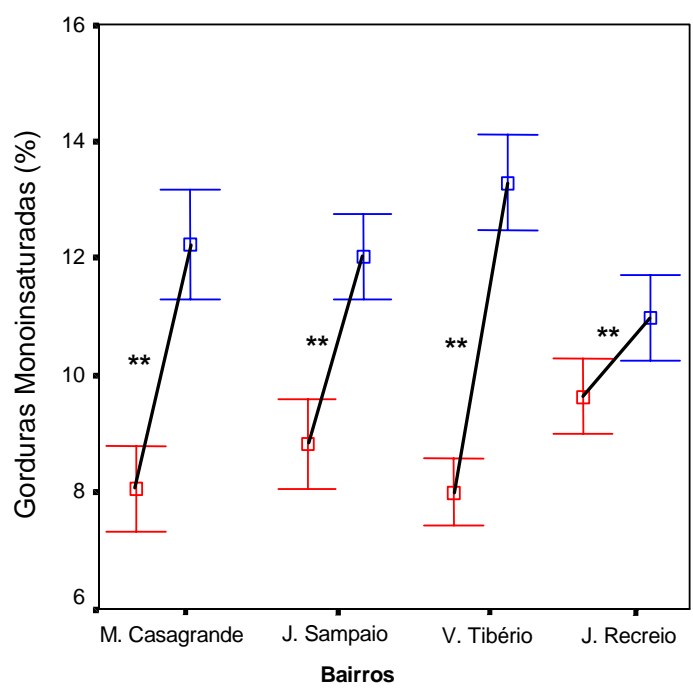

SEPA (1)

CADI (2)

$* 0,01<\mathbf{p}<0,05$

** $\mathbf{p}<\mathbf{0 , 0 1}$

n.s. = não significativo 
Finalmente, o consumo médio de gorduras do tipo polinsaturadas que em 1991/93 era de $5,08 \pm 2,00 \%$ elevou para $6,01 \pm 2,03 \%$ em 2001/03 e estes valores encontrados foram estatisticamente significantes $(\mathrm{p}=0,000)$.

Os bairros também apresentaram diferenças estatisticamente significantes $(p=$ 0,002). A Vila Tibério registrou um aumento de 4,96 \pm 1,39\% em 1991/93 para 6,33 \pm 1,79\% em 2001/03 e o Jardim Recreio também elevou a ingestão de gorduras do tipo polinsaturadas de 4,58 \pm 1,54\% em 1991/93 para 5,44 $\pm 1,49 \%$ em 2001/03. Apesar do aumento também ter sido verificado no Maria Casagrande e no José Sampaio, esses dois bairros não apresentaram resultados estatisticamente significantes e não se diferenciaram entre si (Gráfico 10).

Gráfico 10 - Percentual do consumo de gorduras polinsaturadas (médias) pelos indivíduos dos estudos SEPA (1) e CADI (2), nos bairros visitados. Ribeirão Preto, 1991/93 e 2001/03.

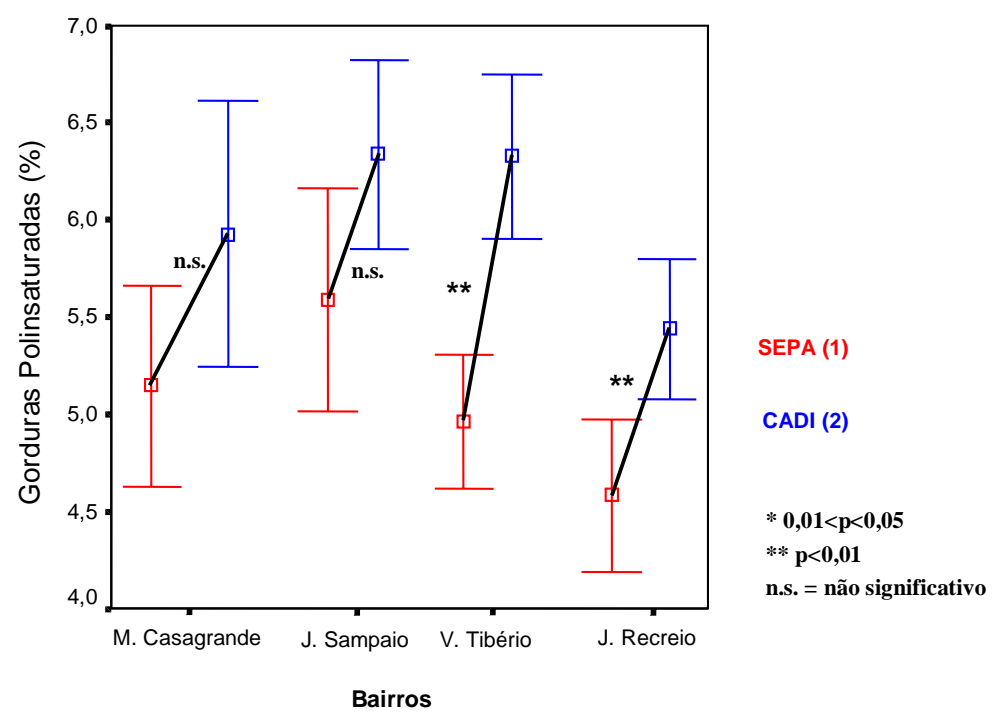


Ao estudar a interação dos fatores, os valores não representaram resultados significantes estatisticamente $(\mathrm{p}=0,541)$, sendo válido afirmar que embora nos bairros, isoladamente, tenha ocorrido alteração das médias de ingestão, ao longo do estudo esses locais não se diferenciaram entre si.

\subsubsection{Colesterol}

O colesterol, mais uma variável dependente da pesquisa, também foi avaliado segundo o tipo de estudo, os bairros e a intersecção bairro x estudo.

Constataram-se valores estatisticamente significativos em duas das análises, ou seja, para tipo de estudo e para os bairros avaliados. A intersecção bairro $\mathrm{x}$ estudo não apresentou valores de significância estatística.

Pode-se afirmar que de um ano para outro de trabalho houve aumento do consumo de colesterol de 169,44 \pm 49,99mg (SEPA) para 271,61 $\pm 171,31 \mathrm{mg}(\mathrm{CADI})(\mathrm{p}=0,000)$.

Em relação aos bairros verificamos aumento de colesterol em todos eles, entretanto, dois se diferenciaram entre si quanto à média de consumo da substância: Maria Casagrande, com a menor média de consumo $(153,42 \pm 42,36 \mathrm{mg}$ em 1991/93 para 224,76 $\pm 151,08 \mathrm{mg}$ em 2001/03) e Vila Tibério, com a maior média de consumo $(204,44 \pm 51,07 \mathrm{mg}$ em 1991/93 para 295,96 $\pm 225,27 \mathrm{mg}$ em 2001/03). Já o José Sampaio não se diferenciou dos demais bairros, nem tampouco o Jardim Recreio e ambos não se diferenciaram entre si (Gráfico 11). 
Gráfico 11 - Consumo médio de colesterol pelos participantes dos estudos SEPA (1) e CADI (2) nos bairros visitados. Ribeirão Preto, 1991/93 e 2001/03.

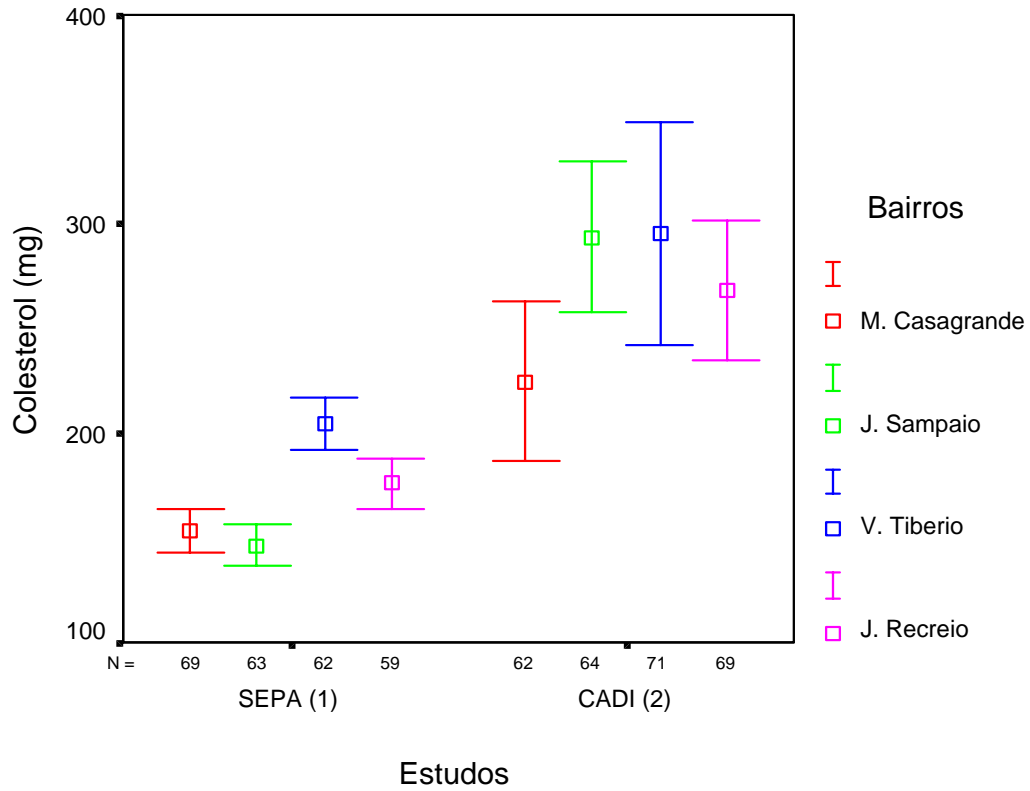

Quanto à intersecção, vale ressaltar que todos os bairros avaliados tiveram o mesmo tipo de comportamento quanto à ingestão do colesterol, isto é, todos aumentaram o consumo, sendo o Maria Casagrande e Vila Tibério nos extremos opostos com menor e maior ingestão, respectivamente, e o José Sampaio e Jardim Recreio nos níveis intermediários de consumo do colesterol. Portanto, a interação dos bairros com os estudos não resultou em significância estatística $(p=0,092)$.

\subsubsection{Fibras}

A análise do consumo de fibras na população estudada nos estudos de 1991/93 e 2001/03, nos indicou valores estatisticamente significantes para o tipo de estudo. Portanto, podemos concluir que durante a pesquisa, obtivemos um aumento na ingestão média de 
fibras que em 1991/93 era de 2,24 $\pm 1,77 \mathrm{~g}$ e em 2001/03 elevou para $16,77 \pm 9,74 \mathrm{~g}(\mathrm{p}=$ $0,000)$.

Quando avaliado o consumo médio de fibras nos bairros isoladamente, os valores também se apresentaram estatisticamente significantes e houve aumento da ingestão em todos os locais visitados $(\mathrm{p}=0,013)$. Maria Casagrande que em 1991/93 consumia média de $1,86 \pm 2,31 \mathrm{~g}$ de fibras, em 2001/03 elevou sua ingestão para 20,29 $\pm 12,02 \mathrm{~g}$. Em seguida, Vila Tibério que em 1991/93 apresentava média de 2,72 \pm 1,66g alterou para 16,73 \pm 9,31g em 2001/03. Jardim Recreio registrava consumo de 2,69 $\pm 1,52 \mathrm{~g}$ em 1991/93 subiu para $14,69 \pm 7,15 \mathrm{~g}$ em 2001/03 e, por fim, José Sampaio que ingeria média de $1,80 \pm 1,06 \mathrm{~g}$ fibras em 1991/93 atingiu 15,66 \pm 9,47g em 2001/03. Todos eles não se diferenciaram entre si (Gráfico 12).

Gráfico 12 - Consumo médio de fibras pelos participantes dos estudos SEPA (1) e CADI (2), segundo os bairros avaliados. Ribeirão Preto, 1991/93 e 2001/03.

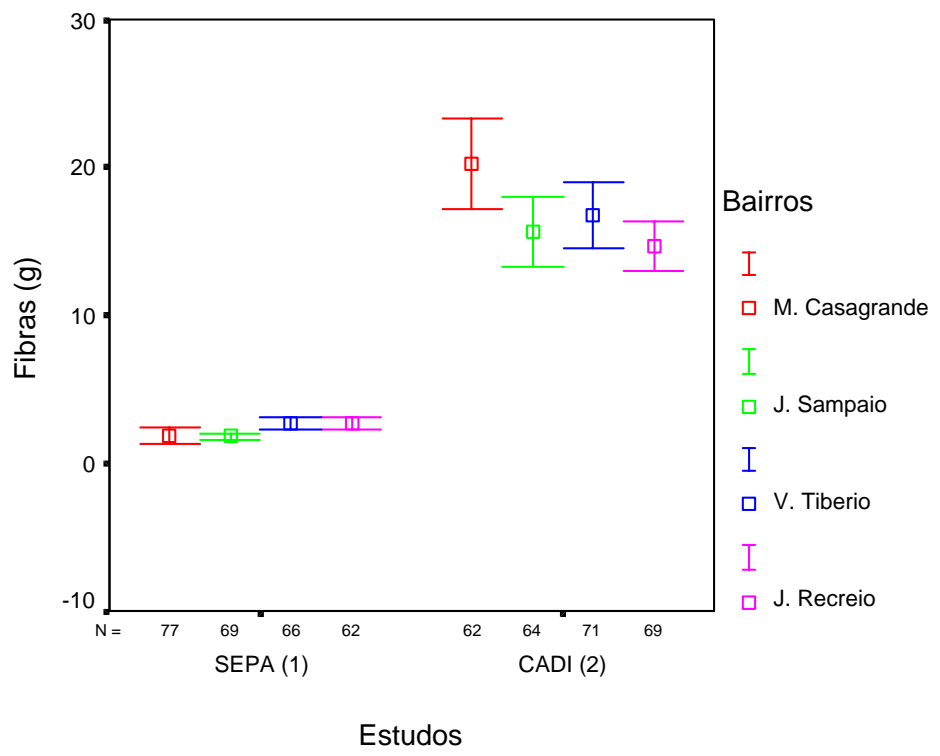


A intersecção bairro $\mathrm{x}$ estudo também foi estatisticamente significante e, embora todos os bairros tenham se comportado de maneira semelhante ao longo do estudo, ou seja, todos registraram aumento da ingestão de fibras, esse crescimento foi suficientemente alto para indicar um grau de significância no estudo $(\mathrm{p}=0,001)$.

\subsubsection{Qualidade da Alimentação}

A análise da qualidade da alimentação foi realizada com $25 \%$ da amostra dos indivíduos adultos de ambos os sexos, participantes dos projetos SEPA (1991/93) e CADI (2001/03) e com idade variando de 30 a 49 anos. Essa parcela populacional foi selecionada pela inviabilidade de analisar todos os registros, sendo a escolha aleatória e devido à maior porcentagem de indivíduos na faixa etária citada. Portanto, o estudo da qualidade da alimentação baseou-se num total de 143 pessoas (76 participantes do estudo de 1991/93 e 67 do estudo de 2001/03).

Foi considerado nessa análise o registro do recordatório de 24 horas referente ao consumo alimentar dos dias de semana e não o realizado nos finais de semana e feriados, pois nessas ocasiões, geralmente a ingestão alimentar não representa o consumo habitual dos indivíduos.

As refeições consumidas pelos entrevistados foram transformadas em número de porções alimentares, segundo os grupos de alimentos da Pirâmide Alimentar Brasileira (PHILIPPI et al., 1999b) e os valores foram digitados em planilha do SPSS para realização dos testes estatísticos. Os mesmos testes empregados na análise do consumo de nutrientes foram utilizados na análise da qualidade alimentar dos participantes. 


\subsubsection{Consumo de cereais}

A média e o desvio-padrão do consumo de cereais pelos indivíduos do projeto SEPA em 1991/93 foi de 3,92 \pm 0,26 porções e, dez anos após (projeto CADI), os indivíduos passaram a consumir média de 3,46 $\pm 0,28$ porções desse grupo. $\mathrm{O}$ consumo, apesar de discretamente menor, não foi considerado estatisticamente significante $(\mathrm{p}=0,24)$.

Quando se verifica o consumo desse grupo alimentar nos bairros, observa-se que de 1991/93 para 2001/03 todos eles diminuíram a ingestão de cereais (Maria Casagrande: 4,22 $\pm 3,32$ para 3,77 $\pm 2,48$; José Sampaio: $3,63 \pm 1,91$ para 3,51 $\pm 1,84$; Vila Tibério: $3,74 \pm$ 1,54 para 3,58 $\pm 2,00$ e Jardim Recreio: $4,08 \pm 2,37$ para 2,99 $\pm 0,82$ ). Embora a redução tenha ocorrido em todos os bairros, os testes estatísticos não apontaram significância estatística entre eles $(\mathrm{p}=0,79)$. O Gráfico 13 indica esses valores e aponta a grande variação em torno da média (I.C.) nos quatro bairros em 1991/93 e no Maria Casagrande, José Sampaio e Vila Tibério em 2001/03.

Gráfico 13 - Consumo médio de cereais pelos participantes dos projetos SEPA (1) e CADI (2), segundo os bairros visitados. Ribeirão Preto, 1991/93 e 2001/03.

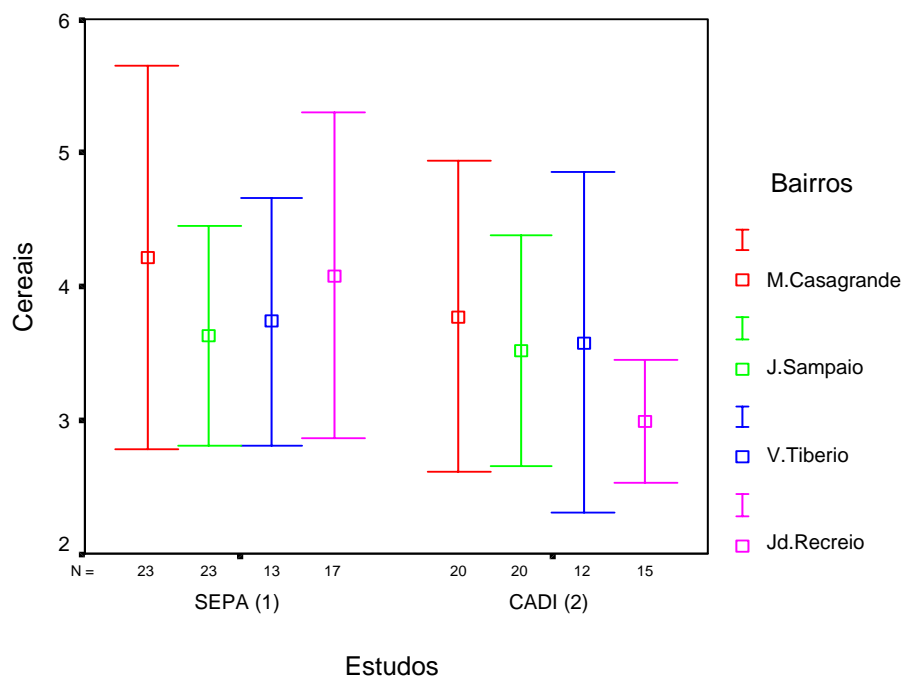


A intersecção dos bairros com os estudos também não resultou em valores estatisticamente significativos $(\mathrm{p}=0,80)$, o que vale afirmar que em dez anos de pesquisa a ingestão média de cereais não sofreu grandes alterações e os bairros não se diferenciaram entre si e nem tampouco entre um estudo e outro.

\subsubsection{Consumo de hortaliças}

Ao analisar o consumo médio de hortaliças (verduras e legumes) nota-se que em 2001/03, os indivíduos elevaram a ingestão deste grupo alimentar $(1,99 \pm 0,2) \mathrm{em} 60 \%$ em relação à quantidade ingerida em 1991/93 $(1,19 \pm 0,19)$. Apesar do aumento ter sido pequeno em termos absolutos, a diferença foi estatisticamente significante $(p=0,003)$. Portanto, pode-se afirmar que houve maior consumo de hortaliças pela população avaliada em 2001/03.

Quanto aos bairros, isoladamente, também se notou aumento do consumo médio de hortaliças em todos eles (Maria Casagrande: 0,81 \pm 1,01 para 1,80 \pm 1,97; José Sampaio: $1,07 \pm 1,02$ para 2,23 $\pm 2,18$; Vila Tibério: $1,14 \pm 1,25$ para 1,48 $\pm 1,02$ e Jardim Recreio: $1,73 \pm 1,60$ para $2,47 \pm 1,94$ ), embora esse aumento não tenha sido estatisticamente significante $(\mathrm{p}=0,134)$. O gráfico 14 ilustra essas pequenas diferenças na média de consumo de hortaliças entre os bairros em 1991/93 e 2001/03. 
Gráfico 14- Consumo médio de hortaliças pelos participantes dos projetos SEPA (1) e CADI (2) nos bairros visitados. Ribeirão Preto, 1991/93 e 2001/03.

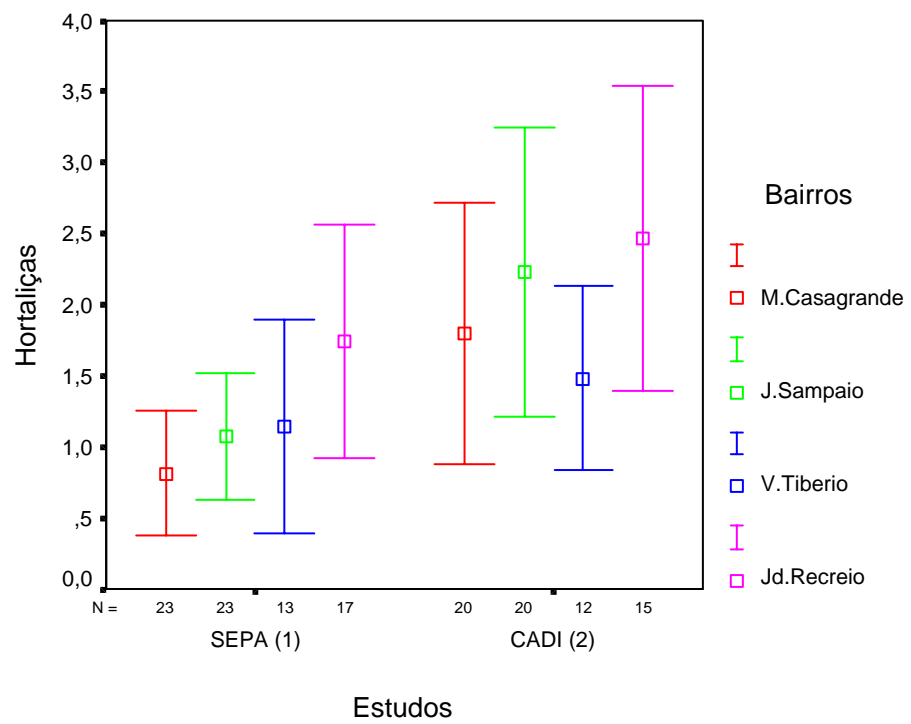

$\mathrm{Na}$ intersecção dos bairros com o tipo de estudo, o comportamento dos bairros ao longo de dez anos não representou diferenças estatisticamente significantes, ou seja, entre um período e outro não houve grande alteração do consumo médio de porções de hortaliças nos locais visitados $(\mathrm{p}=0,753)$.

\subsubsection{Consumo de frutas}

O consumo de frutas teve aumento de 1991/93 para 2001/03. A ingestão média dos indivíduos no estudo 1 (SEPA) foi de 2,16 $\pm 0,44$ porções e a dos indivíduos no estudo 2 (CADI) foi de 3,79 $\pm 0,47$ porções. Esses valores foram significantes estatisticamente $(\mathrm{p}=$ $0,012)$.

Considerando o consumo médio nos bairros, também constatamos elevação do consumo médio de frutas, com exceção da Vila Tibério. Todavia, os testes estatísticos 
não indicaram valores significativos para ingestão de frutas nos bairros $(p=0,708)$ (Gráfico15).

Gráfico 15 - Consumo médio de frutas pelos participantes dos projetos SEPA (1) e CADI (2), segundo os bairros visitados. Ribeirão Preto, 1991/93 e 2001/03.

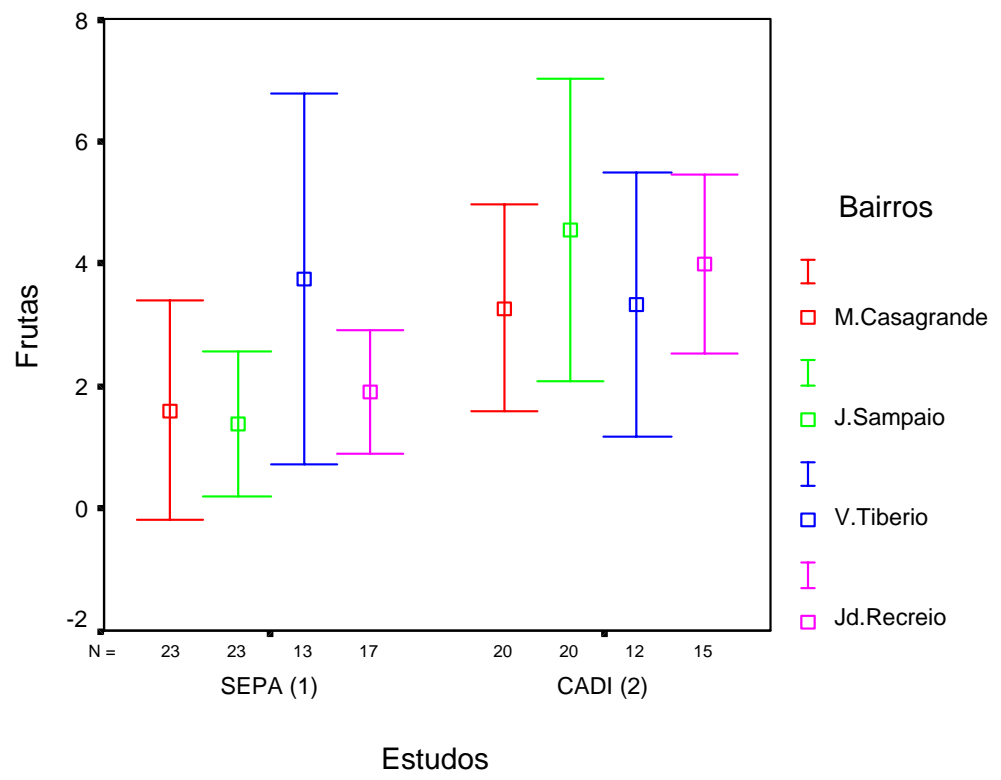

A intersecção dos bairros com o tipo de estudo também não representou diferenças estatisticamente significantes, portanto os bairros não se diferenciaram entre si e nem ao longo dos dez anos de estudo com relação à ingestão média de frutas $(\mathrm{p}=0,306)$.

\subsubsection{Consumo de leguminosas}

Apesar da média de consumo de leguminosas (feijão, ervilha, soja, grão-de-bico,...) no projeto CADI ter sido um pouco maior que a média de consumo no SEPA, respectivamente, $1,18 \pm 0,16$ e 1,16 $\pm 0,15$ porções, a ingestão desse grupo alimentar 
nos estudos realizados não apresentou diferenças estatisticamente significantes ( $\mathrm{p}=$ $0,909)$.

Nos bairros, isoladamente, verificou-se que o Maria Casagrande e o José Sampaio diminuíram o consumo de leguminosas de um estudo para outro, ou seja, alterou de $2,19 \pm 1,76$ para $1,41 \pm 1,76$ porções de leguminosas no primeiro bairro e de $0,93 \pm$ 0,93 para $0,83 \pm 0,88$ porções de leguminosas no segundo.

Na Vila Tibério e no Jardim Recreio, a situação foi inversa, isto é, de um estudo para outro houve aumento do consumo médio de leguminosas, respectivamente, de 1,01 $\pm 1,08$ para $1,37 \pm 1,38$ porções na Vila Tibério e de $0,49 \pm 0,69$ para $1,10 \pm 1,17$ no Jardim Recreio.

Os testes estatísticos indicaram significância nos bairros avaliados $(p=0,002)$ e verificou-se que o Maria Casagrande se diferenciou do José Sampaio e do Jardim Recreio, porém estes dois últimos não se diferenciaram entre si (Gráfico 16).

Gráfico 16 - Consumo médio de leguminosas nos estudos SEPA (1) e CADI (2), segundo os bairros visitados. Ribeirão Preto, 1991/93 e 2001/03.

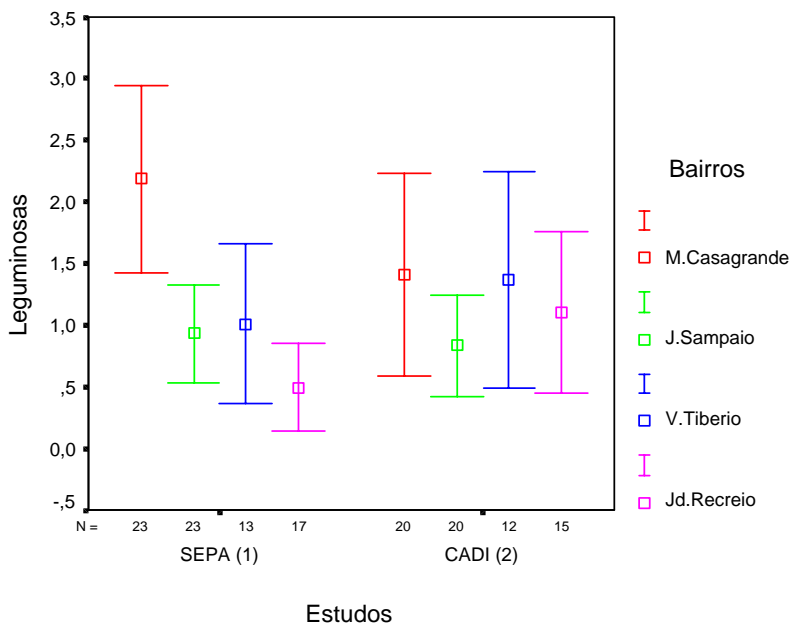


$\mathrm{Na}$ avaliação da intersecção dos fatores (bairros x estudos) não houve resultados estatisticamente significantes indicando que nos bairros, ao longo do período pesquisado, as mudanças na ingestão média de leguminosas não resultaram em alterações significativas $(\mathrm{p}=0,108)$.

\subsubsection{Consumo de carnes e ovos}

O consumo médio de carnes e ovos no estudo 1 (SEPA) atingiu o valor de 1,83 \pm 0,19 porções. Dez anos após, no estudo 2 (CADI), o número médio de porções ingeridas aumentou para 2,5 $\pm 0,21$. Portanto, um crescimento significativo ao longo do período da pesquisa $(\mathrm{p}=0,018)$.

Nos bairros, a ingestão de carnes e ovos não foi estatisticamente significante ( $\mathrm{p}=$ 0,075), embora nos locais avaliados foram encontradas mudanças no consumo médio desse tipo de grupo alimentar.

Pode-se notar que todos os bairros, exceto o Jardim Recreio, aumentaram o consumo médio de carnes e ovos entre um período e outro da pesquisa.

O gráfico 17 ilustra essa situação e aponta a grande variação em torno da média no Maria Casagrande, José Sampaio e Vila Tibério no segundo momento do estudo (2001). 
Gráfico 17 - Consumo médio de carnes e ovos pelos indivíduos dos projetos SEPA (1) e CADI (2), segundo os bairros avaliados. Ribeirão Preto, 1991/93 e 2001/03.

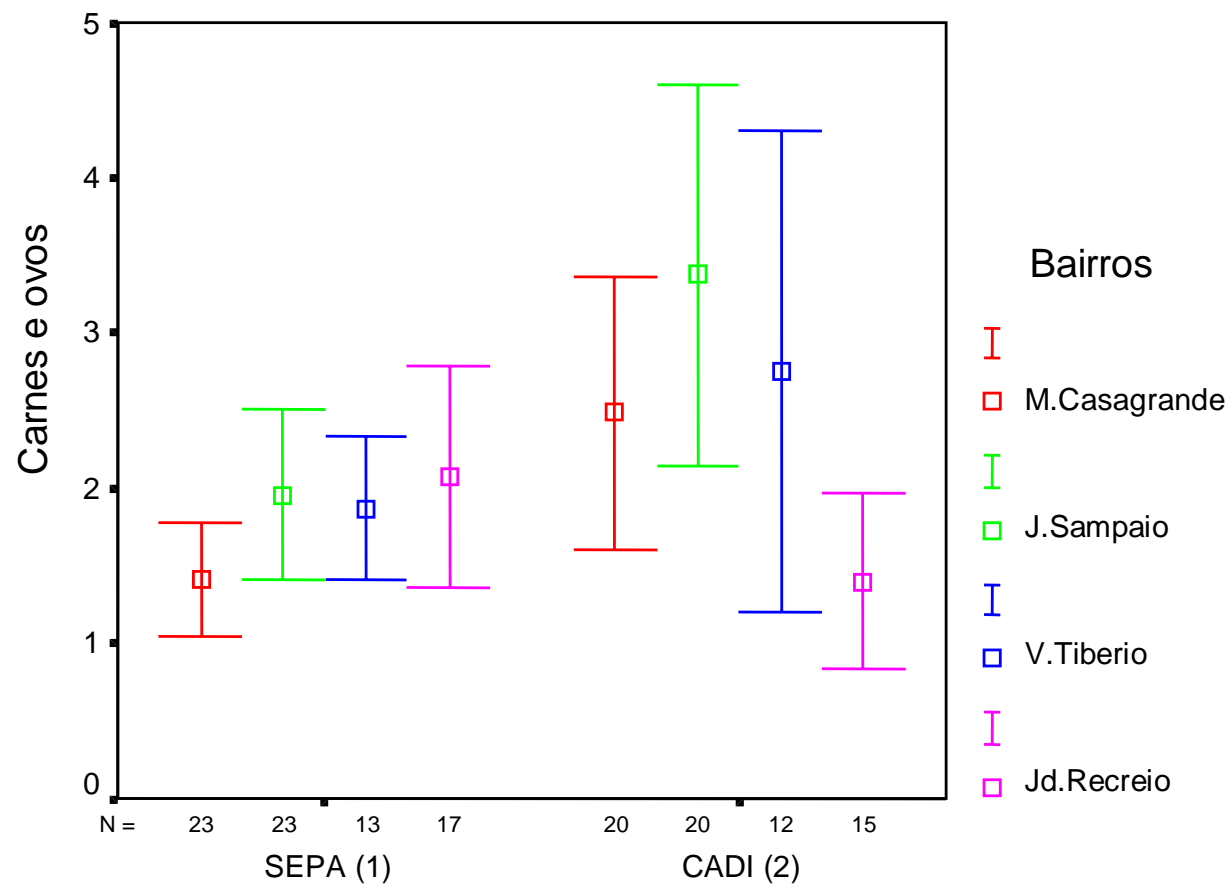

Estudos

Entre 1991/93 e 2001/03, a ingestão média de carnes e ovos nos bairros avaliados teve comportamento diferenciado ao longo da pesquisa, resultando em alterações estatisticamente significantes. Essa condição é satisfeita pelo valor significativo do teste de intersecção realizado entre o tipo de estudo e os bairros visitados $(p=0,047)$.

\subsubsection{Consumo de leite e derivados}

Quanto ao consumo de leite e seus derivados, notamos que, no geral, o primeiro estudo (1991/93) apontou ingestão média de 0,95 $\pm 0,11$ porções de lácteos e no segundo momento da pesquisa (2001/03) o consumo médio foi de 1,17 $\pm 0,12$ porções. 
Apesar desse aumento, os testes não indicaram significância estatística quanto ao tipo de estudo avaliado $(\mathrm{p}=0,161)$.

Nos bairros, a situação encontrada foi diferente, ou seja, os testes apontaram alto grau de significância estatística $(p=0,000)$ e todos os bairros visitados, com exceção do Jardim Recreio, tiveram aumento no consumo médio de leite e seus produtos derivados.

O gráfico 18 ilustra essas diferenças e, dentre os locais, o Jardim Recreio foi o único que se diferenciou do Maria Casagrande, do José Sampaio e da Vila Tibério e estes não se diferenciaram entre si.

Gráfico 18 - Consumo médio de leite e derivados pelos participantes dos projetos SEPA (1) e CADI (2), segundo os bairros visitados. Ribeirão Preto, 1991/93 e 2001/03.

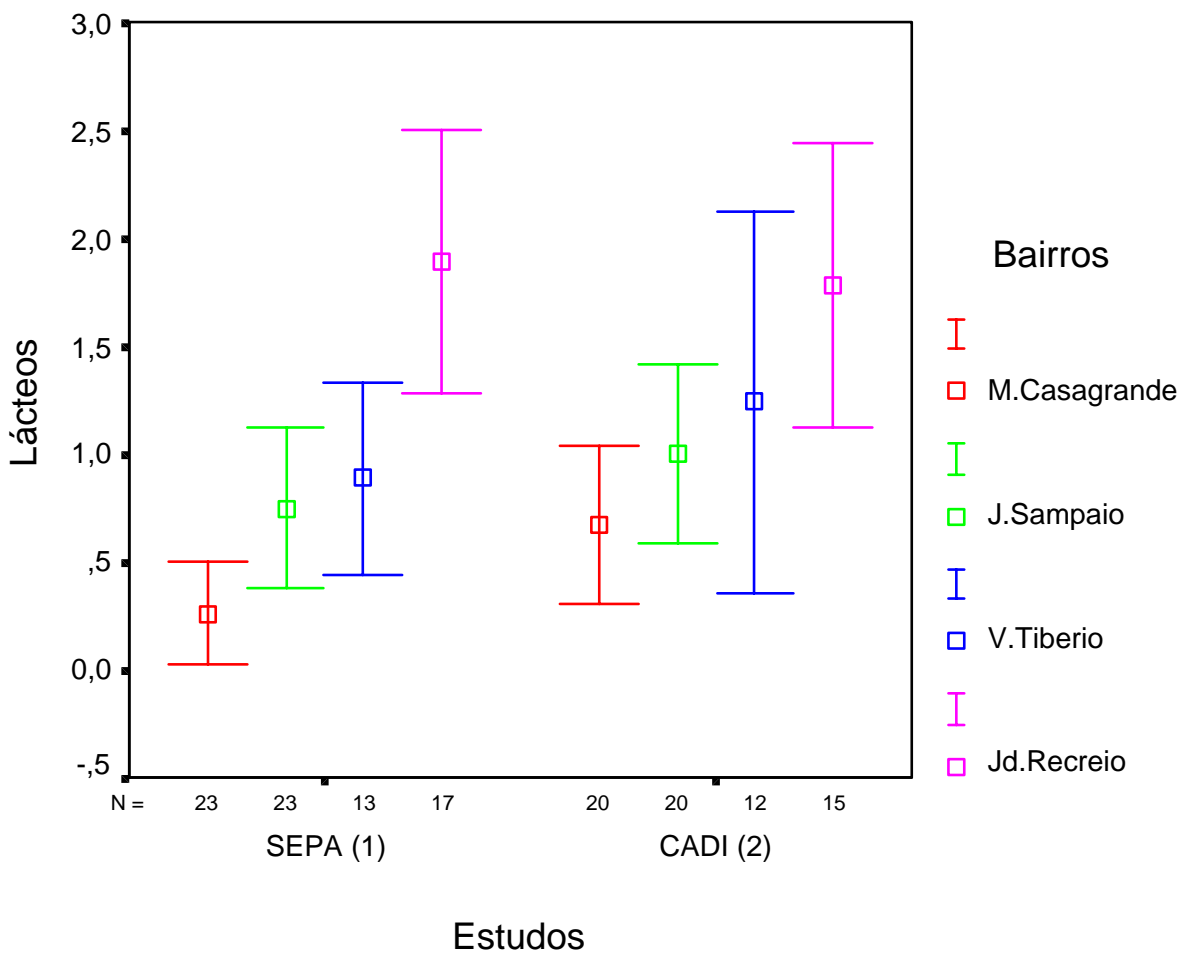


Com relação à intersecção do tipo de estudo com os bairros visitados, não houve em todo o período da pesquisa alterações significativas estatisticamente no consumo médio de leite e seus derivados, apesar das diferenças observadas nos locais, isoladamente $(\mathrm{p}=$ 0,662). Portanto, é válido afirmar que ao longo de dez anos o comportamento dos bairros quanto à ingestão média dos produtos lácteos não teve mudanças.

\subsubsection{Consumo de Açúcar}

O grupo alimentar açúcar representa todos os tipos de doces ingeridos pelos indivíduos avaliados, ou seja, além do açúcar puro, também os bolos recheados, leite condensado, doces de frutas, geléias, pudins, refrigerantes, etc.

De um período para outro, no geral, registrou-se aumento no consumo médio desse grupo. Em 1991/93, os indivíduos consumiam, em média, 2,21 \pm 0,4 porções de açúcar e em 2001/03 esse consumo passou para 3,91 \pm 0,42 porções. Essa diferença de valores foi estatisticamente significante, segundo apontaram os testes realizados $(p=0,004)$.

Quando analisado o comportamento da ingestão média de açúcar nos bairros, isoladamente, notou-se que todos eles também aumentaram o consumo desse grupo alimentar (Maria Casagrande alterou de 2,20 $\pm 2,83$ para 3,23 $\pm 2,19$; José Sampaio de $1,97 \pm 1,94$ para 5,59 $\pm 6,64$; Vila Tibério de $2,35 \pm 1,33$ para 4,28 $\pm 3,51$ e, finalmente, o Jardim Recreio de 2,32 $\pm 2,23$ para 2,53 $\pm 3,01$ ) , embora essa situação não tenha representado significância estatística nos testes realizados $(\mathrm{p}=0,309)$.

O gráfico 19 mostra as diferenças no consumo médio de açúcar nos bairros e a grande variação em torno da média no segundo momento da pesquisa (2001/03), principalmente no José Sampaio. 
Gráfico 19 - Consumo médio de açúcar pelos participantes do projeto SEPA (1) e CADI (2) nos bairros visitados. Ribeirão Preto, 1991/93 e 2001/03.

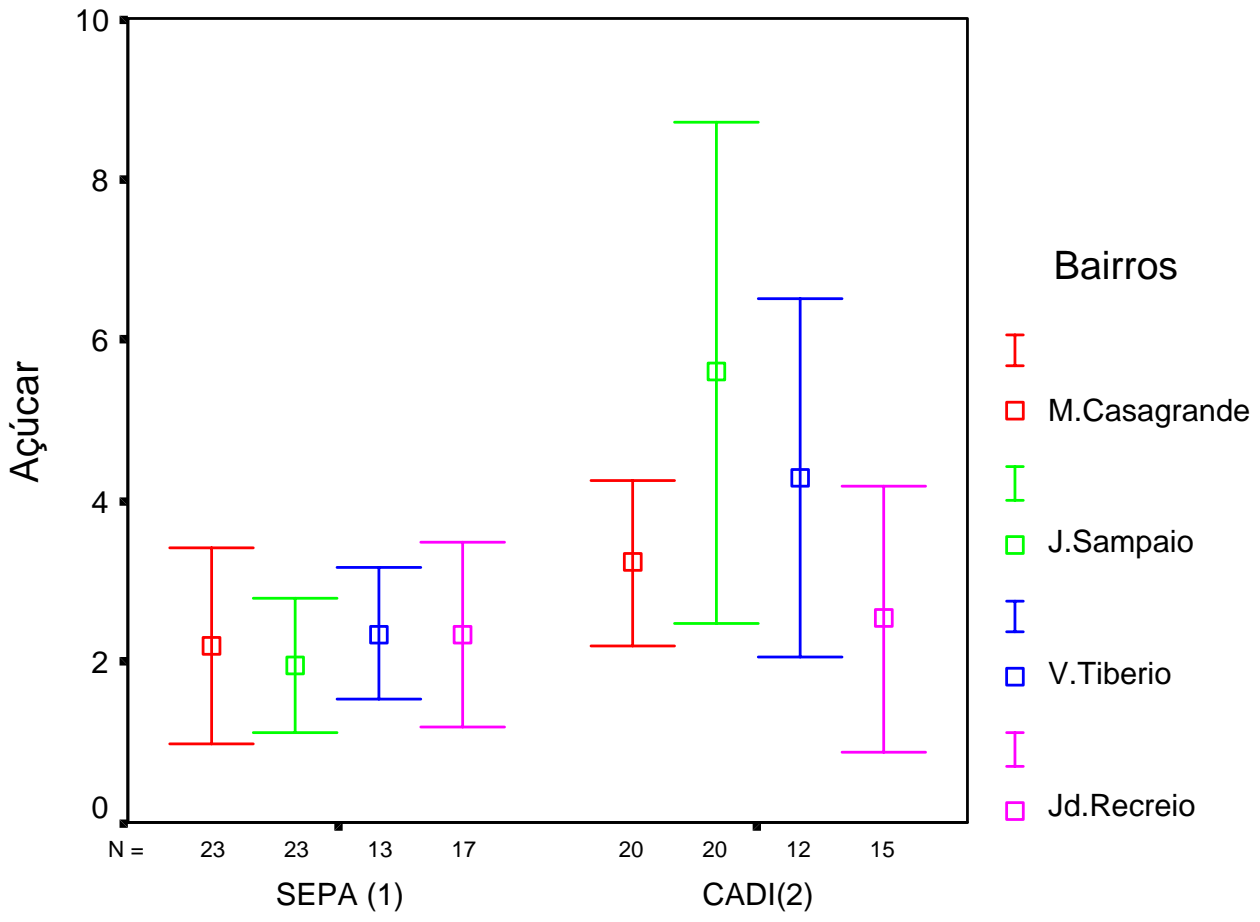

\section{Estudos}

A análise da intersecção do tipo de estudo com os bairros não foi significativa estatisticamente $(\mathrm{p}=0,148)$, portanto ao longo do período de dez anos de pesquisa, não se pode afirmar que o comportamento diferenciado nos locais entre um período e outro representou alterações relevantes.

\subsubsection{Consumo de Gorduras}

O grupo alimentar das gorduras não somente representa as gorduras de adição (óleos vegetais, banha de porco, toucinho), mas também outros tipos de gordura como maionese, manteiga, margarina, creme de leite, etc. 
Em relação a cada estudo, o consumo médio de gorduras em 1991/93 foi de 3,37 \pm 0,20 porções e em 2001/03 atingiu o valor de 2,01 \pm 0,21 porções. Houve diminuição significativa entre um período e outro da pesquisa $(p=0,000)$.

Nos bairros também verificou-se diminuição do consumo médio de gorduras entre um ano e outro, ou seja, o Maria Casagrande que em 1991 consumia 3,97 \pm 2,20 porções de gordura, passou a consumir 2,49 \pm 1,98 porções em 2001; o José Sampaio passou de $3,59 \pm 1,76$ para $2,33 \pm 1,58$; a Vila Tibério de $3,73 \pm 1,71$ para $1,57 \pm 1,48$ e o Jardim Recreio passou de 2,18 $\pm 1,00$ para 1,66 $\pm 0,96$ porções de gordura.

Os testes estatísticos foram significantes no estudo dos bairros isoladamente $(\mathrm{p}=$ 0,01) e o Jardim Recreio foi o local que se diferenciou do Maria Casagrande e do José Sampaio, porém estes dois últimos não se diferenciaram entre si (Gráfico 20).

Gráfico 20 - Consumo médio de gorduras pelos participantes dos estudos SEPA (1) e CADI (2), segundo os bairros visitados. Ribeirão Preto, 1991/93 e 2001/03.

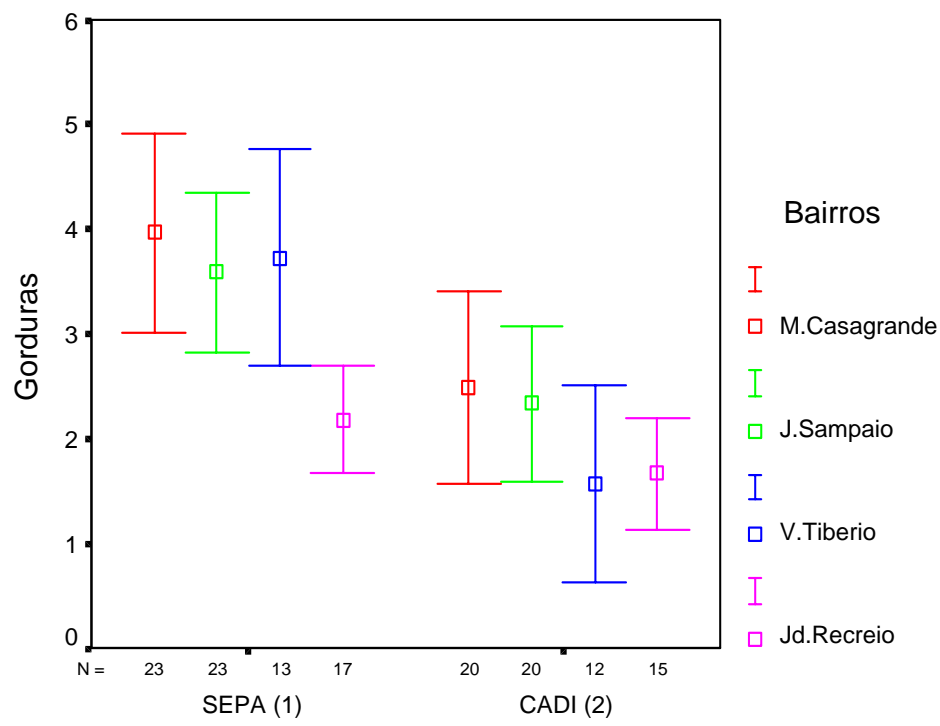

Estudos 
A análise da intersecção do tipo de estudo com os bairros não foi estatisticamente significante $(\mathrm{p}=0,330)$, portanto ao longo da pesquisa a ingestão média de gorduras nos bairros entre um ano e outro não representou mudanças relevantes. 


\section{DISCUSSÃO}

O objetivo deste estudo foi avaliar e comparar o estado nutricional e o consumo alimentar de uma parcela da população de Ribeirão Preto - SP por meio do cálculo do IMC e das análises da quantidade e qualidade da alimentação consumida pelos participantes.

Ao se tentar obter dados para analisar o estado nutricional e o consumo alimentar da população brasileira, os desafios encontrados são muitos. As dificuldades podem começar na etapa do planejamento e se estender até a análise dos dados. Além dos obstáculos metodológicos, há poucos estudos nacionais disponíveis sobre a avaliação do consumo alimentar da população brasileira (MARCHIONI; SLATER; FISBERG, 2003). As principais referências são o Estudo Nacional sobre Despesa Familiar (ENDEF) de 1974/1975, as Pesquisas de Orçamento Familiar (POFs) de 1986/1988, 1995/1996 e 2002/2003 e a Pesquisa Nacional sobre Saúde e Nutrição (PNSN) de 1989, todos elaborados pelo Instituto Brasileiro de Geografia e Estatística - IBGE.

Embora estas publicações baseiem suas conclusões no estudo da disponibilidade alimentar nos domicílios ao invés do consumo individual e, ainda, não considerem a fração desperdiçada de alimentos e nem as refeições que são feitas fora de casa, esses achados apontam para modificações importantes e preocupantes na alimentação da população brasileira.

No geral, tem-se observado diminuição na ingestão de alimentos tradicionais da dieta do brasileiro, como o arroz e o feijão, e elevado consumo de produtos industrializados (embutidos, enlatados, refeições prontas), ricos em gordura e carboidratos simples, como biscoitos, açúcar e refrigerantes (MONTEIRO et al., 1994, 1995, 2000; LEVY-COSTA et al., 2005). 
No período em que se realizou essa pesquisa (1991/93-2001/03), pode-se notar algumas alterações na alimentação dos indivíduos participantes da mesma. O consumo de cereais como arroz, pães, macarrão, raízes e tubérculos praticamente se manteve, com tendência à diminuição, entre 1991/93 e 2001/03. No geral, o consumo em 1991/93 que era de $3,92 \pm 0,26$ porções, passou para $3,47 \pm 0,28$ porções em $2001 / 03$, permanecendo abaixo dos níveis recomendados pelo guia da Pirâmide Alimentar Brasileira que é de 5 a 9 porções diárias. Também foi constatada diminuição desse grupo alimentar nos quatro bairros visitados entre 1991/93 e 2001/03.

Embora esse declínio não tenha sido significativo, o resultado encontrado indica tendência da baixa ingestão de cereais, corroborando dados de outros estudos (GALEAZZI. M.A.; DOMENE, S.M.A.; SICHIERI, R, 1997; IBGE, 2004; MOLINA, 2004).

Quanto ao consumo de carboidratos (principal nutriente do grupo dos cereais), a ingestão média em 1991/93 foi de 46,3\% do valor calórico total da alimentação e em 2001/03, 47,9\%. Apesar do consumo deste tipo de nutriente ter aumentado de 1991/93 para 2001/03, a quantidade ingerida está quase 10\% abaixo do mínimo recomendado pela Organização Mundial da Saúde (OMS) para uma alimentação saudável (entre 55\% e 75\%.) (WHO, 2003).

Percebeu-se, durante o levantamento dos dados dos inquéritos, que grande parte do carboidrato ingerido foi do tipo simples e as fontes alimentares principais foram o açúcar, doces em geral e refrigerantes.

Em relação ao consumo de gorduras totais, houve diminuição, em média, de dois pontos percentuais (de $35 \%$ para $33 \%$ do valor calórico total) de um estudo para outro, porém os valores permaneceram acima dos níveis recomendados que é de 30\% (WHO, 2003). O mesmo comportamento foi verificado nos bairros, com exceção do Maria 
Casagrande que teve seus níveis de lipídios aumentados de um período para outro da pesquisa. Com relação ao consumo do número de porções alimentares pertencentes ao grupo das gorduras, também constatou-se diminuição entre um ano e outro. Em 1991/93, a média atingiu 3,4 0,2 porções e em 2001/03 baixou para 2,0 0,2 porções, estando no limite da recomendação que é de 1 a 2 porções diárias.

Os resultados da ingestão de gorduras do tipo saturada foram semelhantes à ingestão dos lipídios totais, isto é, entre um período e outro, o percentual do consumo desse tipo de gordura também diminuiu. Em 1991/93 os indivíduos consumiam 12,0\% 0,2 e em 2001/03 a ingestão baixou para 11,3\% 0,2. Da mesma forma, nos bairros, houve diminuição dos valores no José Sampaio, Vila Tibério e Jardim Recreio e aumento da ingestão no Maria Casagrande.

Apesar de ter ocorrido diminuição das gorduras saturadas nos três bairros citados, seus valores ultrapassaram a recomendação da OMS (10\%) e os moradores do Maria Casagrande que em 1991/93 consumiam cerca de 8\% do valor calórico total da alimentação desse nutriente, em 2001/03 passaram a ingerir cerca de 10,3\%, portanto também acima do nível desejável.

As demais frações de gordura total sofreram aumento do consumo nos dois períodos avaliados e constatou-se elevação mais expressiva dos percentuais das gorduras monoinsaturadas se comparadas às gorduras polinsaturadas. O consumo da primeira foi de $8,6 \% \pm 0,2$ em 1991/93 e atingiu 12,1\% \pm 0,2 em 2001/03. Com relação às polinsaturadas,

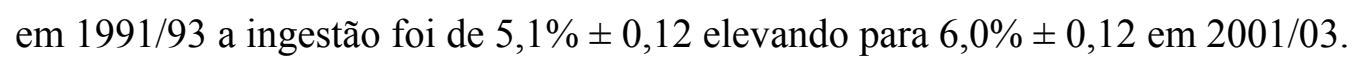

O cálculo das frações de gordura (saturada, monoinsaturada e polinsaturada) é uma das grandes dificuldades encontrada nos estudos de avaliação de consumo alimentar, pois a 
maioria das tabelas brasileiras de composição de alimentos não possuem informações desses nutrientes. Em grande parte, quando se deseja obter tais dados, tem-se que recorrer às tabelas internacionais que não refletem a realidade do consumo dos alimentos no Brasil devido às variabilidades resultantes de fatores genéticos, ambientais (tipo de solo, por exemplo), de preparo e processamento dos produtos (RIBEIRO et al., 2003).

Neste trabalho, os valores de frações de gordura dos inquéritos de 2001/03 foram sistematicamente calculados e revisados após detectada inconsistência no valor total de lipídios e suas partes, ou seja, a soma das gorduras totais apontava resultado superior à soma das gorduras saturadas, monoinsaturadas e polinsaturadas, isoladamente. Durante o trabalho de revisão, constatou-se que o programa de computador utilizado para realizar o cálculo dos inquéritos alimentares não continha dados completos das frações de gordura de alguns alimentos reconhecidamente fontes de tais nutrientes. Para preencher essa lacuna, os dados que faltavam foram localizados em outras tabelas e inseridos no programa.

Os aplicativos computacionais disponíveis na área de nutrição ajudam muito na análise da alimentação de indivíduos e populações pela rapidez e praticidade do cálculo dos nutrientes. Entretanto, também têm suas limitações na medida em que faltam informações de substâncias em alimentos fontes de determinados micronutrientes e macronutrientes essenciais.

Geralmente, as informações da composição dos alimentos disponíveis no banco de dados dos programas são o resultado de uma compilação de dados de tabelas nacionais e internacionais. Por isso, antes da escolha de qual tipo utilizar, deve-se ter muito claro o objetivo do estudo e o que se pretende analisar com a informação obtida. Daí a necessidade de observar atentamente as informações relacionadas ao sistema e ao conteúdo do programa de avaliação nutricional (FISBERG; MARTINI; SLATER, 2005). 
Nos últimos anos, cresceu muito o mercado de produtos que facilitam e tornam mais ágeis as tarefas diárias dos profissionais da saúde e foi mais recentemente que se notou o avanço de aplicativos computacionais específicos na área de nutrição. Há 15 anos, portanto em 1990, os programas disponíveis eram poucos e muito limitados nas suas análises. A partir de meados da década de 1990 surgiram versões mais atualizadas e melhoradas dos mesmos (FISBERG; MARTINI; SLATER, 2005).

Ao longo desta pesquisa, em 2001/03, decidiu-se utilizar um programa mais moderno, com melhores opções de cálculo e banco de dados mais amplo, diferentemente daquele utilizado em 1991/93. Embora a escolha tenha sido com o propósito de melhorar a avaliação da composição alimentar dos indivíduos, essa alternativa pode ter interferido na análise de alguns nutrientes, como as gorduras monoinsaturas, polinsaturadas, o colesterol e as fibras cujos valores apresentaram-se subestimados em 1991/93.

Em busca de maior consistência nos dados obtidos e enriquecimento do estudo, foi essencial incluir a análise da qualidade da alimentação pelo cálculo do número de porções consumidas em função dos oito grupos de alimentos correspondentes, conforme recomendado por PHILIPPI et al. (1999b). Dessa forma, foi possível comparar se o aumento ou diminuição da ingestão de alguns nutrientes estava coerente ou não com o aumento ou diminuição do número de porções alimentares consumidas.

Assim, como o consumo de proteínas aumentou de um período para outro da pesquisa (em 1991/93 a média foi de $14 \pm 2,2 \%$ e em 2001/03 de $15 \pm 2,2 \%$ ), podemos observar também que a ingestão dos grupos alimentares das carnes e ovos e do leite e seus derivados acompanhou essa elevação. A alteração foi significativa e em 2001/03 a média da ingestão de carnes e ovos chegou a 2,5 $\pm 0,2$ porções diárias, contra $1,8 \pm 0,2$ porções em 1991/93. Nos bairros, com exceção do Jardim Recreio, também houve aumento da ingestão 
e todos ultrapassaram a recomendação máxima para o consumo desse grupo alimentar ( 1 a 2 porções diárias).

Quanto ao consumo de leite e derivados, o resultado foi significativo nos bairros e da mesma forma sofreu aumento de um período para outro $(0,95 \pm 0,11$ porções em 1991/93 para $1,17 \pm 0,12$ porções em 2001/03), com exceção novamente do Jardim Recreio. Apesar disso, o número de porções ingeridas ainda está bem abaixo da recomendação diária (3 porções). Em média, no estudo todo, o consumo chegou a 1,00 \pm 1,06 porção/dia.

O apoio das ciências econômicas auxiliou bastante na busca do entendimento da elevação do consumo de carnes e ovos e leite e derivados em dez anos de estudo. Em meados da década de 1990, uma das propostas políticas do então presidente em exercício, Fernando Henrique Cardoso, era reduzir a inflação a fim de estabilizar a economia do país, tornando-a atraente e segura para os investimentos nacionais e internacionais. Dessa forma, implantou-se o Plano Real, onde R \$ 1,00 (um real) passou a ter o mesmo valor de US\$1,00 (um dólar). Essa plataforma de governo proporcionou à população economicamente menos favorecida maior poder de compra para consumir produtos mais caros e portanto, de maior valorização social, como é o caso dos produtos de origem animal, particularmente as carnes. Essas mudanças econômicas também foram responsáveis pelo aumento da oferta de produtos industrializados (queijos, iogurtes, biscoitos, etc) de marcas concorrentes a outras similares no mercado, porém de preço mais acessível à população de menor rendimento.

Da mesma maneira que o consumo de carnes e ovos e gorduras saturadas sofreram alterações entre um período e outro, a ingestão do colesterol não foi diferente, ou seja, entre 1991/93 e 2001/03, o colesterol dietético aumentou consideravelmente, passando de 169,4 $\pm 50,0 \mathrm{mg}$ em $1991 / 93$ para $271,6 \pm 171,3 \mathrm{mg}$ em 2001/03. O mesmo comportamento foi 
verificado nos quatro bairros visitados, sendo a média de ingestão no Maria Casagrande a menor em relação aos demais locais visitados. Possivelmente, uma das justificativas para esse fenômeno esteja na quantidade menor de alimentos consumidos pelos moradores do bairro de menor renda média familiar.

Como outros estudos apontam, à medida que cresce o consumo de alimentos com alta densidade energética, a ingestão de fibras fica prejudicada (FORNES et al., 2002; MATTOS; MARTINS, 2003). Neste trabalho, o consumo dos alimentos ricos em carboidratos simples, como doces em geral e refrigerantes tiveram crescimento entre um período e outro e apesar de ter ocorrido aumento do consumo de fibras e do número de porções de hortaliças e frutas, a ingestão dessas substâncias permaneceram abaixo dos índices recomendados pela OMS (WHO, 2003) e pelo guia alimentar adaptado à população brasileira (PHILIPPI et al., 1999b).

Nos bairros, também se verificou aumento no consumo destas substâncias e a diferença entre os locais não foi significativa para a ingestão de frutas e hortaliças, ao contrário do observado para o consumo de fibras.

Os resultados desta pesquisa são consistentes com dados de alguns estudos realizados pelo IBGE (as pesquisas de orçamento familiar - POFs), além de outros de caráter regional sobre o consumo alimentar no país (IBGE, 1996; GALEAZZI; DOMENE; SICHIERI, 1997; MONTEIRO; CONDE, 1999; IBGE, 2004; MOLINA, 2005). Excetuando uma ou outra diferença metodológica, o que se nota no hábito alimentar do brasileiro é a semelhança na escolha de uma alimentação com alta densidade energética, isto é, baixa ingestão de carboidratos complexos e fibras e alto consumo de carboidratos simples (açúcares e refrigerantes) e gorduras. Esse panorama é um reflexo das mudanças 
que vêm ocorrendo ao longo dos 30 anos na alimentação do povo brasileiro (MONDINI; MONTEIRO, 1994; MONTEIRO et al., 2000).

Antes deste período, as preocupações com o hábito de vida e alimentar da população estavam focadas no combate às doenças infecciosas relacionadas ao quadro de desnutrição e de carências nutricionais específicas que atingiam não somente os adultos, mas principalmente as crianças. Com a melhoria sanitária, o desenvolvimento de vacinas e o maior acesso aos serviços de saúde e alimentação, o perfil demográfico e de morbimortalidade das populações se alterou. Atualmente, o Brasil e outros países da América Latina, além da China, Coréia do Sul, Tailândia, África do Sul, países do Caribe e outros locais de economia emergente, convivem ao mesmo tempo com o problema da desnutrição e com o surgimento das doenças crônicas não transmissíveis, como diabetes, certos tipos de cânceres, hipertensão arterial e obesidade (DREWNOWSKI, 2000; POPKIN, 2002; MARCHIONI et al., 2003).

Logo, o problema alimentar deixa de ser apenas circunscrito aos países em desenvolvimento (caso do Brasil) e associado ao problema de acesso aos alimentos. Tratase de questionar o tipo de alimentação das sociedades industrializadas e a sua relação com o aumento da incidência de várias doenças.

Os países em desenvolvimento estão reproduzindo o que já tinha sido documentado nos países mais ricos, embora com velocidade muito maior que dificulta o processo de adaptação às mudanças advindas com a urbanização das cidades, a industrialização e a modernidade crescentes (MONTEIRO et al., 1995; ESCODA, 2002; POPKIN, 2002; GARCIA, 2003).

POPKIN et al. (1993) denominam de transição nutricional essas mudanças seculares em padrões nutricionais que resultam de modificações na estrutura da dieta dos 
indivíduos e que se correlacionam com mudanças econômicas, sociais, demográficas e relacionadas à saúde.

Alguns autores usam a expressão dieta ocidental (MONTEIRO et al., 1995), outros dieta afluente (GARCIA, 2003) e há quem utilize o termo farinização da dieta (ESCODA, 2002) para ilustrar as mudanças ocorridas no padrão da alimentação das sociedades em desenvolvimento, conseqüência do fenômeno da transição nutricional. Alterações concomitantes na composição corporal, em particular o aumento da obesidade, estão associadas com o predomínio desta modificação alimentar e com o declínio da atividade física dos indivíduos.

As relações entre as mudanças demográficas, sócio-econômicas e epidemiológicas que levam à transição nutricional são complexas e, de modo geral, as coortes mais jovens estão mudando mais rapidamente, portanto o predomínio da dieta ocidental ou afluente ou sua farinização e o aumento da obesidade tendem a crescer. Essas mudanças, acompanhadas de um estilo de vida sedentário, parecem ocorrer primeiro em áreas urbanas, estendendo-se depois aos segmentos de renda mais elevada das áreas rurais, frequentemente coexistindo com estratos da população ainda submetidos a déficits energéticos (POPKIN, 1994; MONTEIRO et al., 1995; SICHIERI, 1998).

Em um estudo desenvolvido com uma coorte jovem de Ribeirão Preto - SP, foram obtidas informações sobre o hábito de consumo alimentar de 2063 participantes (homens e mulheres) por meio do Questionário de Freqüência Alimentar, além das características sócio-demográficas e questões sobre o estilo de vida. A faixa etária destes indivíduos era de 24 a 25 anos. Concluiu-se que esses jovens estavam consumindo, em média, uma alimentação rica em gordura $(35,4 \%)$, com baixa ingestão de carboidratos $(47,5 \%)$ e fibras 
$(15,2 \mathrm{~g})$. Do total da amostra, $34 \%$ apresentavam excesso de peso e o grau de inatividade física atingia quase metade da população (48\%) (MOLINA, 2005).

Outro trabalho, cujos dados foram obtidos em estudo realizado entre 1987 e 1991 em cinco núcleos urbanos do Município de Cotia-SP, também demonstrou quadro de inadequação alimentar. Foram entrevistados 557 indivíduos com idade variando de 20 a 88 anos e a análise por percentil identificou consumo exagerado (25\% da amostra) de lipídios e proteínas em detrimento dos carboidratos. A energia, distribuição calórica e quantidade de colesterol foram adequadas em apenas $5 \%$ das dietas. A prevalência de obesidade atingiu $38 \%$ do total da amostra, sendo a maior parte dos indivíduos $(62,4 \%)$ sedentários, ou seja, praticantes de atividades leves (CERVATO et al., 1997).

No Estudo Multicêntrico sobre Consumo Alimentar, concluiu-se que embora a proporção do consumo de gordura nas cidades avaliadas ficasse ao redor ou abaixo de $30 \%$ do total de energia, houve consumo desproporcional de gordura saturada e de colesterol. $\mathrm{O}$ consumo deste último pareceu, inclusive, ser mais inadequado nas coortes mais jovens com possível efeito deletério quando estes jovens atingirem idades mais avançadas (GALEAZZI; DOMENE; SICHIERI, 1997).

Na publicação mais recente do IBGE sobre os dados de orçamento familiar, a evolução do perfil antropométrico-nutricional da população adulta é avaliada entre 19741975 e 2002-2003 (IBGE, 2004). Os indicadores do estado nutricional que são utilizados no estudo são baseados na relação entre o peso e a altura ao quadrado dos indivíduos, ou seja, no Índice de Massa Corporal (IMC $-\mathrm{Kg} / \mathrm{m}^{2}$ ) e a classificação em déficit de peso (IMC $<18,5 \mathrm{Kg} / \mathrm{m}^{2}$ ), excesso de peso (IMC $\geq 25 \mathrm{Kg} / \mathrm{m}^{2}$ ) e obesidade (IMC $\geq 30 \mathrm{Kg} / \mathrm{m}^{2}$ ) segue os padrões da Organização Mundial da Saúde (WHO, 2003). 
A conclusão que se chega é que está ocorrendo diminuição contínua do déficit de peso em ambos os sexos e intenso aumento do excesso de peso e obesidade, particularmente entre os homens. Nas mulheres, o que se observa é o crescimento do excesso de peso e obesidade entre os períodos de 1974-1975 e 1989 e relativa estabilidade entre 1989 e 2002-2003.

Uma das interpretações para esse comportamento diferenciado das mulheres em relação aos homens vem da análise da situação econômica dos indivíduos. A obesidade, que inicialmente predominava nas classes econômicas de maior renda, vem apresentando evolução temporal com predominância nas populações mais pobres, principalmente entre as mulheres.

A prevalência do excesso de peso em homens indica aumento contínuo e intenso do problema em todas as regiões do país e em todas as classes de rendimento. No caso da população feminina, aumento generalizado de prevalência do excesso de peso é observado no primeiro período de estudo (de 1974-1975 a 1989). No segundo período (de 1989 a 2002-2003), a prevalência do excesso de peso em mulheres continua aumentando apenas na Região Nordeste e, de modo geral, entre famílias com rendimento mensal até meio salário mínimo per capita. Nas demais regiões e nas classes de maior renda, a prevalência do excesso de peso se estabiliza ou mesmo declina. Desta forma, o estudo do IBGE concluiu que, no período mais recente, o problema do excesso de peso em mulheres tendeu a se deslocar para a Região Nordeste e, de modo geral, para as classes de menor renda (IBGE, 2004).

No atual estudo, a participação maior foi de mulheres, inclusive nos quatro bairros avaliados. O estado nutricional dos indivíduos foi medido pelo Índice de Massa Corporal (IMC) e verificou-se que não houve significância estatística entre um período e outro, 
embora, em 2001/03, a média do IMC tenha atingido o valor de 25,24 $\pm 0,31 \mathrm{Kg} / \mathrm{m}^{2}$. Portanto, os indivíduos do segundo período da pesquisa, em geral, seriam classificados com sobrepeso (WHO, 2003).

Ao analisar os bairros, notamos que o Maria Casagrande apresentou comportamento diferenciado em relação aos demais locais, ou seja, foi o único em que o aumento do IMC foi significativo de um período para outro e, embora o valor não tenha atingido a categoria de sobrepeso $\left(24,75 \pm 5,29 \mathrm{Kg} / \mathrm{m}^{2}\right.$ em $\left.2001 / 03\right)$, a situação preocupa pois as análises do perfil alimentar desta população apontam para uma tendência de elevação desse índice.

Assim como vem acontecendo com a população brasileira ao longo das últimas três décadas, nesta pesquisa as diferenças socioeconômicas entre os bairros também foi indicativa de alterações importantes na análise do consumo alimentar e do estado nutricional dos indivíduos avaliados.

Na classificação dos bairros com menor e maior renda familiar média estão o Maria Casagrande e o Jardim Recreio, respectivamente. O José Sampaio e a Vila Tibério ocupam posições intermediárias e seus moradores se classificam entre as classes média e médiabaixa.

Observou-se no Maria Casagrande comportamento alimentar típico das classes de menor rendimento e, portanto, com maior prevalência de excesso de peso e outras doenças associadas. Neste bairro, verificou-se aumento no consumo de lipídios totais e gorduras do tipo saturada, fato não observado nos demais locais estudados. Associado ao aumento destes nutrientes, notou-se também elevação na ingestão de alimentos pertencentes ao grupo das carnes e ovos e diminuição no consumo das leguminosas (feijão, soja, grão-debico) e cereais (arroz, batata, milho). 
No Jardim Recreio, constatou-se diminuição da ingestão de lipídios totais e gorduras saturadas entre 1991/93 e 2001/03 e o consumo das porções dos grupos das carnes e ovos permaneceu dentro dos parâmetros recomendáveis (1 a 2 porções diárias). Apesar da ingestão de leite e seus derivados ter ficado abaixo da recomendação em todos os bairros, o Jardim Recreio ainda é o local com maior consumo desse grupo alimentar.

Esses contrastes indicam maneiras de se comportar diferentes diante da oferta de alimentos e segundo o nível socioeconômico da população.

Se em um contexto de escassez de alimentos, que há décadas dominou grande parte do território nacional, as restrições econômicas eram os elementos determinantes das escolhas alimentares, no contexto atual de maior oferta de produtos estas restrições tornamse secundárias. Neste último caso, os consumidores escolhem sua alimentação em função de fatores culturais, sociais e psicológicos (LAMBERT et al., 2005).

Os efeitos da globalização mundial são determinantes da mudança das práticas alimentares na sociedade contemporânea. A economia globalizada atinge não só a indústria de alimentos, mas também o setor agropecuário, a distribuição de alimentos em redes de mercados e grandes cadeias de lanchonetes e restaurantes. O consumidor se vê diante de uma gama enorme de produtos novos e cada vez mais sofisticados que associados à sua propaganda e marketing, interferem no seu modo de viver e em suas escolhas (BLEIL, 1998; GARCIA, 2003; BRAGA, 2004).

Uma das conseqüências desta modernidade está no ritmo mais acelerado que as pessoas têm adotado para suas vidas, na busca de melhores condições econômicas em um mercado de trabalho cada vez mais exigente. O "tempo", nos dias atuais, torna-se um elemento chave no mundo contemporâneo e seguindo essa tendência vemos aumentar intensamente as redes de fast-foods que são ágeis, poupam o tempo de preparo e de 
ingestão dos alimentos e são deslocáveis para qualquer espaço. Da mesma forma, as prateleiras dos supermercados se enchem de produtos industrializados cujo preparo quase que instantâneo é um atrativo que se encaixa perfeitamente às necessidades do mundo moderno (MENDONÇA; ANJOS, 2004).

Garcia (2003) destaca em seu artigo dados de uma empresa especializada em pesquisa de mercado a qual se utiliza da produção de embalagens para suas estimativas. Os números indicam que houve incremento importante no mercado nacional da produção de iogurtes líquidos e outras bebidas lácteas entre 1990 e 1996 da ordem de 252\% e 829\%, respectivamente. Os alimentos congelados cresceram 126\% no mesmo período, os biscoitos 108\% e a produção de refrigerantes, nos últimos dez anos, elevou-se em 90\%. Os valores encontrados na última pesquisa do IBGE também chamaram a atenção pelo aumento do consumo de produtos industrializados (refrigerantes e biscoitos) em 400\% (IBGE, 2004).

Nesta presente pesquisa, o cálculo isolado do consumo de refrigerantes não foi realizado, mas pode-se afirmar que o aumento do número de porções de açúcares registrado de um ano para outro teve como efeito o consumo deste tipo de bebida, além dos bolos prontos e chocolates. No grupo das frutas, que também teve aumento de 1991/93 para 2001/03, grande parte da ingestão não era de frutas in natura e sim de sucos de frutas industrializados, portanto altamente concentrados em açúcar e com reduzido teor de fibras.

O crescimento de lanchonetes norte-americanas no Brasil reflete a adesão ao que representa o "ideal americano" ou a "ocidentalização" dos costumes. Para se ter uma idéia, a oitava maior rede de McDonald's do mundo é a brasileira, a qual também é a quinta que mais cresce. O faturamento da empresa no país, em 2001, foi de $\mathrm{R} \$ 1,60$ bilhão com o atendimento de 514 milhões de clientes - média de 1,4 milhão de clientes a cada dia. De 
fato, o crescimento em termos de número de lojas é exponencial desde sua introdução em 1979, principalmente a partir dos anos 90 (MENDONÇA; ANJOS, 2004).

Esse panorama do mundo moderno e globalizado atinge de forma direta a sociedade dos países em desenvolvimento como o Brasil e faz surgir questões direcionadas à busca de soluções diante de tamanha complexidade.

A evolução dos hábitos alimentares é muito mais lenta que a de outros hábitos correntes da vida cotidiana. Em dez anos de pesquisa, foi possível observar mudanças da qualidade da alimentação dos participantes que futuramente podem afetar o estado nutricional e estilo de vida dessas pessoas.

O padrão recomendado de consumo alimentar (figura 1) parece difícil de se alcançar em curto espaço de tempo e permanece distante do cotidiano de muitas famílias. As figuras 2 e 3 ilustram a avaliação do consumo alimentar dos participantes dessa pesquisa nos dois períodos estudados. 
Figura 1 - Padrão recomendado de consumo alimentar de acordo com o número de porções dos grupos alimentares da pirâmide alimentar brasileira, segundo Phillip et al (1999b).

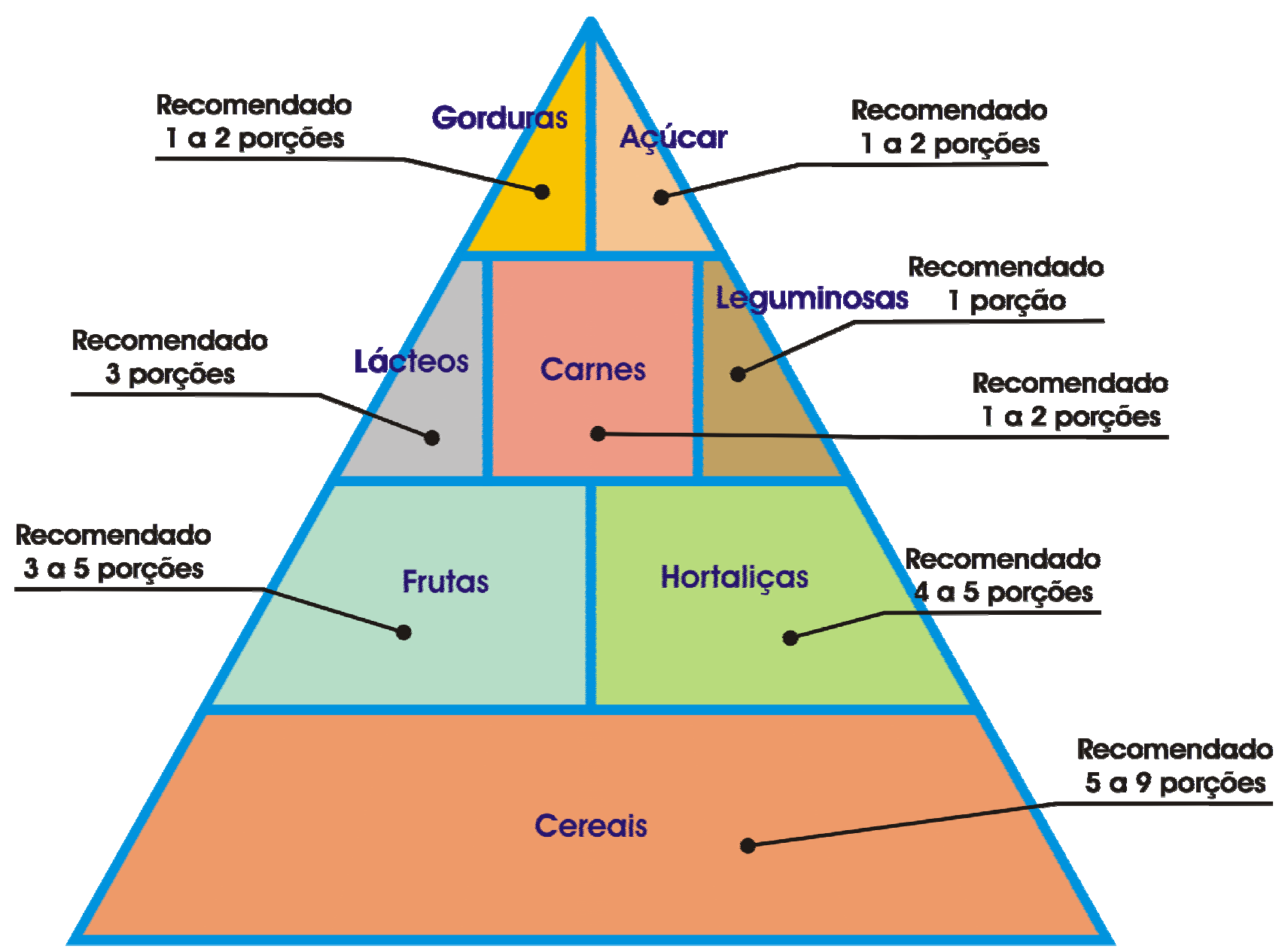


Figura 2 - Consumo médio do número de porções alimentares ingeridas pelos participantes do estudo SEPA (1991/93), segundo padrões de recomendação da pirâmide alimentar brasileira.

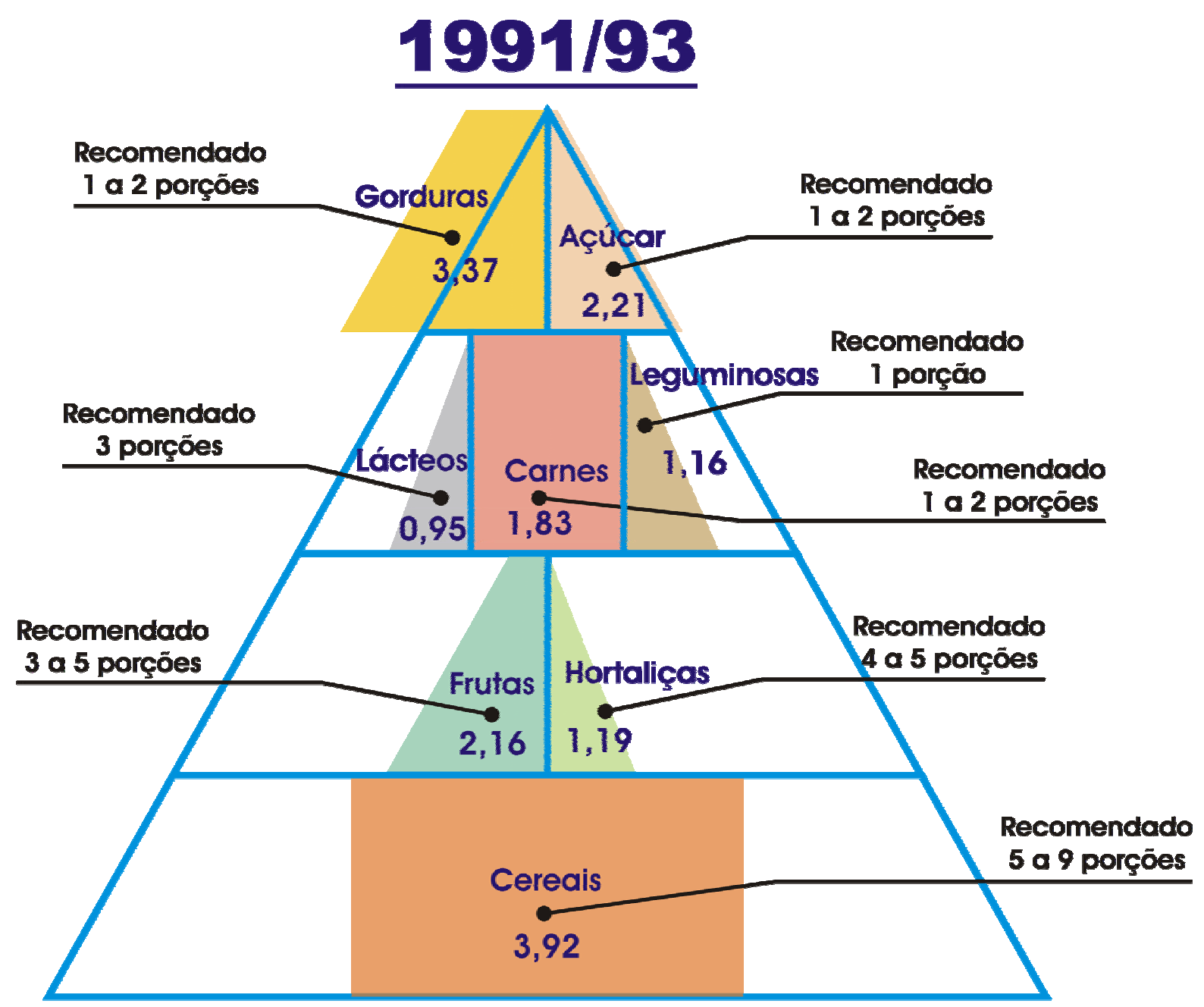


Figura 3 - Consumo médio do número de porções alimentares ingeridas pelos participantes do estudo CADI (2001/03), segundo padrões de recomendação da pirâmide alimentar brasileira.

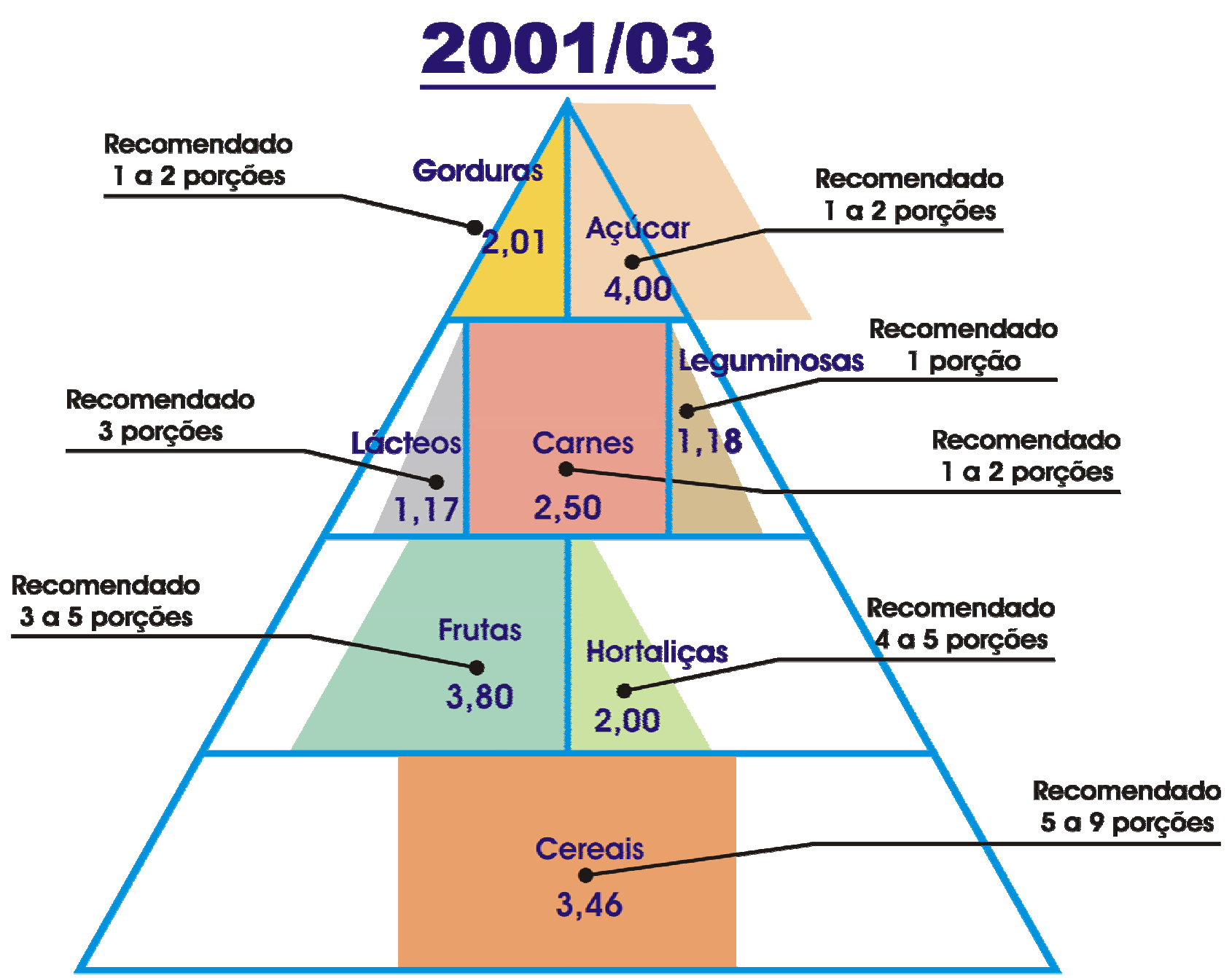


Pode-se notar que alterações significativas ocorreram durante o período de avaliação desta pesquisa. O consumo de cereais praticamente se manteve inalterado, com discreta diminuição entre um ano e outro, e continuou inadequado em relação ao número de porções diárias recomendáveis.

O grupo das leguminosas também não sofreu modificação entre 1991/93 e 2001/03, entretanto o consumo médio nos dois períodos atingiu os níveis adequados da recomendação.

A ingestão de frutas, hortaliças e leite melhorou, mas os índices ficaram bem abaixo da recomendação para o grupo dos lácteos e das hortaliças e no limite mínimo recomendável para o grupo das frutas.

O consumo médio do grupo das carnes e ovos e do grupo dos açúcares piorou entre 1991/93 e 2001/03, pois constatou-se aumento da ingestão de ambos, ultrapassando os limites da recomendação no segundo período de estudo.

Ribeirão Preto é uma cidade de quase 600 mil habitantes e, assim como outras grandes metrópoles e regiões do território nacional, sua população vem sendo diretamente afetada pelos efeitos da globalização e da modernidade. A ocorrência dessas mudanças alimentares no período de 1991/93 para 2001/03 reflete aspectos das influências política, econômica e social que dominam e ditam as regras da sociedade em detrimento dos prejuízos que venham causar.

É crescente o número de pessoas na cidade cada vez mais jovens afetadas pelas doenças crônicas não-transmissíveis (hipertensão, diabetes, obesidade), sobrecarregando o sistema público de saúde que não consegue atender a demanda de indivíduos portadores de tais patologias (MOLINA, 2005). 
Para o diagnóstico da situação alimentar e a conseqüente atuação nessa área, faz-se necessária a adoção de métodos de análise capazes de apreender os vários fatores determinantes do consumo e sua evolução, bem como a interação entre eles. Trata-se de uma abordagem multidisciplinar que envolve as ciências naturais, como a Nutrição, a Medicina, mas também engloba as áreas humanas onde estão inseridas a Antropologia, a Sociologia, a Psicologia, a Economia.

Não é trabalho simples, mas se não se levar em consideração o estudo dos inúmeros aspectos que interferem na escolha dos hábitos alimentares das pessoas, corre-se o risco de não se realizar uma análise completa de toda a situação, tornando-a simples e reducionista. Logo, levantamentos importantes para a solução de alguns problemas permanecerão obscuros e a eficácia de algumas medidas de intervenção ficará comprometida. 


\section{CONCLUSÃO}

Esse estudo comparativo dos anos de 1991/93 e 2001/03 que buscou avaliar o estado nutricional e o consumo alimentar dos adultos moradores de quatro bairros de diferentes níveis socioeconômicos em Ribeirão Preto - SP, permitiu concluir que:

- Houve alteração, embora não significativa estatisticamente, do estado nutricional dos participantes da pesquisa. Em 1991/93 a média do IMC estava dentro da normalidade, porém em 2001/03 os valores atingiram a categoria de sobrepeso.

- Houve coerência nos resultados das análises da quantidade e da qualidade da alimentação dos indivíduos.

- No geral, registrou-se baixo consumo de carboidratos complexos (arroz, macarrão, pães) e cereais e alto consumo de carboidratos simples (açúcar e doces em geral), lipídios totais, lipídios saturados e alimentos do grupo das gorduras.

- Houve aumento do consumo de proteínas e colesterol, da mesma maneira que também elevou-se a ingestão dos alimentos pertencentes aos grupos das carnes e ovos e leite e derivados.

- Permaneceu abaixo das recomendações o consumo de fibras, hortaliças e frutas.

- As diferenças socioeconômicas entre os bairros de menor renda e maior renda, respectivamente Maria Casagrande e Jardim Recreio, acompanharam tendências de estudos atuais que demonstram a predominância do consumo de uma alimentação altamente energética seguido de elevação de peso nas populações de baixa renda e comportamento inverso dos indivíduos pertencentes às camadas de maior rendimento econômico. 


\section{CONSIDERAÇÕES FINAIS}

Esta pesquisa teve papel de destaque, pois fez parte de estudo pioneiro no Município de Ribeirão Preto - SP em se tratando dos métodos de análise adotados.

Buscou-se avaliar os aspectos da quantidade e da qualidade alimentar a fim de tornar os dados mais consistentes e fidedignos, o que foi possível obter, pois houve coerência no comportamento dos resultados relativo ao consumo dos nutrientes e dos grupos alimentares.

É importante ressaltar o período em que as informações foram colhidas e avaliadas. O espaço entre uma coleta e outra foi de 10 anos e, inerente à qualquer trabalho de semelhante magnitude, naturalmente surgiram algumas dificuldades.

Devido este estudo fazer parte de um amplo projeto de pesquisa, o tempo de coleta dos dados somou-se, no total, quatro anos (1991-1993, no primeiro período e 2001-2003, no segundo período). Tomou-se especial cuidado em adotar os mesmos instrumentos metodológicos aplicados num momento e outro, pois em uma década novos métodos podem surgir e, se não houvesse a preocupação em conservá-los, o trabalho tornaria inviável já que seus resultados não poderiam ser comparáveis.

Avaliar a quantidade e qualidade alimentar da população não é tarefa fácil. Outros autores que também pesquisam sobre o assunto são unânimes em concordar.

O método recordatório de 24 horas adotado nesta pesquisa foi ideal pela praticidade e agilidade de aplicação do mesmo, entretanto situações que dependem da memória do entrevistado comprometem em parte o fornecimento correto das informações. Além disso, alguns indivíduos sabendo que estão sendo avaliados podem omitir dados importantes.

Esses foram alguns dos problemas encontrados no período de levantamento das informações. Numa etapa posterior, de maior avanço da pesquisa, a escolha de um melhor 
programa de computador que transmitisse corretamente os resultados também foi outro obstáculo enfrentado. A falta de dados completos dos nutrientes tanto nos programas quanto nas tabelas nacionais de composição alimentar dificultaram a conclusão do estudo, resultando em maior dispêndio de tempo pela equipe para solucionar esses problemas.

Somando-se a essas situações, poucos são os trabalhos sobre consumo alimentar brasileiro que podemos nos embasar para desenvolver pesquisas de aprimoramento de métodos e/ou simples comparação de resultados.

Recentemente, dados de instituições internacionais e nacionais como a Organização Mundial de Saúde e o Instituto Brasileiro de Geografia e Estatística têm alertado para as mudanças na composição alimentar da sociedade e suas implicações no estado de saúde dos indivíduos.

Nas últimas décadas tem crescido cada vez mais o número de pessoas portadoras de doenças crônicas não-transmissíveis (obesidade, diabetes, câncer, hipertensão arterial). Calcula-se que 72\% das mortes no Brasil em 2005 tiveram como causa as doenças crônicas e estima-se que para os próximos 10 anos a prevalência de obesidade nos homens chegue aos $67 \%$ e nas mulheres, $74 \%$.

Essas estatísticas são parte de documento publicado pela OMS que juntamente com outros países lançou algumas diretrizes propondo mudanças na alimentação e prática de atividades físicas para reverter esse quadro até 2025.

Diante disso, o Ministério da Saúde propôs na Semana Mundial de Alimentação, realizada em outubro de 2005, as Diretrizes do Guia de Alimentação para a População Brasileira. Foi uma iniciativa oportuna do governo para melhorar os padrões da dieta nacional. Governantes ligados à área da saúde assustaram-se com os dados do IBGE sobre a qualidade da alimentação do brasileiro que piorou nos últimos 30 anos. É o próprio 
ministério quem afirma que 260 mil mortes anuais seriam evitadas se o brasileiro mantivesse uma alimentação saudável.

Hoje em dia ficou muito mais fácil tomar conhecimento das informações que a mídia escrita, televisiva e virtual veiculam. A sociedade está mais consciente dos problemas que a rodeia e quando questionados sobre seus hábitos alimentares são poucos os que não sabem apontar o tipo de alimentação ideal para um estilo de vida mais saudável. Mas por que o discurso adotado difere da prática? O que está faltando?

As informações, como bem mencionado, são muitas, mas o comportamento alimentar não é norteado somente pelos conceitos do que é bom ou ruim de se comer e as implicações fisiológicas desse ato.

As práticas alimentares também se orientam pelos aspectos subjetivos, como, por exemplo, as questões culturais envolvidas na escolha de um determinado alimento. Os alimentos são carregados de símbolos e significados e cada grupo se comporta de maneira a se adequar aos padrões do que é aceito socialmente.

O churrasco aos domingos na casa de amigos ou familiares, o "cafezinho" depois das refeições, a “cervejinha” no final de um expediente exaustivo são momentos em que o ato de se alimentar é parte bem maior do componente social da alimentação do que do componente fisiológico em que se contabilizam as calorias, as gorduras, o colesterol, etc.

Lançar um olhar sobre essas questões também se faz necessário para entender os propósitos de certos comportamentos no momento em que o indivíduo opta por um alimento e não por outro.

Este estudo vem contribuir para a compreensão parcial dos sentimentos envolvidos nas escolhas alimentares. A magnitude da complexidade do assunto demanda elaboração de mais pesquisas e criação de novas metodologias para entender o fenômeno por completo. 
Faz-se necessária a busca de conceitos em outras áreas de estudo como a Filosofia, a Sociologia, a Antropologia, a Economia. A interdisciplinaridade é o primeiro passo para a compreensão dos fenômenos envolvidos na dinâmica do comer e do nutrir-se. 


\section{REFERÊNCIAS BIBLIOGRÁFICAS}

ADAIR, L. S. Early nutrition conditions and later risk of disease. In: CABALLERO, B.;

POPKIN, B. M. The Nutrition Transition: Diet and Disease in the Developing World. Academic Press, 2002. cap.7, p.129-145.

AGROMIDIA SOFTWARE LTDA. DietPro: versão 3.0. Viçosa: Incubadora de Empresas/FUNARB/Universidade Federal de Viçosa, 2000.

ANÇAO, M.; CUPPARI, L.; TUDISCO, E. S.; DRAIBE, S. A.; SIGULEM, D. Programa de apoio à Nutrição: versão 2.5. São Paulo: Centro de Informática em Saúde/Escola Paulista de Medicina, 1996.

BLEIL, S. I. O Padrão Alimentar Ocidental: considerações sobre a mudança de hábitos no Brasil. Cadernos de Debate, v. VI, p.1-25, 1998.

BRAGA, V. Cultura Alimentar: contribuições da antropologia da alimentação. Saúde em Revista, Piracicaba, v.6, n.13, p. 37-44, 2004.

BRAY, G. A.; POPKIN, B. M. Dietary fat intake does affect obesity! American Journal of Clinical Nutrition, v.68, p.1157-1173, 1998. 
CERVATO, A.M.; MAZZILLI, R.N.; MARTINS, I.S.; MARUCCI, M.F.N. Dieta habitual e fatores de risco para doenças cardiovasculares. Revista de Saúde Pública, v.31, n.03, p. 1-15, 1997.

DOMENE, S. M. A. Indicadores nutricionais e políticas públicas. Estudos Avançados, v.17, n.48, p.131-135, 2003.

DRESSLER, W. W. Social class, skin color and arterial blood pressure in two societies. Ethnicity and Disease, v.1, p.60-77, 1991. . Using cultural consensus analysis to develop a measurement: a Brazilian example.

Cultural Anthropological Methods, v.8, p.6-8, 1996.

DRESSLER, W. W.; RIBEIRO, R. P. P.; BALIEIRO, M. C.; OTHS, K. C.; SANTOS, J. E. DOS. Eating, drinking and being depressed: the social, cultural and psychological context of alcohol consumption and nutrition in a brazilian community. Social Science and Medicine, v.59, n.4, p.709-720, Agosto, 2003.

DRESSLER, W. W.; SANTOS, J. E. DOS. Correlações socioculturais da pressão arterial. Revista Brasileira de Hipertensão, v.8, n.2, p.225-229, 2001. Social and cultural dimensions of hypertension in Brazil: a review. Cadernos de Saúde Pública, v.16, p.303-315, 2000. 
DRESSLER, W. W.; SANTOS, J. E. DOS.; BALIEIRO, M. C. Culture, skin color and arterial blood pressure in Brazil. American Journal of Human Biology, v.11, p.49-59, 1999.

. Culture, socioeconomic status and physical and mental health in Brazil. Medical Anthropology Quarterly, v.12, p.424-446, 1998.

. Studying diversity and sharing in culture: an example of lifestyle in Brazil. Journal of Anthropological Research, v.52, p.331-353, 1996.

. The cultural construction of social support in Brazil: associations with health outcomes. Culture, Medicine and Psychiatry, v.21, p.303-335, 1997.

DRESSLER, W. W.; SANTOS, J. E. DOS; GALLAGHER JR, P. N.; VITERI, F. E. Arterial blood pressure and modernization in Brazil. American Anthropologist, v.89, p.389-409, 1987.

. Social and dietary predictors of serum lipids: a Brazilian example. Social Science and Medicine, v.32, p.1229-1235, 1991.

DRESSLER, W. W.; SANTOS, J. E. DOS; VITERI, F. E. Blod pressure, ethnicity and psychosocial resources. Psychomatic Medicine, v.48, p.509-519, 1986. 
. Social and cultural influences in the risk of cardiovascular disease in urban Brazil.

In: SCHELL, L. M.; SMITH, M. T.; BILSBOROUGH, A. Urban Health and Ecology in the Third World. Cambridge: Cambridge University Press, p.10-25, 1993.

DRESSLER, W. W.; VITERI, F. E.; CHAVEZ, A.; GRELL, G. A. C.; SANTOS, J. E. DOS. Comparative research in social epidemiology: measurement issues. Ethnicity and Disease, v.1, p.379-393, 1991.

DREWNOWSKI, A. Nutrition Transition and Global Dietary Trends. Nutrition, v.16, n.7/8, 2000.

DU, S.; LU, B.; ZHAI, F.; POPKIN, B. M. The nutrition transition in China: a new stage of the Chinese diet. In: CABALLERO, B.; POPKIN, B. M. The Nutrition Transition: Diet and Disease in the Developing World. Academic Press, 2002. cap. 11, p.205-221.

ESCODA, M.S.Q.; Para a crítica da transição nutricional. Ciência \& Saúde Coletiva, v.07, n.02, p.219-226, 2002.

FERRARI, A. A.; SAWAYA, A. L. Desnutrição urbana no Brasil em um período de transição. São Paulo: Cortez, 1997.

FISBERG, R.M.; MARTINI, L.A.; SLATER, B. Métodos de Inquéritos Alimentares. In: FISBERG, R.M.; SLATER, B.; MARCHIONI, D.M.L.; MARTINI, L.A. Inquéritos alimentares: métodos e bases científicos. Barueri, SP: Manole, 2005, cap.1, p.24. 
FISCHLER, C. A “McDonaldização” dos costumes. In: FLANDRIN, J. L.; MONTANARI, M. História da alimentação. Tradução: Luciano Vieira Machado e Guilherme J. F. Teixeira. São Paulo: Estação Liberdade, 1998. cap.47, p.841-862.

FORNES, N.S., MARTINS, I.S.; VELÁSQUEZ -MELÉNDEZ, G.; LATORRE, M.R.D.O. Escores de consumo alimentar e níveis lipêmicos em população de São Paulo, Brasil. Revista de Saúde Pública, v.36, n.01, 2002.

GALEAZZI, M. A. M.; DOMENE, S. M. A.; SICHIERI, R. Estudo Multicêntrico sobre Consumo Alimentar. Cadernos de Debate, NEPA/UNICAMP, 1997. Volume Especial.

GARCIA, R. W. D. Reflexos da globalização na cultura alimentar: considerações sobre as mudanças na alimentação urbana. Revista de Nutrição, v.16, n.4, p.483-492, out./dez.2003.

- Representações sobre o consumo alimentar e suas implicações em inquéritos alimentares: estudo qualitativo em sujeitos submetidos à prescrição dietética. Revista de Nutrição, v.17, n.1, p.15-28, jan./mar., 2004.

GEERTZ, C. A. A interpretação das culturas. Rio de Janeiro: Zahar, 1979.

HOFFMAN, D.; HEYSMFIELD, S. B.; WAITZBERG, D. L. Composição corpórea. In: WAITZBERG, D. L. Nutrição Oral, Enteral e Parenteral na Prática Clínica. São Paulo: Atheneu, 2004, cap.14, v.1, p.225-239. 
INSTITUTO BRASILEIRO DE GEOGRAFIA E ESTATÍSTICA - IBGE. Pesquisa de Orçamentos Familiares 1987 e 1996. Rio de Janeiro: IBGE; 1999. Disponível em htpp:॥www.sidra.ibge.gov.br/bda/tabela/listabl.asp?c=419\&z=p80=8.

Pesquisa de Orçamentos Familiares 2002-2003. Análise da disponibilidade domiciliar de alimentos e do estado nutricional no Brasil. Rio de Janeiro, 2004.

KAMIMURA, A. K.; BAXMANN, A.; SAMPAIO, L. R.; CUPPARI, L. Avaliação Nutricional. In: CUPPARI, L. Guia de nutrição: nutrição clínica no adulto. (Guias de medicina ambulatorial e hospitalar). Barueri, SP: Manole, 2002. cap.5, p.71-109.

LAMBERT, J.L.; BATALHA, M.O.; SPROESSER, R.L.; SILVA, A.L.; LUCCHESE, T. As principais evoluções dos comportamentos alimentares: o caso da França. Revista de Nutrição, Campinas, v.18, n.5, p.577-591, set./out., 2005.

LEVY-COSTA, R.B.; SICHIERI, R.; PONTES, N.S.P.; MONTEIRO, C.A. Disponibilidade domiciliar de alimentos no Brasil: distribuição e evolução (1974-2003). Revista de Saúde Pública, v.39, n.4, p.530-40, 2005.

LOHMAN, T. G.; ROCHE, A. F.; MARTORELL, R. Anthropometric Standardization Reference Manual. Illinois: Human Kinectis Books, 1988.

MARCHIONI, D.M.L.; SLATER. B.; FISBERG, R.M. O estudo da dieta: considerações metodológicas. Cadernos de debate, Campinas, SP, v.X, p.62-76, set.2003. 
MARINHO, S. P.; MARTINS, I. S.; PERESTRELO, J. P. P.; OLIVEIRA, D. C. Obesidade em adultos de segmentos pauperizados da sociedade. Revista de Nutrição, Campinas, v.16, n.2, p.195-201, abr./jun., 2003.

MATTOS, L.L.; MARTINS, I.S. Consumo de fibras alimentares em população adulta.

Revista de Saúde Pública, v.34, n.01, p. 50-55, 2000.

MENDONÇA, C. P.; DOS ANJOS, L. A. Aspectos das práticas alimentares e da atividade física como determinantes do crescimento do sobrepeso/obesidade no Brasil. Cadernos de Saúde Pública, Rio de Janeiro, v.20, n.3, p.698-709, mai/jun. 2004.

MINTZ, S. W. Comida e Antropologia - uma breve revisão. Revista Brasileira de Ciências Sociais, v.16, n.47, p.31-41, outubro. 2001.

MOLINA, M.C. Análise do consumo alimentar de adultos jovens de uma coorte nascida em 1978/79 em Ribeirão Preto, SP. Dissertação de Mestrado apresentada à Faculdade de Medicina de Ribeirão Preto/USP. Ribeirão Preto, SP, 2005.

MONDINI, L.; MONTEIRO, C. A. Mudanças no padrão de alimentação da população urbana brasileira (1962-1988). Revista de Saúde Pública, v.28, n.6, p.433-439, 1994.

MONTEIRO, C. A.; MONDINI, L. SOUZA, A. L. M.; POPKIN, B. M. Da desnutrição para a obesidade: a transição nutricional no Brasil. In: MONTEIRO, C. A. Velhos e novos males da saúde no Brasil: a evolução do país e de suas doenças. São Paulo: HucitecNupens/USP, cap.14, p.247-255, 1995. 
MONTEIRO, C. A.; CONDE, W. L. Evolução da obesidade nos anos 90: a trajetória da enfermidade segundo estratos sociais no nordeste e sudeste do Brasil. In: Evolução da obesidade nos anos 90, cap.24. p.421-431, 1999.

MONTEIRO, C. A.; MONDINI, L.; COSTA, R. B. L. Mudanças na composição e adequação nutricional da dieta familiar nas áreas metropolitanas do Brasil (1988-1996). Revista de Saúde Pública, v.34, n.3, p.251-258, 2000.

MONTEIRO, C. A.; CONDE, W. L.; POPKIN, B. M. Trends in under- and overnutrition in Brazil. In: CABAlLERO, B.; POPKIN, B. M. The Nutrition Transition: Diet and Disease in the Developing World. Academic Press, 2002. cap.12, p.223-240.

OLIVEIRA, S. P.DE; THÉBAUD-MONY, A. Estudo do consumo alimentar: em busca de uma abordagem multidisciplinar. Revista de Saúde Pública, v.31, n.2, p.201-208, 1997.

OTHS, K. S.; CAROLO, A; SANTOS, J. E. DOS. Social status and food preferences in southeast Brazil. Ecology of Food and Nutrition, v.40, 2003.

PHILIPPI, S. T. Guia Alimentar para o Ano 2000. In: DE ANGELIS, R. C. Fome oculta, impacto para a população do Brasil. São Paulo: Editora Atheneu, cap.32, p.160-176, 1999a. 
PHILLIP, S. T.; LATERZZA, A. R.; CRUZ, A. T. R.; RIBEIRO, L. C. Pirâmide alimentar adaptada: guia para escolha dos alimentos. Revista de Nutrição, Campinas, v.12, n.1, p.65-80, jan./abr.1999b.

PINHEIRO, A. R. O.; FREITAS, S. F. T.; CORSO, A. C. T. Uma abordagem epidemiológica da obesidade. Revista de Nutrição, Campinas, v.17, n.4, p.523-533, out./dez.,2004.

POLIT, D. F.; HUNGLER, B. P. Nursing research: principles and methods. New York: Lippincott, 1999.

POPKIN, B. M. Nutritional Patterns and Transitions. Popul. Devel. Rev., v.19, p.138-157, 1993.

POPKIN, B.M.; KEYOU, G.; ZHAI, F.; GUO, X.; MA H.; ZOHOORI, N. The nutrition transition in China: a cross-sectional analysis. European Journal of Clinical Nutrition, v.47, p.333-46, 1993.

POPKIN, B.M. The nutrition transition in low income countries: an emerging crisis. Presented at the Diet and Chronic Diseases in Countries in Socio-economic Transition Experimental Biology Conference, April 24-28, Anaheim, CA, 1994. 
- The dynamics of the dietary transition in the developing world. In:

CABALlERO, B.; POPKIN, B. M. The Nutrition Transition: Diet and Disease in the

Developing World. Academic Press, 2002. cap.6, p.111-128.

POULAIN, J. P.; PROENÇA, R. P. C. Reflexões metodológicas para o estudo das práticas alimentares. Revista de Nutrição, Campinas, v.16, n.4, p.365-386, out./dez., 2003.

PREFEITURA DE RIBEIRÃO PRETO. Dados municipais. Disponível em: <http:॥ www.ribeiraopreto.sp.gov.br>. Acesso em maio 2005.

RIBEIRO, P.; MORAIS, T.B.; COLUGNATI, F.A.B.; SIGULEM, D.M. Tabela de composição química de alimentos: análise comparativa com resultados laboratoriais. Revista de Saúde Pública, v.37, n.02, p.216-25, 2003.

SANTOS, J. E. DOS; OTHS, K. S.; DRESSLER, W. W. Socioeconomic factors and adult body composition in a developing society. Revista Brasileira de Hipertensão, v. 8, n.2, p.173-178, 2001.

SICHIERI, R. Epidemiologia da obesidade. Rio de Janeiro: Eduerj, 1998.

SICHIERI, R.; CASTRO, J. F. G.; MOURA, A. S. Fatores associados ao padrão de consumo alimentar da população brasileira urbana. Cadernos de Saúde Pública, Rio de Janeiro, v.19, supl. 1, 2003. 
SISTEMA ESTADUAL DE ANÁLISE DE DADOS (FUNDAÇÃO SEADE). Perfil municipal de Ribeirão Preto. São Paulo, 2005. Disponível em: <http:\\ www.seade.gov.br>. Acesso em maio 2005.

SORCINELLI, P. Alimentação e saúde. In: FLANDRIN, J. L.; MONTANARI, M. História da alimentação. Tradução: Luciano Vieira Machado e Guilherme J. F. Teixeira. São Paulo: Estação Liberdade, 1998. cap.44, p.792-805.

SPSS INCORPORATION. SPSS for Windows. Statistical Package for the Social Sciences. Release 10.1. Chicago: SPSS Inc., 1995.

STAMLER, J. SHEKELLE, R. Dietary cholesterol and human coronary heart disease: the epidemiological evidence. Arch. Pathol. Lab. Med., v.112, p.1032-1040, 1988.

STAR GUIA NET. Lista comercial de bolso de Ribeirão Preto. Informações gerais, 2001.

WORLD HEALTH ORGANIZATION (WHO). Report of a WHO Consultation on Obesity. Obesity, Preventing and Management the Global Epidemic. Geneva, 1997.

_. Study Group on Diet, Nutrition and Preventing of Chronic Diseases; 1989;

Geneva. Report. Geneva: World Health Organization, 1990. [WHO - Technical Report Series, 797]. 
Diet, Nutrition and the Prevention of Chronic Diseases. 2003; Geneva. Report.

Geneva: World Health Organization, 2003. [WHO - Technical Report Series, 916].

ZABOTTO, C. B.; VIANA, R. P. T.; GIL, M. F. Registro fotográfico para inquéritos dietéticos: utensílios e porções. Campinas, SP: UNICAMP e Goiânia: UFG, 1996, 74p.

ZLOTNIK, H. Demographic trends. In: CABALLERO, B.; POPKIN, B. M. The Nutrition Transition: Diet and Disease in the Developing World. Academic Press, 2002. cap.5, p.71-107. 


\section{Anexo A - Parecer de aprovação do comitê de ética do Hospital das Clínicas de Ribeirão Preto}

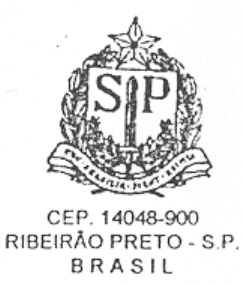

Oficio $n^{\circ} 506 / 2002$

$\mathrm{CEP} / \mathrm{SPC}$

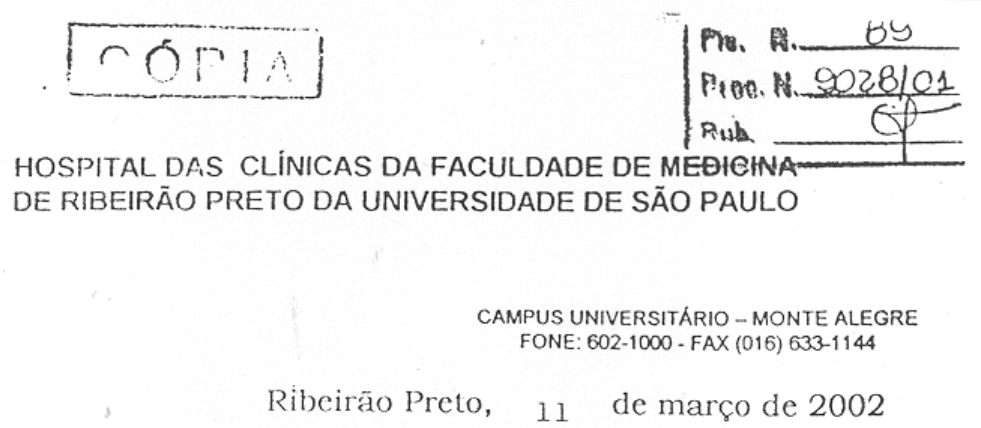

Ribeirão Preto, 11 de março de 2002

Senhor Professor:

$$
\text { O trabalho intitulado "CULTURA E }
$$

ADAPTAÇÃo INDIVIDUAL", foi analisado pelo Comitê de Ética em Pesquisa, em sua $125^{a}$ Reunião Ordinária realizada em 04/03/2002, e enquadrado na categoria: APROVADO, bem como o Termo de Consentimento Livre e Esclarecido, de acordo com o Processo HCRP nº 9028/2001. Lembramos que devem ser encaminhados a este CEP relatórios semestrais e relatório final da pesquisa.

\section{Entretanto, deve-se aguardar a manifestação} da CONEP, pois o projeto será eacaminhado para apreciação e aprovação.

Aproveito a oportunidade para apresentar a Vossa Senhoria protestos de estima c consideração.

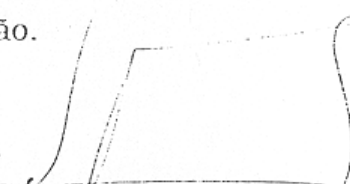

PROF.DR. SERGIO PEREIRA DA CUNHA

Coordenador do Comitê de Ética em Pesquisa do HCFMRP-USP

Ilustrissimo Senhor

PROF.DR. JOSÉ ERNESTO DOS SANTOS

Depto. de Clinica Medica

Em mãos 


\section{Anexo B - Recordatório de 24 horas}

\section{Projeto CADI \\ Inquérito Dietético}

1. Sítio:

2. Família:

3. Pessoa:

Nome:

Endereço:

Data:

Idade

Sexo: M/F Entrevistadora:

Tipo e quantidades de alimentos e bebidas consumidas nas últimas 24 horas - dia da semana:

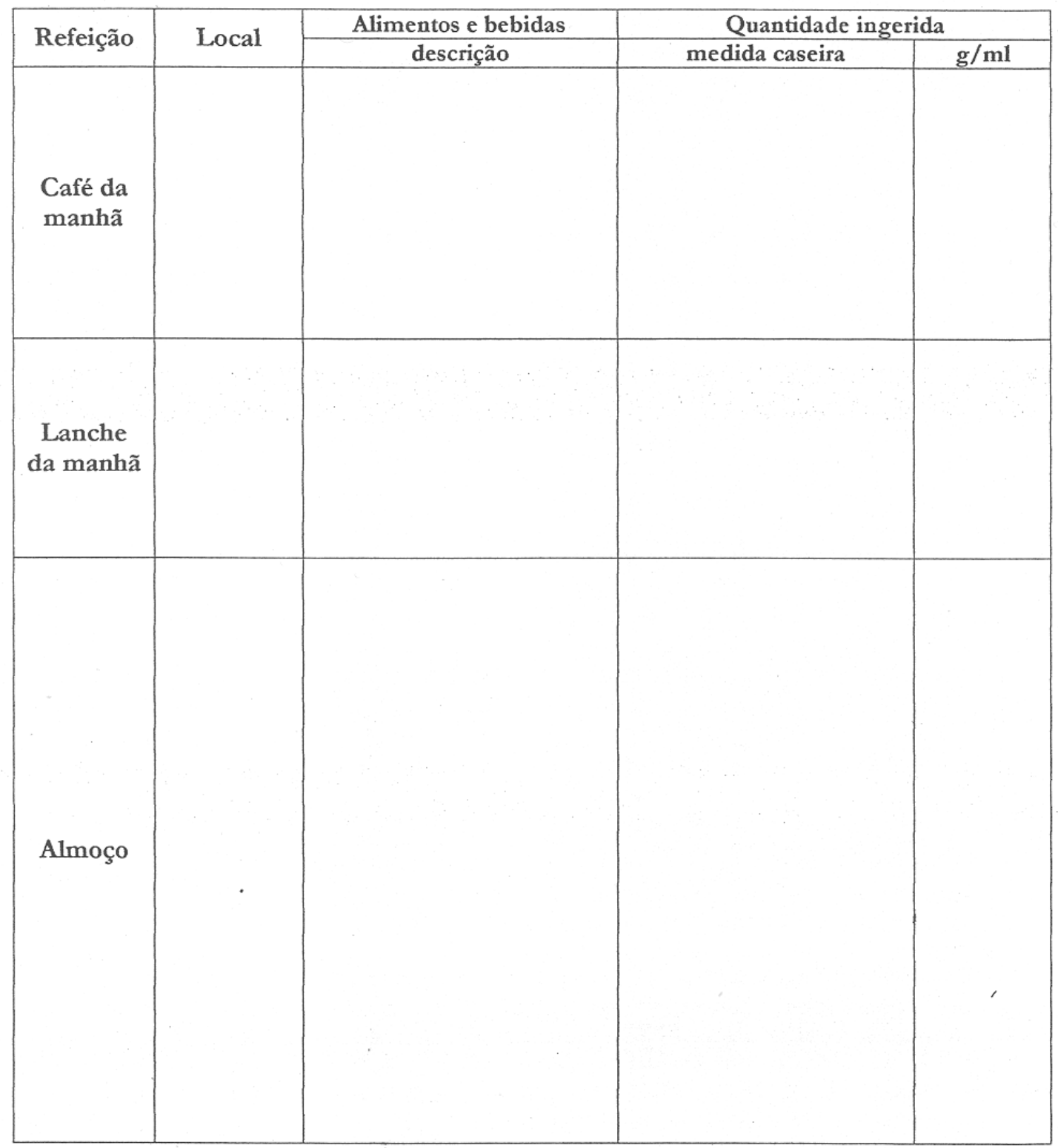




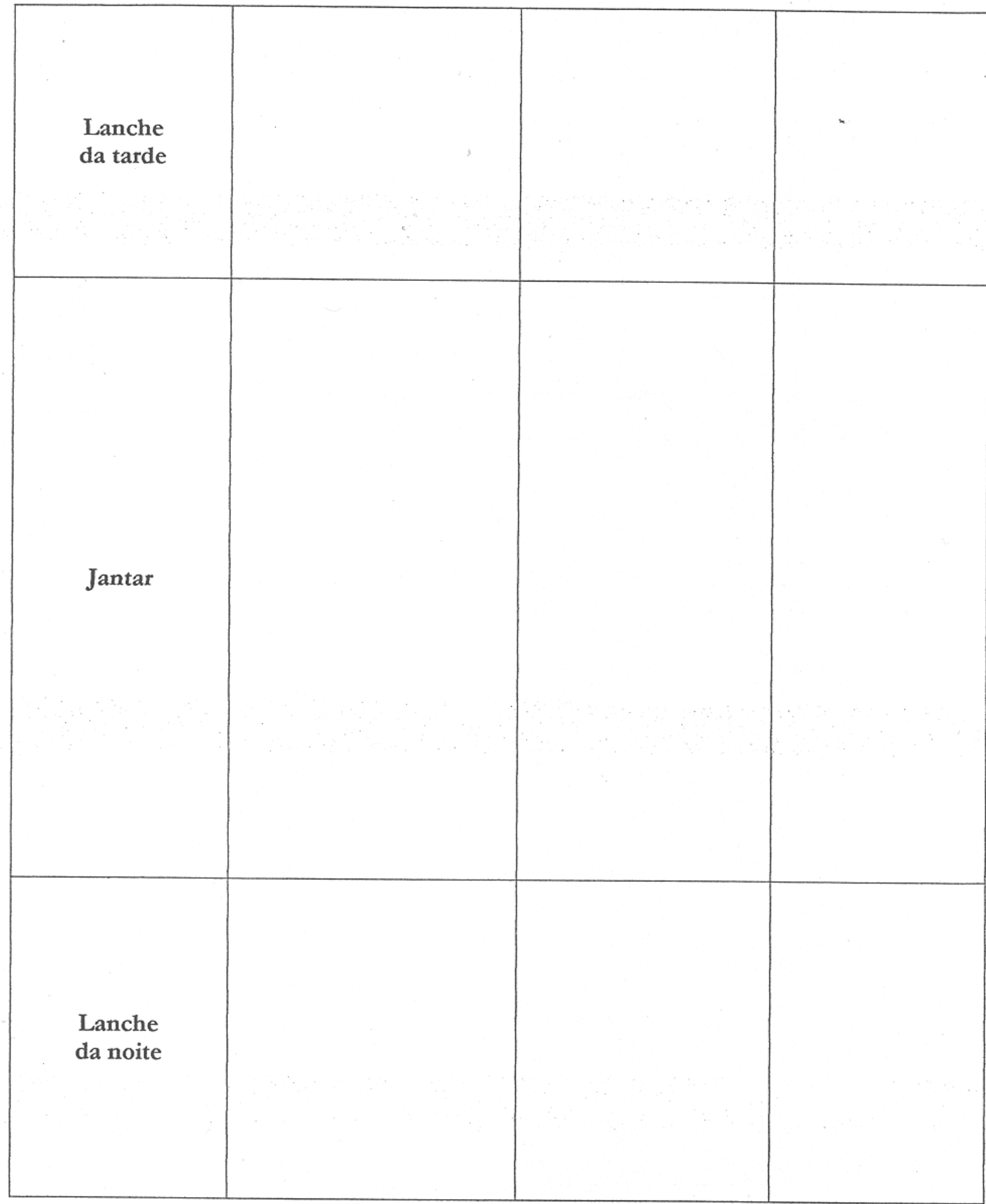

Suplementos - vitaminas:

Ferro:

Cálcio: 


\section{Anexo C - Carta de apresentação do projeto}

Prezado(a) Sr.(a):

Estamos escrevendo para convidar o(a) senhor(a) e a sua família para participar de um projeto de saúde que estamos desenvolvendo. Como o(a) senhor(a) provavelmente sabe, as doenças do coração atingem cada vez mais as pessoas todos dias no Brasil e também em Ribeirão Preto. Estamos tentando entender quais os fatores relacionados com isso. Entendemos mais-ou-menos algumas causas - como fatores de alimentação- que podem provocar doenças do coração. Não entendemos bem outras causas-como o estresse que pessoas enfrentam todos os dias - e que também podem provocar as doenças. E, especialmente, nós não entendemos bem a maneira como fatores diferentes podem se combinar e aumentar o risco dessas doenças.

Nosso projeto está planejado para investigar como é que muitos fatores se combinam e aumentam o risco de doenças do coração. Estamos convidando familias de diferentes bairros em Ribeirão Preto para participarem. É importante incluir famílias com e sem doenças do coração para determinar o que está diferente entre estas famílias. As familias que aceitarem o convite para participar deste estudo receberão visitas diferentes de membros de nossa equipe. Na visita inicial, um membro da equipe entrevistará o(a) senhor(a) sobre vários aspectos da sua vida - seu trabalho, a composição da sua família, e suas opiniões sobre coisas diferentes. Na segunda e terceira visitas, um membro da equipe entrevistará o(a) senhor(a) para conhecer a sua alimentação. Na quarta visita, uma enfermeira fará uma visita para obter informações sobre saúde, incluindo medida da pressão arterial e coleta de uma pequena amostra de sangue para determinar o nivel de colesterol.

Depois destas visitas, enviaremos ao senhor(a) um relatório com todas a informações sobre a sua saúde. Também, se a informação indicar, dependendo do resultado encontrado, poderemos sugerir e agendar uma consulta médica para uma avaliação mais cuidadosa.

Queremos enfatizar uma coisa muito importante: somos professores universitários com bastante experiência em projetos científicos. A equipe do projeto é formada por pessoas com especializações na área. Será seguro para o(a) senhor(a) e a sua família participarem do projeto sendo que ele foi aprovado pelos comitês de ética da Universidade de Alabama nos Estados Unidos e da Universidade de São PauloRibeirão Preto. O projeto vai ser conduzido com o mais alto nivel ético, incluindo a proteção e segurança de informações dadas sobre o(a) senhor(a) e a sua família.

Esperamos que o(a) senhor(a) possa e tenha tempo para nos ajudar com este importante projeto.

Com os nossos cumprimentos,

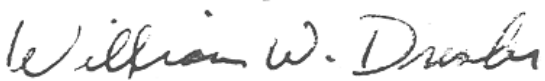

Dr. William W. Dressler

Department of Anthropology and

School of Social Work

The University of Alabama

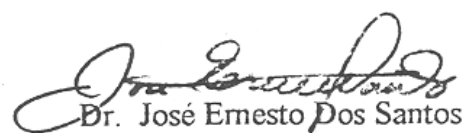

Faculdade de Medicina de Ribeirão Preto Universidade de São Paulo 


\title{
Anexo D - Termo de Consentimento Livre e Esclarecido
}

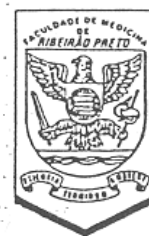

\author{
FACULDADE. DE MEDICINA DE RIBEIRĀO PRETO \\ DA UNIVERSIDADE DE SĀO PAULO

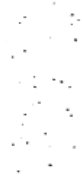 \\ Consentimento Informado para Participar no Projeto CADI
}

Estamos convidando o(a) senhor(a) para participar de uma pesquisa. Os investigadores principais deste projeto são Dr. William W. Dressler da Universidade de Alabama nos Estados Unidos, e Dr. José Ernesto Dos Santos da Faculdade de Medicina de Ribeirão Preto da Universidade de São Paulo. Nesta pesquisa, estamos tentando descobrir as causas de doenças cardiovasculares aqui em Ribeirão Preto. Nesta pesquisa, estamos perguntando a pessoas como você, em entrevistas, sobre diferentes aspectos da vida, incluindo temas como o trabalho, a vida familiar, a vida cotidiana e outros; entrevistas sobre a alimentação e uma avaliação clínica. Se você concordar em participar, as etapas serão os seguintes:

- Uma entrevistadora vai visitar você para uma entrevista inicial.

- Depois, uma outra entrevistadora vai visitar você duas vezes para obter informações sobre a sua alimentação.

- Finalmente, uma enfermeira vai visitar você para obter informações sobre a sua saúde, incluindo pressão arterial e uma pequena amostra do seu sangue para determinar o nivel de colesterol. Para a última entrevista é importante entender que: você não pode comer ou beber qualquer coisa depois das oito horas da noite no dia anterior da entrevista. É um processo muito comum e muito simples, mas às vezes uma pessoa pode sentir um certo desconforto, e, muito raramente, pode haver complicações. Se caso isso ocorra, a enfermeira vai tonar as providências necessárias.

- Se você estiver interessado em participar, é muito importante para você entender que: (1) todos os dados são anônimos, ninguém pode associar as suas respostas a você;

(2) sua participação é voluntária e a qualquer momento pode desistir de participar; e,

(3) você está livre para não responder as perguntas se você quiser.

Se você tiver outras perguntas, pode contatar Dr. José Emesto Dos Santos, Hospital das Clinicas, USP (602-2366).

$\mathrm{Eu}$, , li e concordo em participar.

Assinatura - Participante

Assinatura - Assistente da Pesquisa 